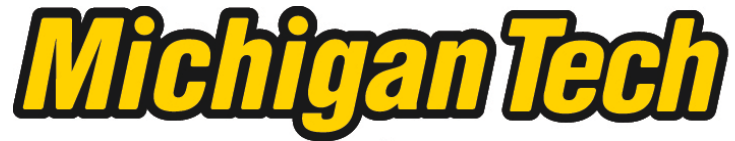 \\ Michigan Technological University Create the Future Digital Commons @ Michigan Tech
}

Dissertations, Master's Theses and Master's Reports - Open

Dissertations, Master's Theses and Master's

Reports

2011

\section{Technique to measure heats of reaction of Ti-B, Al-Ti-B, and Al-Ti- B4C powder blends}

Andrew H. Baker

Michigan Technological University

Follow this and additional works at: https://digitalcommons.mtu.edu/etds

Part of the Engineering Science and Materials Commons

Copyright 2011 Andrew H. Baker

\section{Recommended Citation}

Baker, Andrew H., "Technique to measure heats of reaction of Ti-B, Al-Ti-B, and Al-Ti-B4C powder blends", Master's Thesis, Michigan Technological University, 2011.

https://doi.org/10.37099/mtu.dc.etds/30

Follow this and additional works at: https://digitalcommons.mtu.edu/etds

Part of the Engineering Science and Materials Commons 
A TECHNIQUE TO MEASURE HEATS OF REACTION OF Ti-B, Al-Ti-B, AND AlTi-B $\mathrm{B}_{4} \mathrm{C}$ POWDER BLENDS

\author{
By \\ Andrew H. Baker

\begin{abstract}
A THESIS
Submitted in partial fulfillment of the requirements for the degree of MASTER OF SCIENCE

(Materials Science and Engineering)
\end{abstract}

MICHIGAN TECHNOLOGICAL UNIVERSITY

2011

(C) 2011 Andrew H. Baker 
This thesis, "A Technique to Measure Heats of Reaction of Ti-B, Al-Ti-B, and Al-Ti-B ${ }_{4} \mathrm{C}$ Powder Blends," is hereby approved in partial fulfillment of the requirements for the Degree of MASTER OF SCIENCE IN MATERIALS SCIENCE AND ENGINEERING.

Department of Materials Science and Engineering

Signatures:

Thesis Advisor

Stephen L. Kampe

Committee Member

Douglas J. Swenson

Committee Member

Daniel A. Crowl

Department Chair

Mark R. Plichta

Date 
To my mother, June Van Atta, and my father, Robert Baker 


\section{Table of Contents}

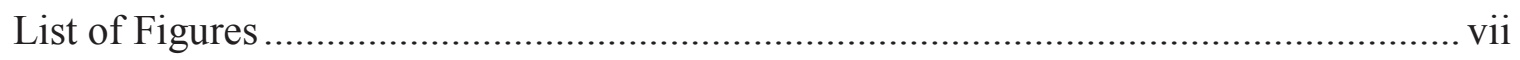

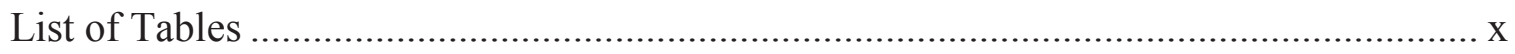

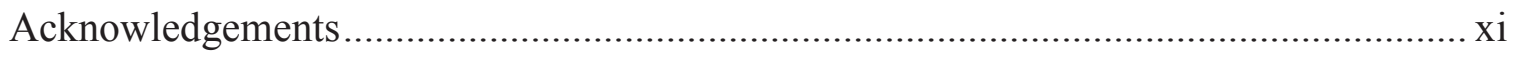

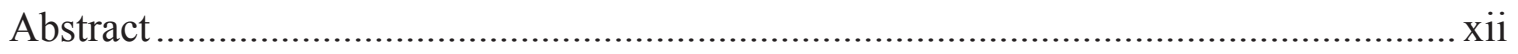

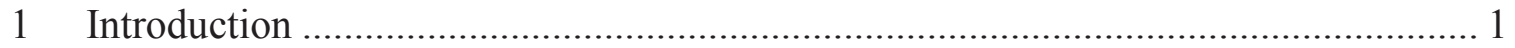

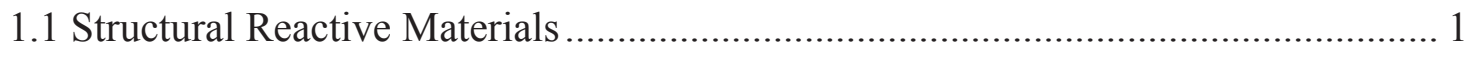

1.2 Self-Propagating High Temperature Synthesis (SHS) ....................................... 2

2 Approach and Hypotheses ........................................................................................ 6

3 Experimental Background \& Procedures ............................................................... 9

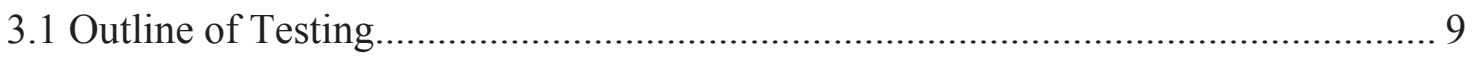

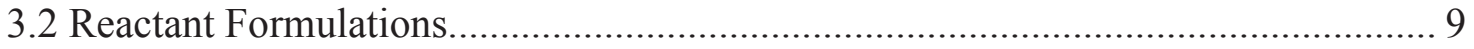

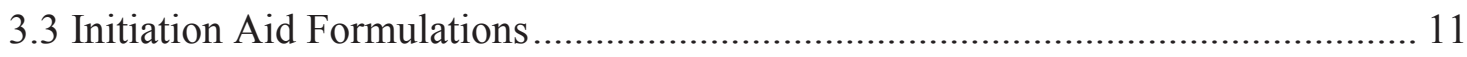

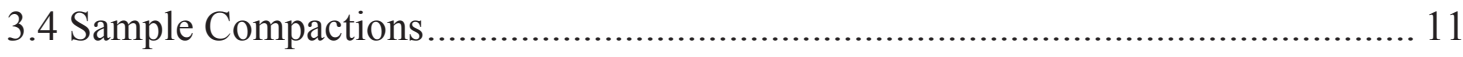

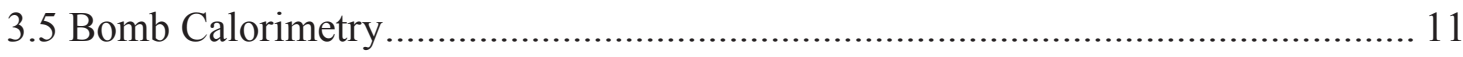

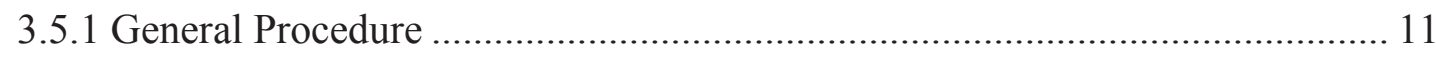

3.5.2 Initiation in Bomb Calorimetry ………………........................................ 12

3.5.3 Bomb Calorimetry Assumptions ……………………............................... 14

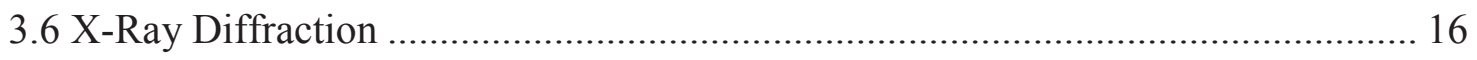

3.6.1 General Procedure ……………………………...................................... 16

3.6.2 X-Ray Diffraction Assumptions ..................................................................... 17

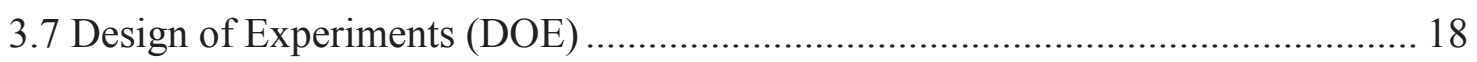

3.7.1 Overview of Design of Experiments ......................................................... 18

3.7.2 Regression Development ........................................................................ 19

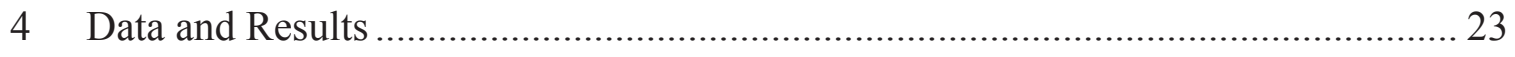

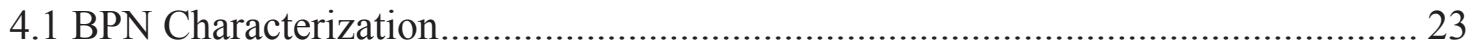

4.2 $\mathrm{TiB}_{2}$ Synthesis for Technique Validation............................................................ 24

4.2.1 Process Variable Screening ............................................................................. 24 
4.2.2 Calorimetry Regression Development....................................................... 25

4.2.3 Qualitative X-Ray Diffraction .................................................................... 28

4.2.4 Quantitative X-Ray Diffraction ................................................................... 29

4.2.5 Summary of Results: $\mathrm{TiB}_{2}$ Validation Study.................................................... 31

4.3 Application of Technique to Al-Ti-B ............................................................... 32

4.3.1 Process Variable Screening ........................................................................... 32

4.3.2 Calorimetry Regression Development............................................................ 33

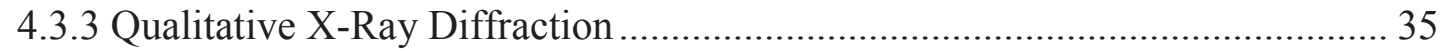

4.3.4 Quantitative X-ray Diffraction .................................................................. 38

4.3.5 Summary of Results: Al-Ti-B Reactant System.............................................. 42

4.4 Preliminary Application of Technique to Al-Ti-B ${ }_{4} \mathrm{C}$ Reactant System .................. 43

4.4.1 Regression Development .............................................................................. 43

4.4.2 Qualitative X-Ray Diffraction ................................................................... 43

4.4.3 Summary of Results: Al-Ti-B ${ }_{4}$ C Reactant System......................................... 45

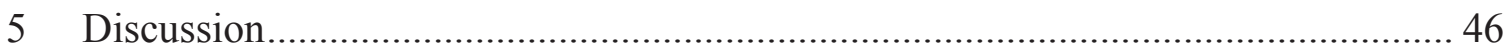

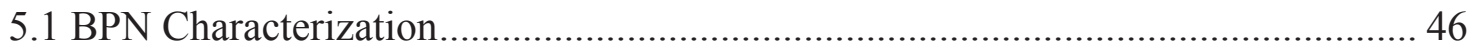

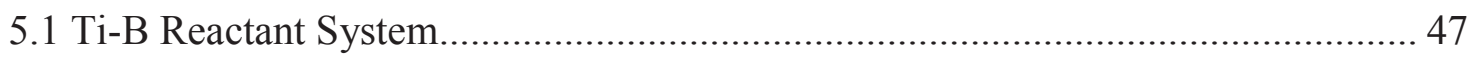

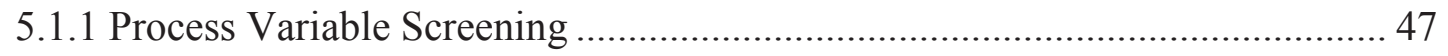

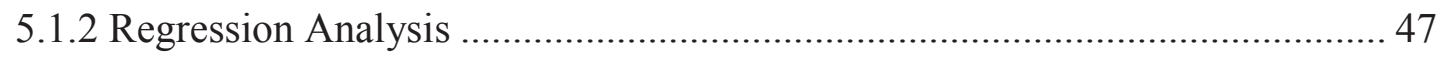

5.1.2 Qualitative X-Ray Diffraction ..................................................................... 47

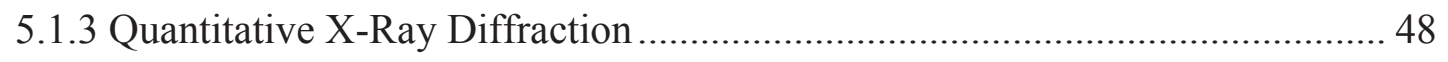

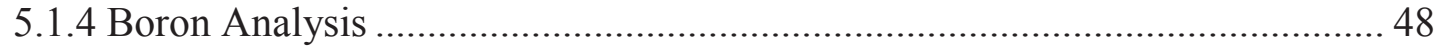

5.2 Al-Ti-B Reactant System .............................................................................. 49

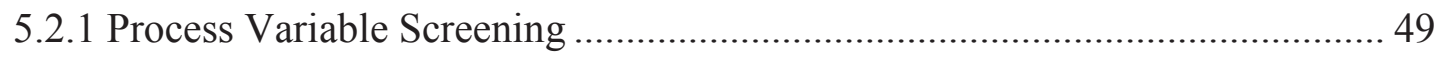

5.2.2 Regression Analysis ................................................................................... 49

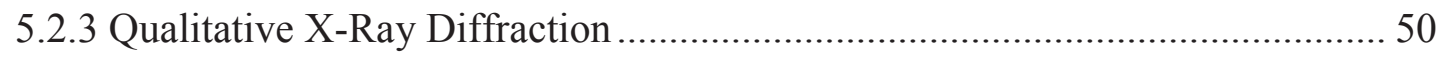

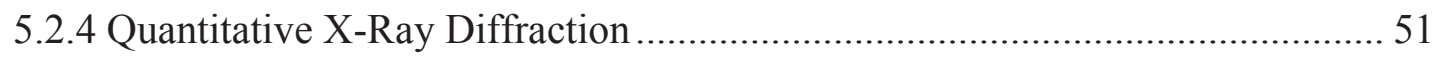

5.3 Al-Ti-B4C Reactant System …………………….......................................... 52

5.3.1 Calorimetry Regression Development............................................................ 52

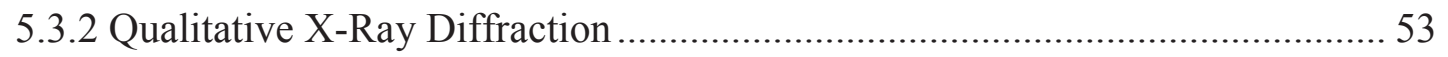




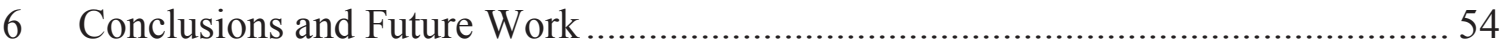

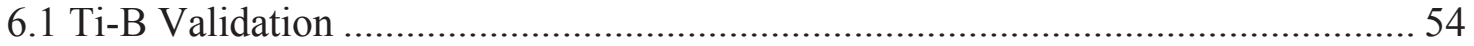

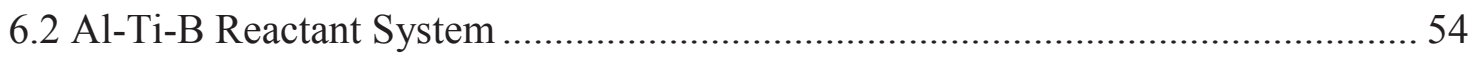

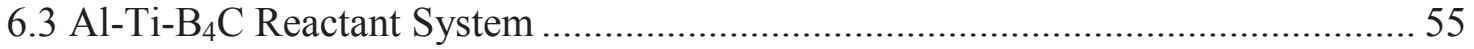

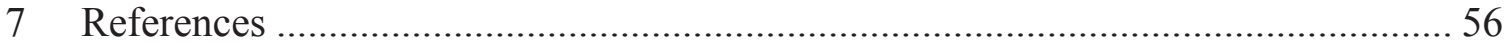

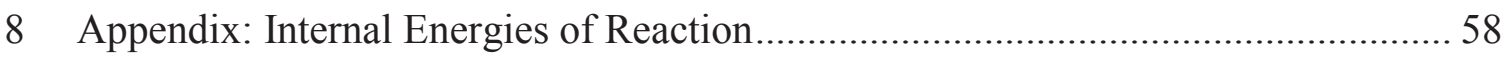

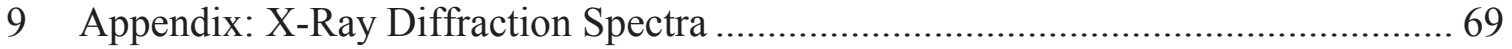




\section{List of Figures}

Figure 1.1 Modes of SHS initiation, (a) propagating (b) volumetric.............................. 2

Figure 1.2 Enthalpy vs. temperature with respect to reactants and products in SHS

(reprinted with permission) [2] .............................................................. 3

Figure 1.3 Temperature vs. time in a SHS reaction (reprinted with permission) [2] ....... 4

Figure 3.1 Standard ignition setup for bomb calorimetry (applied for Al-Ti-B) ............ 13

Figure 3.2 Standard initiation aid setup for bomb calorimetry (applied using a BPN external initiation aid and a primary sample of Al-Ti-B) ........................... 13

Figure 3.3 Modified setup for initiation in bomb calorimetry (blending of BPN initiation aid into primary powder blend) ................................................................ 14

Figure 4.1 X-ray diffraction pattern of product of BPN reaction ................................. 23

Figure 4.2 Internal energy vs. $\mathrm{KNO}_{3}$ wt. fraction for the BPN reaction......................... 24

Figure 4.3 Normal plot displaying significance or non-significance of screening variables for $\mathrm{TiB}_{2}$ validation study..... 25

Figure 4.4 Internal energy change of reaction vs. total initiation aid wt. fraction with respect to fraction of $\mathrm{KNO}_{3}$ in the $\mathrm{B} / \mathrm{KNO}_{3}$ blend for the $\mathrm{TiB}_{2}$ validation study.

Figure 4.5 Interaction plot between IA fraction and $\mathrm{KNO}_{3}$ fraction. Interaction is indicated by lack of a parallel nature between lines

Figure 4.6 X-ray diffraction pattern of a sample with 0.25 initiation aid level, 0.80 internal initiation aid fraction, and $0.85 \mathrm{KNO}_{3}$ initiation aid fraction for the $\mathrm{TiB}_{2}$ validation study.

Figure 4.7 X-ray diffraction pattern of residue of a 0.25 initiation aid fraction, 0.80 internal initiation aid fraction, $0.85 \mathrm{KNO}_{3}$ initiation aid fraction sample for the $\mathrm{TiB}_{2}$ validation study 30

Figure 4.8 Volume percents of $\mathrm{TiB}_{2}$ vs. total initiation aid wt. fraction for $\mathrm{TiB}_{2}$ validation study (w/respect to unknown BPN product)

Figure 4.9 Volume percents of $\mathrm{TiN}_{0.5}$ vs. total initiation aid wt. fraction for $\mathrm{TiB}_{2}$ validation study (w/respect to unknown BPN product)

Figure 4.10 Normal effects plot showing significance and non-significance of factors for $\alpha=0.05$ in the Al-Ti-B study

Figure 4.11 Experimental and predicted reaction enthalpy change vs. vol. $\% \mathrm{TiB}_{2}$ (formulated) for the $\mathrm{Al}_{3} \mathrm{Ti} / \mathrm{TiB}$ s study.

Figure 4.12 X-ray diffraction pattern of a product with formulation factor levels: $0.50 \mathrm{IA}$

Frac, 0.80 Int Frac, $0.4 \mathrm{TiB}_{2}$ Frac for the Al-Ti-B study 36 
Figure 4.13 X-ray diffraction pattern of residue of a 0.50 initiation aid, 0.80 internal initiation aid, $0.70 \mathrm{KNO}_{3}$ initiation aid fraction sample at $0.20 \mathrm{vol}$. fraction $\mathrm{TiB}_{2}$ (formulated) for the Al-Ti-B study

Figure 4.14 X-ray diffraction pattern of residue of a 0.50 initiation aid, 0.80 internal initiation aid, $0.70 \mathrm{KNO}_{3}$ initiation aid fraction sample at 0.40 vol. fraction $\mathrm{TiB}_{2}$ (formulated) for the $\mathrm{Al}_{3} \mathrm{Ti} / \mathrm{TiB}$ study....

Figure 4.15 Volume percents of $\mathrm{TiB}_{2}$ vs. total initiation aid for the Al-Ti-B study (w/respect to the BPN product volumes) 39

Figure 4.16 Volume percents of $\mathrm{Al}_{3} \mathrm{Ti}$ vs. total initiation aid for the Al-Ti-B study (w/respect to the BPN product volumes) 40

Figure 4.17 Volume percents of Al vs. total initiation aid for the Al-Ti-B study (w/respect to the BPN product volumes).....

Figure 4.18. Volume percents of $\gamma-\mathrm{Al}_{2} \mathrm{O}_{3}$ vs. total initiation aid for the Al-Ti-B study (w/respect to the BPN product volumes)

Figure 4.19 Volume percents of TiN vs. total initiation aid for the Al-Ti-B study (w/respect to the BPN product volumes) 42

Figure 4.20 Experimental reaction energies vs. weight fraction of the internally added initiation aid 44

Figure 4.21 X-ray diffraction pattern of a product with formulation factor levels: 0.25 initiation aid, 0.80 internal initiation aid fraction, $0.70 \mathrm{KNO}_{3}$ initiation aid fraction, and 0.20 vol. fraction $\mathrm{TiB}_{2}+\mathrm{TiC}$ (formulated) for the $\mathrm{Al}-\mathrm{Ti}-\mathrm{B}_{4} \mathrm{C}$ study

Figure 5.1 X-ray diffraction pattern of 'commercially amorphous' boron showing crystalline nature 50

Figure 9.1 Ti-B, 0.125 total initiation aid wt. fraction, 0.80 internal fraction of total initiation aid, $0.85 \mathrm{wt}$. fraction $\mathrm{KNO}_{3}$ initiation aid 70

Figure 9.2 Ti-B, 0.25 total initiation aid wt. fraction, 0.80 internal fraction of total initiation aid, 0.85 wt. fraction $\mathrm{KNO}_{3}$ initiation aid................................. 70

Figure 9.3 Ti-B, 0.50 total initiation aid wt. fraction, 0.80 internal fraction of total initiation aid, 0.85 wt. fraction $\mathrm{KNO}_{3}$ initiation aid..

Figure 9.4 Ti-Al-B, 0 vol. \% $\mathrm{TiB}_{2}, 0.375$ total initiation aid wt. fraction, 0.80 internal fraction of total initiation aid, 0.85 wt. fraction $\mathrm{KNO}_{3}$ initiation aid. 71

Figure 9.5 Ti-Al-B, 0 vol. $\% \mathrm{TiB}_{2}, 0.50$ total initiation aid wt. fraction, 0.80 internal fraction of total initiation aid, 0.85 wt. fraction $\mathrm{KNO}_{3}$ initiation aid.............. 72

Figure 9.6 Ti-Al-B, 0 vol. \% $\mathrm{TiB}_{2}, 0.625$ total initiation aid wt. fraction, 0.80 internal fraction of total initiation aid, 0.85 wt. fraction $\mathrm{KNO}_{3}$ initiation aid. 72

Figure 9.7 Ti-Al-B, 20 vol. \% $\mathrm{TiB}_{2}, 0.25$ total initiation aid wt. fraction, 0.80 internal fraction of total initiation aid, 0.85 wt. fraction $\mathrm{KNO}_{3}$ initiation aid. 73

Figure 9.8 Ti-Al-B, 20 vol. $\% \mathrm{TiB}_{2}, 0.375$ total initiation aid wt. fraction, 0.80 internal fraction of total initiation aid, $0.85 \mathrm{wt}$. fraction $\mathrm{KNO}_{3}$ initiation aid 73 
Figure 9.9 Ti-Al-B, 20 vol. \% $\mathrm{TiB}_{2}, 0.50$ total initiation aid wt. fraction, 0.80 internal fraction of total initiation aid, 0.85 wt. fraction $\mathrm{KNO}_{3}$ initiation aid.............. 74

Figure 9.10 Ti-Al-B, 40 vol. \% $\mathrm{TiB}_{2}, 0.25$ total initiation aid wt. fraction, 0.80 internal fraction of total initiation aid, 0.85 wt. fraction $\mathrm{KNO}_{3}$ initiation aid.............. 74

Figure 9.11 Ti-Al-B, 40 vol. \% $\mathrm{TiB}_{2}, 0.375$ total initiation aid wt. fraction, 0.80 internal fraction of total initiation aid, 0.85 wt. fraction $\mathrm{KNO}_{3}$ initiation aid.............. 75

Figure 9.12 Ti-Al-B, 40 vol. \% $\mathrm{TiB}_{2}, 0.50$ total initiation aid wt. fraction, 0.80 internal fraction of total initiation aid, 0.85 wt. fraction $\mathrm{KNO}_{3}$ initiation aid.............. 75 


\section{List of Tables}

Table 3.1 Summary of experiments for each reactant system ................................... 9

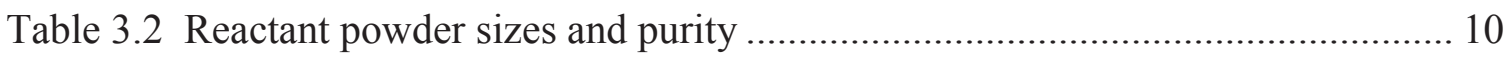

Table 3.3 Formulations of reactant powders for blends ............................................. 10

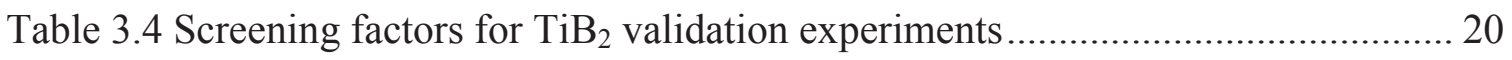

Table 3.5 Factors for regression in the $\mathrm{TiB}_{2}$ validation study .................................... 20

Table 3.6 Screening factors and levels for screening experiments for the Al-Ti-B study 21

Table 3.7 Factors and levels for the regression model for the Al-Ti-B study ................. 21

Table 3.8 Factors and levels for the experiments and regression for the Al-Ti- $\mathrm{B}_{4} \mathrm{C}$ study 22

Table 4.1 ANOVA table for $\mathrm{TiB}_{2}$ validation study with relevant factors ...................... 27

Table 4.2 Experimental and literature enthalpy of reaction values for $\mathrm{TiB}_{2}$ in the $\mathrm{TiB}_{2}$ validation study (amorphous boron enthalpy contribution from Barin[14] in both values) .................................................................................. 28

Table 4.3 Volume percents of products for the $\mathrm{TiB}_{2}$ validation study (w/respect to the unknown BPN volume)........................................................................... 30

Table 4.4 Statistical information for the terms of the enthalpy regression model for the Al-Ti-B study

Table 4.5 Volume percents of products from the Al-Ti-B study samples (w/ respect to the BPN product volumes) 38

Table 4.6 Formulated $\mathrm{TiB}_{2}$ vol. \% vs. experimental $\mathrm{TiB}_{2}$ vol. $\%$ as a result of a regression of the volume percents derived from x-ray diffraction (for the Al-Ti-B study)

Table 8.1 Internal energy measurements for all experiments 59 


\section{Acknowledgements}

I would like to thank the following entities for funding of this research:

- Matsys Inc. (Sterling, VA)

- U.S. Army Armament Research, Development, and Engineering Center (ARDEC) - Picatinny Arsenal, NJ

- MSE Department, Michigan Tech

I would also like to express gratitude to Professor Douglas Swenson, Ed Laitila and Steve Forsell of the Materials Science \& Engineering Department at Michigan Tech for their technical assistance and advice during this research.

Finally, I would like to thank my advisor Professor Stephen Kampe for providing me the research and higher education opportunities at Michigan Tech. 


\section{Abstract}

In this research, a modification to initiation aid ignition in bomb calorimetry that involves systemically blending levels of boron and potassium nitrate initiation aids with a bulk structural energetic elemental power blend is developed. A regression is used to estimate the nominal heat of reaction for the primary reaction. The technique is first applied to the synthesis of $\mathrm{TiB}_{2}$ as a validation study to see if close proximity to literature values can be achieved. The technique is then applied to two systems of interest, Al-Ti-B, and Al-Ti$\mathrm{B}_{4} \mathrm{C}$. In all three investigations, $\mathrm{x}$-ray diffraction is used to characterize the product phases of the reactions to determine the extent and identity of the product phases and any by-products that may have formed as a result of adding the initiation aid. The experimental data indicates the technique approximates the heat of reaction value for the synthesis of $\mathrm{TiB}_{2}$ from Ti-B powder blends and the formation of $\mathrm{TiB}_{2}$ is supported by volume fraction analysis by $\mathrm{x}$-ray diffraction. Application to the Al-Ti-B and Al-Ti- $\mathrm{B}_{4} \mathrm{C}$ blends show some correlation with variation of the initiation aid, with x-ray diffraction showing the formation of equilibrium products. However, these blends require further investigation to resolve more complex interactions and rule out extraneous variables. 


\section{Introduction}

\subsection{Structural Reactive Materials}

Structural reactive materials, also called structural energetic materials, are a class of structurally viable materials, currently under development, that can store chemical energy and release that energy rapidly upon overcoming the kinetic barriers to its release. Structural reactive materials are an example of a multifunctional material, in that both primary functionalities (energy storage and structural viability) are enabled by a single microstructural design that simultaneously achieves both, thus eliminating the need to assemble multiple materials to achieve the same set of attributes [1].

Three primary constraints guide the selection of materials appropriate to creating an effective structural reactive material. First, the materials involved must have the potential to release large magnitudes of energy quickly, whether in the form of an enthalpy reduction and/or a pressure pulse. Second, the materials must have adequate kinetic hindrances so as not to react too easily or spontaneously. Finally, in their pre-reacted state, the materials must have mechanical properties appropriate for high-strength engineering applications. Because of the latter requirement, most candidate SRM formulations presently under development are comprised of reaction-capable powderbased blends of elemental structural metallics (e.g., $\mathrm{Al}$ and/or Ni) and an elemental metalloid (e.g., B, C, or Si).

Fortuitously, the reactivity of such blends has been studied and utilized for many decades within a complementing technology area known as self-propagating high temperature synthesis (SHS), a process methodology used extensively by the ceramics discipline as a means to produce monolithic (stoichiometric) borides, carbides, and silicides. SHS, and its subsequent non-stoichiometric variations, thus provides a basis for the design and understanding of structurally-reactive materials. 


\subsection{Self-Propagating High Temperature Synthesis (SHS)}

Also referred to as reaction synthesis or combustion synthesis, SHS occurs when a thermodynamically-favored reaction is initiated with sufficient energy (heat) being liberated from a localized conversion of reactants to product to sustain the reaction throughout the material until completion [2]. SHS reactions have been utilized and characterized for many systems as a means to produce high purity ceramics, as a means to facilitate elevated temperature processing of a ceramic by utilizing the inherent exothermicity of the SHS reaction, for the production of non-equilibrium and metastable phases of ceramics, and for production of in-situ ceramic-, metallic-, and intermetallicmatrix composites [2-8].

SHS is typically categorized in one of two ways: propagating and volumetric (sometimes referred to as "thermal explosion"), depending how the exothermic reaction is initiated and proceeds, Figure 1.1. In the directionally propagating mode, initiation occurs at a point heat source and the reaction propagates through the material as a "combustion wave," generally proceeding until the unreacted material is consumed.

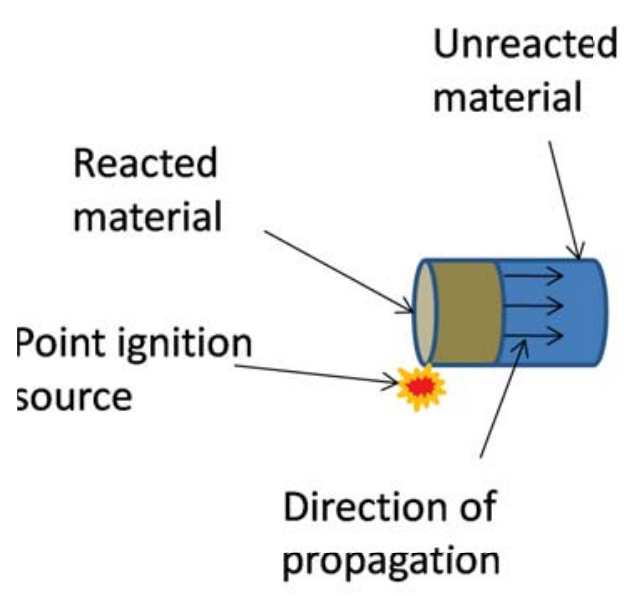

(a)

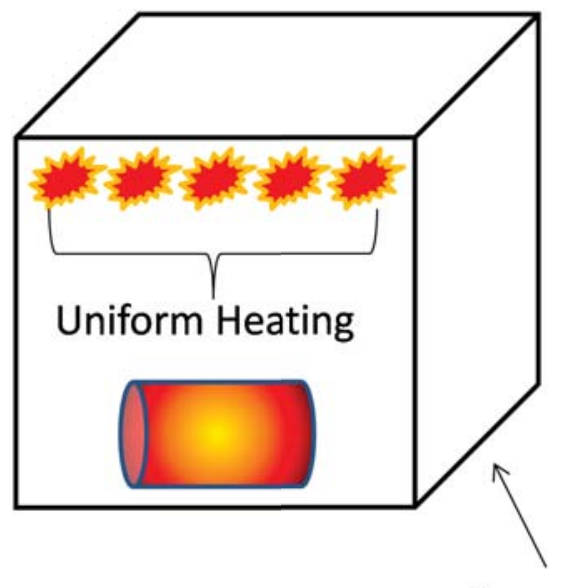

(b)

Figure 1.1 Modes of SHS initiation, (a) propagating (b) volumetric 
In contrast, the volumetric propagating mode involves heating the reactants uniformly until initiation of the reaction. In this mode, there are many sites of initiation of the reaction throughout the sample. The nature and propagation of the wave within both modes is a topic of study in the literature [2-5, 7, 9-11].

In SHS, the total enthalpy change over the entire reaction consists of three critical terms: $\mathrm{H}_{\text {Reac-Ig }}$, the heat required to bring the reactants to their ignition temperature ( $\left.\mathrm{T}_{\mathrm{ig}}\right)$ from the standard temperature $\left(\mathrm{T}_{0}\right), \mathrm{H}_{\text {reac-Stand }}$, the standard enthalpy of the reactants with respect to $\mathrm{T}_{0}$, and $\mathrm{H}_{\text {prod }}$, the standard enthalpy of the products with respect to $\mathrm{T}_{0}$.

$$
\begin{gathered}
\Delta H_{\text {Reac }}=\left(H_{\text {Reac-lg }}+H_{\text {Reac-Standard }}\right) \\
\Delta H=H_{\text {Reac }}+H_{\text {Prod }}
\end{gathered}
$$

The adiabatic temperature, $T_{a d}$, is the maximum possible temperature achieved by the reaction. The actual maximum combustion temperature achieved, $\mathrm{T}_{\mathrm{c}}$, will depend on the heat required to raise the reactant temperature from the initial temperature to ignition temperature. Figure 1.2 provides an illustration of the enthalpy and temperature relationship between products and reactants.

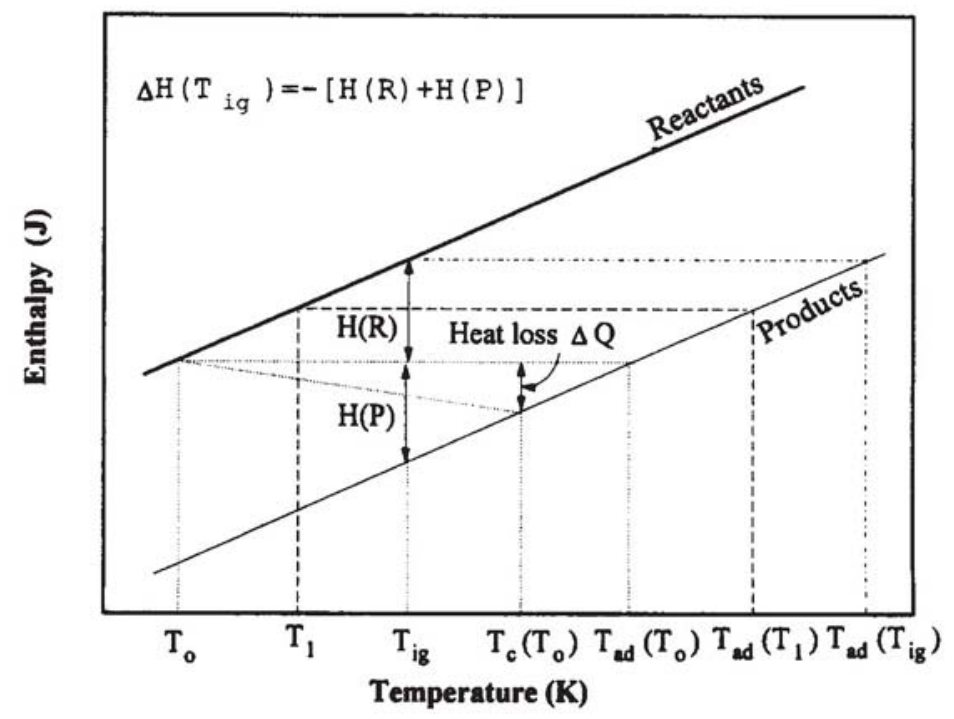

Figure 1.2 Enthalpy vs. temperature with respect to reactants and products in SHS (reprinted with permission) [2] 
Heating to an arbitrary value, $T_{1}$, shows the effect on the $T_{a d}$. In the volumetric heating mode, $T_{c}$ will very closely approximate $T_{a d}$ since the entire sample is preheated to the ignition temperature. In the propagating initiation mode, $\mathrm{T}_{\mathrm{c}}$ will be slightly lower since the reactants must be brought to the ignition temperature at the wave front as the wave propagates.

The time scale over which the reaction occurs is typically relatively short (micro-seconds in many cases), Figure 1.3; the self sustenance of the reaction relies on its ability evolve the heat quickly enough to transfer it to the unreacted material before it extinguishes itself due to dissipation of heat.

SHS offers unique flexibility when attempting to adhere to the constraints of a structural reactive material. By the very necessity of a large enthalpy reduction and high adiabatic reaction temperature being required for a self-propagating state, the reactants inherently have the large chemical energy potential and most instances release the energy in a short enough timeframe required to be a viable structural reactive material.

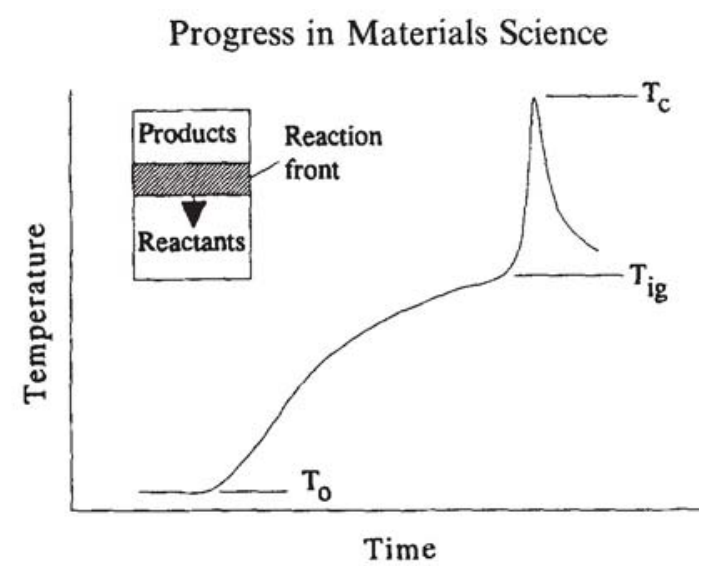

Figure 1.3 Temperature vs. time in a SHS reaction (reprinted with permission) [2] 
Additionally, SHS as applied to metallic and metalloid reactant blends creates the opportunity to design effective and structurally capable composite architectures from these reactants. Since metallic/metalloid SHS reactions are further distinguished as being entirely of a solid thermochemical nature, once initiated, they offer a potential additional benefit of not relying on reactants from the environment (such as oxygen from the air) to sustain and complete the reaction.

While the use of published thermodynamic data can guide in the prediction of high enthalpy release candidates for structural reactive materials, actual heat values for a particular formulation may vary depending on several intrinsic and extrinsic characteristics of the pre-reacted powder blend. These include a variety of thermodynamic and kinetic relevant variables, including the magnitude of the heat of reaction, the temperature of the reaction, the time scale over which the reaction occurs, particle size of the reactants $[2,3,6,11-13]$, degree of homogeneity and density of the powder blend $[2,3,6,13]$, rapid cooling and thermal gradients, and interdiffisional characteristics among the reactants. The presence or degree of influence of these variables on the release of heat is reactant system dependent. Manifestation of these effects often include incomplete or sequential reactions, and non-equilibrium or metastable products [2]. Furthermore, there are occasionally large inconsistencies among published thermodynamic data, such as that which exists for the formation of $\mathrm{TiB}_{2}$ [14$16]$.

Therefore, a need exists to experimentally determine "working" heats of reaction of bulk unreacted powder blends, particularly in the propagating mode, of structural energetic material candidates. Post-reaction characterization of the phase composition of the products would also assist in determining the degree to which the measured heats can be associated with the predicted (equilibrium) reactions. 


\section{Approach and Hypotheses}

In this work, an attempt to measure the heat of reaction of a model SRM formulation using a modified bomb calorimetry technique is made. The reactant formulation is based on blends containing aluminum, titanium, and boron (Al-Ti-B), which in elemental form have been previously demonstrated to respond to SHS processing to form product mixtures comprised of $\mathrm{Al}_{3} \mathrm{Ti}$ and $\mathrm{TiB}_{2}[12,17]$. However, inherent (but desired) kinetic hindrances to the initiation of this reaction prevent the use of traditional bomb calorimetry initiation methods. This research seeks to qualify a novel modification to the traditional initiation approaches used in bomb calorimetry. The technique will be initially applied to a validation study synthesizing monolithic $\mathrm{TiB}_{2}$ followed by an investigation into the use of the technique to determine heats of reactions for formulations that result in mixtures of $\mathrm{Al}_{3} \mathrm{Ti} / \mathrm{TiB}_{2}$.

The synthesis of $\mathrm{TiB}_{2}$ within titanium aluminide matrices to create in-situ intermetallic composites from elemental powders has been studied previously [12, 17-19], which make them good candidates for attempting to apply the new initiation approach using bomb calorimetry. In addition, there is practical interest in the alternative use of $\mathrm{B}_{4} \mathrm{C}$ as a reactant replacement for $\mathrm{B}$ due to certain manufacturing advantages of using $\mathrm{B}_{4} \mathrm{C}$ in a pre-reacted densified compact. In this instance, the SHS reaction proceeds in a similar manner, but differs in that presumably the reduction of $\mathrm{B}_{4} \mathrm{C}$ is required as part of the overall reaction, and that the product mixture will include $\mathrm{TiC}$ in addition to the $\mathrm{Al}_{3} \mathrm{Ti}$ and $\mathrm{TiB}_{2}$.

The synthesis of monolithic $\mathrm{TiB}_{2}$ through SHS from raw elemental powders has been shown to proceed with relative ease to completion, leaving little to no trace of reactant remaining and is insensitive to particle size of the reactants [11]. Thus, the use of this reaction system is consequently an ideal one to validate the initiation technique since deviation from close to complete synthesis of $\mathrm{TiB}_{2}$ would indicate an artifact introduced by the method. Furthermore, the use of only two constituents reduces the likelihood of other extraneous variables not related to the validation of the technique. 
The overarching goal of this research is to develop a technique to accurately measure heats of reaction for candidate structural reactive material formulations using bomb calorimetric techniques. Explicit within this goal will be an assessment of the implications of using an active initiation aid to assist in the ignition of the reaction. In this instance, an initiation aid refers to a set of independent reactants that have very low kinetic hindrance to initiation and produce a large heat of reaction upon ignition. Initiation aids will be introduced in two ways: 1) internally, where the initiation aid is blended directly into the SRM powder formulation, and 2.) externally, where the initiation aid is introduced adjacent to the SRM formulation.

A comparison of the measured heats to predicted heats of reaction as computed from literature-provided thermodynamic data will provide a means to evaluate the deviation of the heats of reaction of formulation products and those of products at complete equilibrium. Therefore, the experimental objectives of this research are to: (1) validate the technique using a reaction that is known to go to equilibrium (SHS of $\mathrm{TiB}_{2}$ ) and (2) Apply the technique to measure the heats of reaction of various stoichiometric bulk powder blends of a structural reactive material candidate (Al-Ti-B formulated to form a $\mathrm{Al}_{3} \mathrm{Ti} / \mathrm{TiB}_{2}$ product, or $\mathrm{Al}-\mathrm{Ti}-\mathrm{B}_{4} \mathrm{C}$ formulated to form $\mathrm{Al}_{3} \mathrm{Ti} / \mathrm{TiB}_{2} / \mathrm{TiC}$ product.

The specific hypotheses of this research are:

(1) If external and internal initiation aids are systematically varied with a nominal $\mathrm{Ti}$ $+\mathrm{B}$ bulk powder blend formulated to form $\mathrm{TiB}_{2}$ via SHS reaction:

a. The nominal literature heat of reaction of $\mathrm{TiB}_{2}$ can be reproduced using an estimation of zero initiation aid from a regression model using heats of reaction values from bomb calorimetry.

b. As initiation aid decreases, the regression of the volume fraction of the products determined by $\mathrm{x}$-ray diffraction will estimate monolithic $\mathrm{TiB}_{2}$ as the only phase present.

(2) If external and internal initiation aids are systematically varied with Al-Ti-B bulk powder blends formulated to form various volume proportions of $\mathrm{Al}_{3} \mathrm{Ti} / \mathrm{TiB}_{2}$ : 
a. The nominal heat of reaction values for the Al-Ti-B blends can be determined using an estimation of zero initiation aid from a regression model using heats of reaction values from bomb calorimetry.

b. As initiation aid decreases, the regression of the volume fraction of the products determined by x-ray diffraction will estimate the nominal phase composition.

c. A thermodynamic model derived from (b) should resemble the experimental model derived in (a).

(3) If external and internal initiation aids are systematically varied with Al-Ti- $\mathrm{B}_{4} \mathrm{C}$ bulk powder blends formulated to form various volume proportions of $\mathrm{Al}_{3} \mathrm{Ti} / \mathrm{TiB}_{2} \mathrm{TiC}$ :

a. The nominal heat of reaction values for the Al-Ti- $\mathrm{B}_{4} \mathrm{C}$ blends can be determined using an estimation of zero initiation aid from a regression model using heats of reaction values from bomb calorimetry.

b. As initiation aid decreases, the regression of the volume fraction of the products determined by x-ray diffraction will estimate the nominal phase composition.

c. A thermodynamic model derived from (b) should resemble the experimental model derived in (a). 


\section{Experimental Background \& Procedures}

\subsection{Outline of Testing}

Three reactant systems of interest were investigated in this study. Experimental testing and analysis treatments, which include process screening, bomb calorimetry, qualitative and quantitative $\mathrm{x}$-ray diffraction (XRD) for each reactant system are specified in Table 3.1 .

\subsection{Reactant Formulations}

$100 \mathrm{~g}$ master batches of reactant powders (Table 3.2) from Atlantic Equipment Engineers (AEE; Bergenfield, NJ) were formulated by weight for the three reactant systems listed in Table 3.3. The formulations were created for various volume percents of the presumptive products by converting the nominal volume fractions of product to a weight fraction using the products' density and subsequently a molar fraction using the products' molar masses. The correct molar proportions of the reactants could be ascertained and converted to a weight fraction for producing the $100 \mathrm{~g}$ master batches (Table 3.3). The blends were sealed in a container with cylindrical zirconia media under high purity (99.999\%) argon in a glove box and allowed to mix overnight.

Table 3.1

Summary of experiments for each reactant system

\begin{tabular}{ccccc}
\hline $\begin{array}{c}\text { Reactant } \\
\text { System }\end{array}$ & $\begin{array}{c}\text { Process } \\
\text { Screening? }\end{array}$ & $\begin{array}{c}\text { Bomb } \\
\text { Calorimetry? }\end{array}$ & $\begin{array}{c}\text { Qualitative } \\
\text { XRD? }\end{array}$ & $\begin{array}{c}\text { Quantitative } \\
\text { XRD? }\end{array}$ \\
\hline Ti-B & Yes & Yes & Yes & Yes \\
Al-Ti-B & Yes & Yes & Yes & Yes \\
Al-Ti-B 4 C & No & Yes & Yes & No \\
\hline
\end{tabular}


Table 3.2

Reactant powder sizes and purity

\begin{tabular}{ccc}
\hline Reaction Powders & $\begin{array}{c}\text { Average Powder } \\
\text { Size }(\boldsymbol{\mu m})\end{array}$ & $\begin{array}{c}\text { Purity } \\
\mathbf{( \% )}\end{array}$ \\
\hline \multirow{2}{*}{$\mathrm{Al}$} & 44 & 99.9 \\
& 149 & 99.8 \\
$\mathrm{Ti}$ & 44 & 99.7 \\
$\mathrm{~B}$ & 149 & 99.7 \\
$($ commercially & $<1$ & $95-97$ \\
amorphous) & & \\
B ${ }_{4} \mathrm{C}$ & 33 & 99.7 \\
\hline
\end{tabular}

Table 3.3

Formulations of reactant powders for blends

\begin{tabular}{|c|c|c|c|c|c|}
\hline $\begin{array}{l}\text { Reaction } \\
\text { Powders }\end{array}$ & $\begin{array}{c}\text { Presumptive } \\
\text { Products }\end{array}$ & $\begin{array}{c}\text { Formulated } \\
\text { Volume Percent of } \\
\mathrm{TiB}_{2} \text { or } \mathrm{TiB}_{2} / \mathrm{TiC}\end{array}$ & $\begin{array}{c}\text { Wt } \% \\
\text { Al }\end{array}$ & $\begin{array}{c}\text { Wt } \% \\
\text { Ti }\end{array}$ & $\begin{array}{l}\text { Wt } \% \text { B } \\
\text { or } B_{4} C\end{array}$ \\
\hline \multirow[t]{3}{*}{ Ti-B } & $\mathrm{TiB}_{2}$ & 100 & 0 & 68.9 & 31.1 \\
\hline & & 0 & 62.8 & 37.2 & 0 \\
\hline & & 20 & 47.0 & 45.2 & 7.8 \\
\hline \multirow[t]{4}{*}{ Al-Ti-B } & $\mathrm{Al}_{3} \mathrm{Ti} / \mathrm{TiB}_{2}$ & 40 & 33.2 & 52.1 & 14.7 \\
\hline & & 60 & 20.8 & 58.4 & 20.9 \\
\hline & & 80 & 9.9 & 63.9 & 26.2 \\
\hline & & 20 & 46.7 & 46.2 & 7.1 \\
\hline \multirow[t]{2}{*}{$\mathrm{Al}-\mathrm{Ti}-\mathrm{B}_{4} \mathrm{C}$} & $\mathrm{Al}_{3} \mathrm{Ti} / \mathrm{TiB}_{2} / \mathrm{TiC}$ & 40 & 32.7 & 53.9 & 13.3 \\
\hline & & 60 & 20.4 & 60.8 & 18.7 \\
\hline
\end{tabular}




\subsection{Initiation Aid Formulations}

The initiation aid formulations contained mixtures of $\mathrm{B}$ and $\mathrm{KNO}_{3}$, also known as BPN. For a preliminary study of the initiation aids, weight percents of 50,70 , and $85 \% \mathrm{KNO}_{3}$ (balance B) were used. Initiation aid compositions for the Ti-B blends included weight percents of 70 and $85 \% \mathrm{KNO}_{3}$. For the Al-Ti-B and Al-Ti-B4C blends, only initiation aids with a 70 wt. $\% \mathrm{KNO}_{3}$ was used. The $\mathrm{KNO}_{3}$, from Fischer Scientific (99\% purity), was crushed to a fine powder using a silica mortar and pestle and the B was then hand blended with the $\mathrm{KNO}_{3}$ to form the initiation aid blend.

\subsection{Sample Compactions}

Preparation of $10 \mathrm{~g}$ samples for the calorimetry experiments utilized a portion of the master batch of the nominal reactant blend as the $\mathrm{B}-\mathrm{KNO}_{3}$ initiation aid which were weighed and hand blended. To create green compacts, the powders were placed in 12.7 $\mathrm{mm}$ diameter natural latex bags from Trexler Industries, Inc. (Bethlehem, PA) and densified in a cold isostatic press at 240-270 MPa. Green compacts of the external initiation aid, consisting of the specified blend of $\mathrm{B}$ and $\mathrm{KNO}_{3}$, were processed under the same procedure.

\subsection{Bomb Calorimetry}

\subsubsection{General Procedure}

For an individual bomb calorimetry experiment, a small piece $(1-4 \mathrm{~g})$ of the $10 \mathrm{~g}$ sample compact was broken off and a corollary amount of compacted external initiation aid were both placed in a fused silica crucible, loosely touching each other in the bomb. A Ni-Cr fuse wire was set in contact with the external initiation aid. The bomb in the calorimeter was charged with argon (99.998\% purity) to seal it and provide an inert environment for the reaction. The charged bomb pressure was set at $414 \mathrm{kPa}$ (60 psi) and $828 \mathrm{kPa}$ (120 psi) for the Ti-B blends, but in all subsequent experiments, only the $828 \mathrm{kPa}$ pressure 
level was used. The bomb was then placed in $2001 \mathrm{~mL}$ of deionized water in a stainless steel jacket.

The sample was then reacted in a Parr 1341 Plain Jacket Bomb Calorimeter and evaluated utilizing the calorimeter model's standard operating procedure where heat loss corrections conform to ASTM standards D240 and D3286. The calorimeter was closed and the temperature of the water allowed to equilibrate for 5 minutes. At such time, the recording of the change in temperature of the water was recorded by hand every minute for 5 minutes to determine the rate of heat loss or gain due to the imperfect adiabacity of the calorimeter. After the 5 minutes, ignition by way of a $1.5 \mathrm{~A}$ current through the $\mathrm{Ni}-\mathrm{Cr}$ resistive wire in contact with the initiation aid was initiated. This current brings the wire to its melting point of $1350-1450^{\circ} \mathrm{C}$. After 45 seconds, temperature measurements were recorded by hand every 15 seconds over a period of 2 minutes to determine the slope of the heat rise during the reaction.

After this period, temperature measurements were then taken by hand every minute until five identical change in temperature observations were recorded consecutively, or the average magnitude over five recordings repeated twice or the average magnitude over give recordings decreased after reaching a maximum. After the reaction was complete, the products (a dense solid from the reacted sample and a powder residue from jettisoned particles on the side of the bomb) were collected and saved for subsequent analyses.

\subsubsection{Initiation in Bomb Calorimetry}

Typical initiation in bomb calorimetry occurs via heat produced by current running through a resistive wire which is placed in contact with the sample. In cases where this heat is insufficient for ignition, an additional source of heat can be added by way of an initiation aid. The amount of heat liberated per mass of the initiation aid is determined beforehand. Usually, a small known mass of initiation aid is placed next to the primary sample and the heat from the current run through the resistive wire ignites the initiation aid, which in turn ignites the primary sample. The heat contribution of the initiation aid is then subtracted in post-analysis to determine the heat produced by the primary sample. 
Both the standard resistive wire method and the traditional initiation aid method (Figures 3.1 and 3.2 respectively) were unsuccessful in consistently initiating the SHS synthesis of $\mathrm{TiB}_{2}$ and $\mathrm{Al}_{3} \mathrm{Ti} / \mathrm{TiB}_{2}$ from their elemental reactant powder blends. In order to promote the ignition of these reactions, initiation aid was blended within the nominal reactant formulations of $\mathrm{TiB}_{2}$ and $\mathrm{Al}_{3} \mathrm{Ti} / \mathrm{TiB}_{2}$ in addition to having an external initiation aid (Figure 3.3).

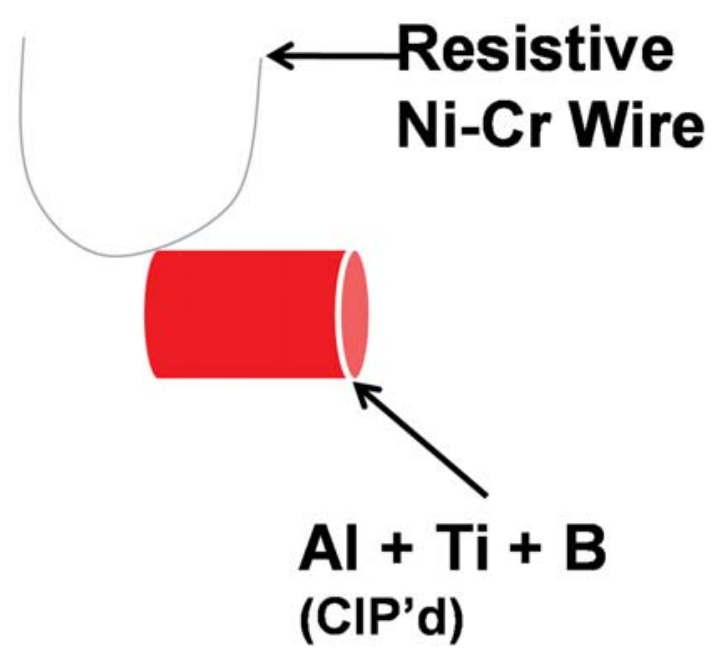

Figure 3.1 Standard ignition setup for bomb calorimetry (applied for Al-Ti-B)

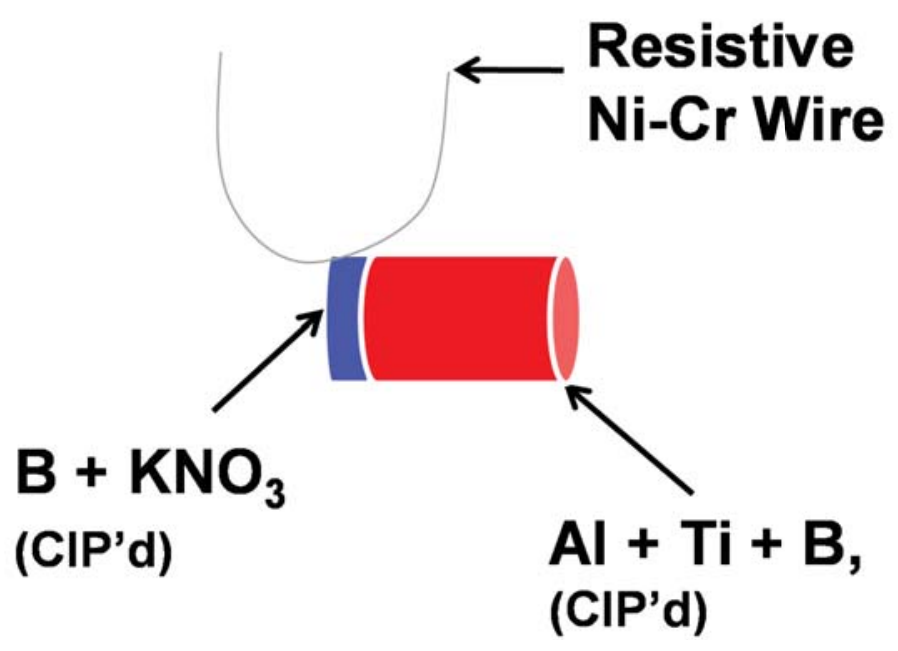

Figure 3.2 Standard initiation aid setup for bomb calorimetry (applied using a BPN external initiation aid and a primary sample of Al-Ti-B) 
Introducing initiation aid into the sample assures a large interaction between the primary reaction and the initiation aid. It is proposed that if the amount of initiation aid, both internally and externally, is systematically varied, a regression can be developed to estimate the nominal heat of reaction of the primary sample and phase composition of the products.

\subsubsection{Bomb Calorimetry Assumptions}

Bomb calorimetry is proposed in these experiments to measure net enthalpy change during reactions. However, the general measurements actually measure the change in internal energy for individual bomb calorimetry experiments and are given by the equation:

$$
d U=c_{\text {bomb }} d T
$$

Where $d U$ is the change in internal energy, $c$ is the heat capacity of the bomb, and $d T$ is the change in temperature of the bomb.

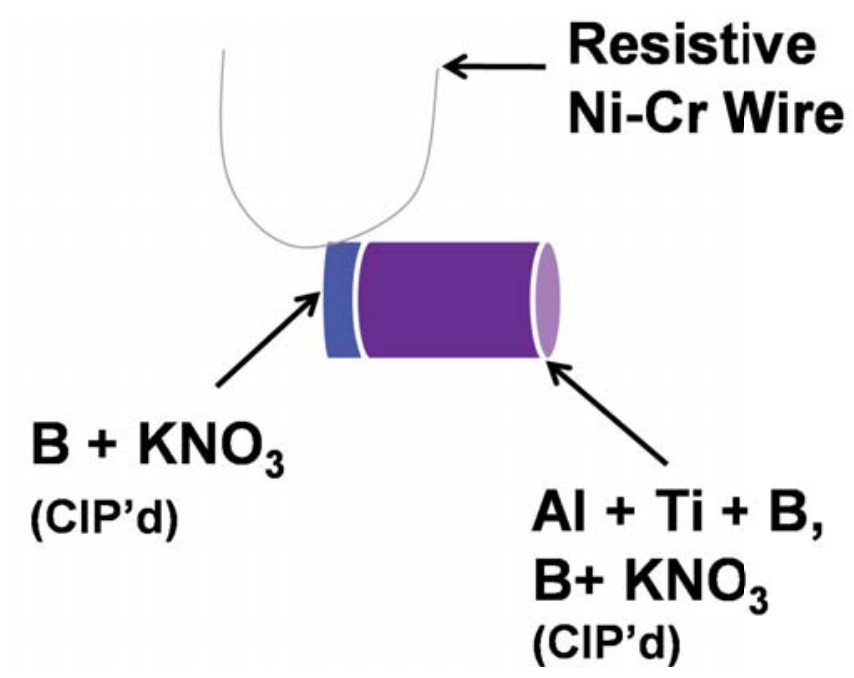

Figure 3.3 Modified setup for initiation in bomb calorimetry (blending of BPN initiation aid into primary powder blend) 
Enthalpy can be related to internal energy by:

$$
d H=d U+d(P V)
$$

Where $d H$ is the change in enthalpy and $d(P V)$ refers to the change in pressure and temperature which expands to:

$$
d(P V)=P d V+V d P
$$

Hence, the change and enthalpy is only equal to the change in internal energy when the $d(P V)$ term is zero. The $d(P V)$ contribution from solids and liquids in the bomb can assumed to be negligible. If it is assumed that the gaseous phase behaves ideally, we can use the ideal gas law to rewrite $d(P V)$ :

$$
d(P V)=R n d T+R T d n
$$

Where $R$ is the ideal gas constant, $n$ is moles of gas, and $T$ is temperature. The change in temperature of the bomb during these experiments is usually only $1-2{ }^{\circ} \mathrm{C}$; therefore the $R n d T$ term is negligible. The final equation shows change of enthalpy as:

$$
d H=d U+R T d n
$$

Introduction of $\mathrm{KNO}_{3}$ as a constituent will liberate nitrogen and oxygen in the gaseous state. The amount of moles of gas produced from experiment to experiment is unknown. However, the moles of gas produced will be directly related to the amount of $\mathrm{KNO}_{3}(\mathrm{PN})$ by:

$$
n_{g a s} \propto n_{P N}
$$

Since the bomb is filled with an inert gas, argon, $\mathrm{KNO}_{3}$ is the only source of gas other than contamination of oxides on the metal powders which is inherent to all the samples. As the initiation aid approaches zero, so should the amount of moles of gas produced. 
Therefore, the regressed output data of the bomb calorimeter should adhere to the assumption:

$$
d H=d U
$$

More complete treatments of these derivations can be found in the literature $[20,21]$.

\subsection{X-Ray Diffraction}

\subsubsection{General Procedure}

A sampling of the collected reaction products was used for $\mathrm{x}$-ray diffraction analysis. The porous solid was crushed using a uniaxial load frame to apply approximately $9 \mathrm{kN}$ of compressive force. The products were then milled into a fine powder in a SPEX mill, using a steel jar and steel ball media. The media and products in the jar were submerged in liquid nitrogen prior to milling to facilitate communition; this also served to decrease the required milling time. The milling was conducted in 3-4 five minute intervals, where liquid nitrogen would be reintroduced after each interval to bring the temperature of the products and jar back down. The milled product was then evaluated for phase constituency using a Scintag XDS 2000 x-ray diffractometer and scanned with monochromatic $\mathrm{CuK \alpha}$ radiation.

Identification of phases present in the product was determined by matching the diffraction patterns to literature patterns in the ICDD database and in Pearsons Crystal Database [22]. Quantitative analysis to determine the relative volume fractions of the products was conducted using the direct comparison method [23]. Here, VOLFRACT [24] software was utilized along with Cromer's method [25] for calculating the atomic scattering factors, to calculate volume fractions. Characteristic peaks and relevant crystal data for calculation from the ICDD database and Pearsons Crystal data were from the following entries: [26-36]. Peak fitting of the raw diffraction data used Pearson VII and Lorenzian fitting models for the peaks and were generated along with background subtraction using Origin (OriginLab Corp., Northampton, MA) software. 
Selected samples of total initiation aid fractions of $0.125,0.25,0.50$, all with 0.80 internal fraction of IA and $0.85 \mathrm{KNO}_{3}$ fraction of IA were analyzed to determine the volume fractions of the product phases in the Ti-B system.

For the Al-Ti-B reactant system, product formulations based on 0,20 , and $40 \mathrm{vol} . \%$ $\mathrm{TiB}_{2}$ with 0.80 internal initiation aid fraction samples were chosen at 3 different total initiation aid levels were evaluated for x-ray phase analysis. The peaks analyzed to determine the relative volume fractions of the products were the (001) and (100) peaks of $\mathrm{TiB}_{2}$, the (112) peak of $\mathrm{Al}_{3} \mathrm{Ti}$, the (111) peak of $\mathrm{Al}$, the (311) and (400) peaks of $\gamma-\mathrm{Al}_{2} \mathrm{O}_{3}$, and the (111) and (200) peaks of TiN. The analyzed volume fractions do not take into account the potentially small volume fraction of other possible BPN reaction products. However, a regressed volume fraction extrapolated to zero total initiation aid should approximate the nominal volume fraction and will be outlined in the x-ray diffraction assumptions section. The error bars in all subsequent volume fraction graphs take into account fitting error of the integrated intensity as well as the variance between different peaks to calculate the volume fractions.

\subsubsection{X-Ray Diffraction Assumptions}

Quantitative x-ray diffraction analysis in this work involves the use of the direct comparison method [23]. This method is defined by two equations; for analysis of a two phase product:

$$
I_{\alpha} R_{\gamma} c_{\gamma}=I_{\gamma} R_{\alpha} c_{\alpha}
$$

and

$$
c_{\alpha}+c_{Y}=1
$$

Where $\gamma$ and $\alpha$ generically refer to the two phases in the product, I is the integrated intensity of a diffraction peak, $\mathrm{R}$ is a coefficient that that consists of phase and crystal specific values, and $\mathrm{c}$ is the phase volume fraction of the product. 
For the particular reaction products in this work, a small volume fraction of the BPN product will be present. However, much like the bomb calorimetry assumption, if we regress the volume fraction to its zero initiation aid point, no BPN product should exist. Therefore, the regressed value of the volume fraction should approximate the actual volume fraction value at zero initiation aid as shown in the equations:

$$
C_{Y}+C_{\alpha}+C_{B P N \text { Product }}=1
$$

\subsection{Design of Experiments (DOE)}

\subsubsection{Overview of Design of Experiments}

Design of experiments (DOE) is a strategy for experimentation that focuses on efficiency of collecting data and maximizing the statistical information gleaned from the data. Matrices of experiments are created using this method to discern particular effects of variables (or factors), as well as interactions between variables [37].

In this research, fractional factorial designs are used to reduce the amount of experiments needed to attain the desired statistical information. For instance, a $2^{5}$ design would imply 5 factors are under study, with two levels of each factor. $2^{5}$ (or 32 experiments would be needed to ascertain the full set of interactive effects between these factors. However, the assumption of sparsity-of-effects can be used to reduce the number of experiments. Sparsity-of-effects implies that higher-order interaction terms are very unlikely to be significant. Higher-order interaction terms usually include four-way interactions (a unique effect of having 4 variables at particular levels, rather than the sum of their individual effects) and higher. Three-way interactions are also sometimes included as a higher-order interaction term as well.

A $2^{5-1}$ fractional factorial DOE reduces the number of experiments from 32 to 16 and would be able to discern single factor and two-way interactive effects. In this model, single factors effects would be aliased (or combined) with a 4-way effect, which under the assumption of sparsity would be negligible. The two-way interactions would be aliased with a three-way effect. Based on the knowledge of the data, this could be 
considered negligible. If a two-way effect was found to be significant and the experimenter was worried that this was actually a three-way effect, further experimentation would be needed to separate these effects.

\subsubsection{Regression Development}

The least squares method of regression was utilized to establish a quantitative trend of enthalpy data and volume fraction data. Mathematics and calculations for the regression were performed using Minitab software (Minitab, Inc., State College, PA). Under the least squares method, the selection of the coefficients $\left(\mathrm{B}_{\mathrm{i}}\right)$ for the significant factors $\left(\mathrm{x}_{\mathrm{i}}\right)$ minimizes the sum of squares of the residual error $(\varepsilon)$ in the equation [37]:

$$
\Delta H_{r}=B_{0}+B_{1}^{*} X_{1}+B_{2}^{*} X_{2}+\ldots B_{i}^{*} X_{i}+\varepsilon
$$

The equation can be expanded to include as many significant factors, $\mathrm{B}_{\mathrm{i}}{ }^{*} \mathrm{x}_{\mathrm{i}}$, as needed.

Before a regression was developed, a selection of process and technique related variables were subjected to a design of experiments (DOE) screening test to determine the significance of any interactive effects between processing variables and the initiation aid fraction. A $2^{5-1}$ screening DOE matrix was used for the Ti-B system with the variables listed in Table 3.4 and was analyzed for main effects and two-way interactions.

Total Initiation Aid (IA) Fraction refers to the total weight fraction of reacting material placed in the bomb that is initiation aid $\left(\mathrm{KNO}_{3} / \mathrm{B}\right)$. Internal Fraction of IA in Compact refers to the weight fraction of the total initiation aid that is blended into the reactive sample formulation. $\mathrm{KNO}_{3}$ Fraction of IA refers to the weight fraction of the initiation aid that is $\mathrm{KNO}_{3}$ (balance is boron).

In order to develop a more refined regression for the Ti-B reactant system, the fraction of initiation aid was varied incrementally further indicated in Table 3.5. The non-significant conditions selected for the new experiments consisted of $149 \mu \mathrm{m}$ Ti particle size, 0.80 internal fraction of IA, and an $830 \mathrm{kPa}$ initial bomb pressure. 
Process variable screening for the $\mathrm{Al}_{3} \mathrm{Ti}_{\mathrm{T}} / \mathrm{TiB}_{2}$ system utilized a similar screening matrix to the $\mathrm{TiB}_{2}$ study. Utilizing a $2^{6-2}$ screening DOE matrix, the following factors in Table 3.6 were analyzed for main effect, two-way and three way-interaction significance.

For the Al-Ti-B reactant system, a regression was created from the levels and factors in Table 3.7. $\mathrm{KNO}_{3}$ fraction of the initiation aid was kept constant at 0.70 .

Table 3.4

Screening factors for $\mathrm{TiB}_{2}$ validation experiments

\begin{tabular}{cc}
\hline Factor (Variable) & Levels \\
\hline $\begin{array}{c}\text { Total Initiation Aid (IA) } \\
\text { Fraction }\end{array}$ & $0.25,0.50$ \\
Internal Fraction of IA in & $0.667,0.80$ \\
Compact & $0.70,0.85$ \\
$\mathrm{KNO}_{3}$ Fraction of IA & $44 \mu \mathrm{m}, 149 \mu \mathrm{m}$ \\
Titanium Particle Size & $415 \mathrm{kPa}, 830 \mathrm{kPa}$ \\
Initial Bomb Pressure
\end{tabular}

Table 3.5

Factors for regression in the $\mathrm{TiB}_{2}$ validation study

\begin{tabular}{cc}
\hline Factor & Levels \\
\hline Total Initiation Aid (IA) Fraction & $0.125,0.25,0.3750 .50$ \\
$\mathrm{KNO}_{3}$ Fraction of IA & $0.70,0.85$ \\
\hline
\end{tabular}


For creation of a least squares regression model, the internal and external contributions were separated to reduce codependence of the variables. This was accomplished by creating the following terms: IA Frac*Int Frac (the internal contribution to the enthalpy change from the initiation aid) and IA Frac*(1-Int Frac) (the external contribution to enthalpy change from the initiation aid). Enthalpies of reaction values for the nominal blends are obtained by entering the particular $\mathrm{TiB}_{2}$ fraction value and zeroing the contributions from the initiation aid.

For the $\mathrm{Al}-\mathrm{Ti}-\mathrm{B}_{4} \mathrm{C}$ reactant system, the factors and levels used for developing a regression are listed in Table 3.8. $\mathrm{KNO}_{3}$ fraction of the initiation aid was kept constant at 0.70 .

Table 3.6

Screening factors and levels for screening experiments for the Al-Ti-B study

\begin{tabular}{cc}
\hline Factor & Levels \\
\hline Initiation Aid (IA) Fraction & $0.25,0.50$ \\
Fraction of IA in Compact & $0.667,0.80$ \\
$\mathrm{KNO}_{3}$ Fraction of IA & $0.70,0.85$ \\
$\mathrm{TiB}_{2}$ vol. Fraction (Formulated) & $0.20,0.40$ \\
Titanium Particle Size & $44 \mu \mathrm{m}, 149 \mu \mathrm{m}$ \\
Aluminum Particle Size & $44 \mu \mathrm{m}, 149 \mu \mathrm{m}$ \\
\hline
\end{tabular}

Table 3.7

Factors and levels for the regression model for the Al-Ti-B study

\begin{tabular}{|c|ccccc|} 
TiB $_{2}$ Levels & 0.0 & 0.2 & 0.4 & 0.6 & 0.8 \\
IA Frac & $0.375,0.50$, & $0.25,0.375$, & $0.25,0.375$, & $0.25,0.375$, & $0.25,0.375$ \\
Levels & 0.625 & 0.50 & 0.50 & 0.50 & 0.50 \\
Int Frac & & $0.401,0.514$, & $0.401,0.514$, & & \\
Levels & $0.667,0.80$ & $0.667,0.80$ & $0.667,0.80$ & $0.667,0.80$ & $0.667,0.80$
\end{tabular}


Regression for the volume fraction of $\mathrm{TiB}_{2}$ in the Al-Ti-B system consisted of the samples identified in the x-ray diffraction section of the Experimental Procedures. Since the volume fractions themselves determined have individual uncertainties, a weighted least squares model was utilized to develop a regression using the reciprocal of the variance of each point as the unbiased weighting coefficient [38-40]. No simplistic analytical technique exists to combine the uncertainty of the individual measurements into the regression. Therefore as a conservative estimate, the standard additive propagation of error is used to combine the average error of the individual measurements and the standard error of the fitted model from the weighted least squares regression.

Table 3.8

Factors and levels for the experiments and regression for the Al-Ti- $\mathrm{B}_{4} \mathrm{C}$ study

\begin{tabular}{|c|ccc|}
$\mathbf{T i B}_{2} / \mathrm{TiC}$ & 0.2 & 0.4 & 0.6 \\
Levels & & & \\
IA Frac & $0.375,0.50,0.625$ & $0.375,0.50,0.625$ & $0.375,0.50,0.625$ \\
Levels & & & 0.667 \\
Int Frac & 0.667 & 0.667 & \\
Levels & & &
\end{tabular}




\section{Data and Results}

\subsection{BPN Characterization}

The x-ray diffraction spectrum of the reacted BPN product in Figure 4.1 reveals a lowsymmetry structure and the possibility of multiple phases. Characteristic peaks of $\mathrm{KNO}_{3}$, likely unreacted, were also identified in the spectrum. Other than $\mathrm{KNO}_{3}$, the identity of the other phases in the spectrum could not reasonably be determined to a high degree of certainty.

The measured internal energy changes in the reaction of $\mathrm{B} / \mathrm{KNO}_{3}$ determined through bomb calorimetry of $\mathrm{KNO}_{3}$ weight fractions of $0.50,0.70$, and 0.85 (balance $\mathrm{B}$ ) are shown in Figure 4.2. Internal energy change at the 0.50 and $0.70 \mathrm{KNO}_{3}$ weight fraction levels are about the same, while the change is less negative at 0.85 weight fraction.

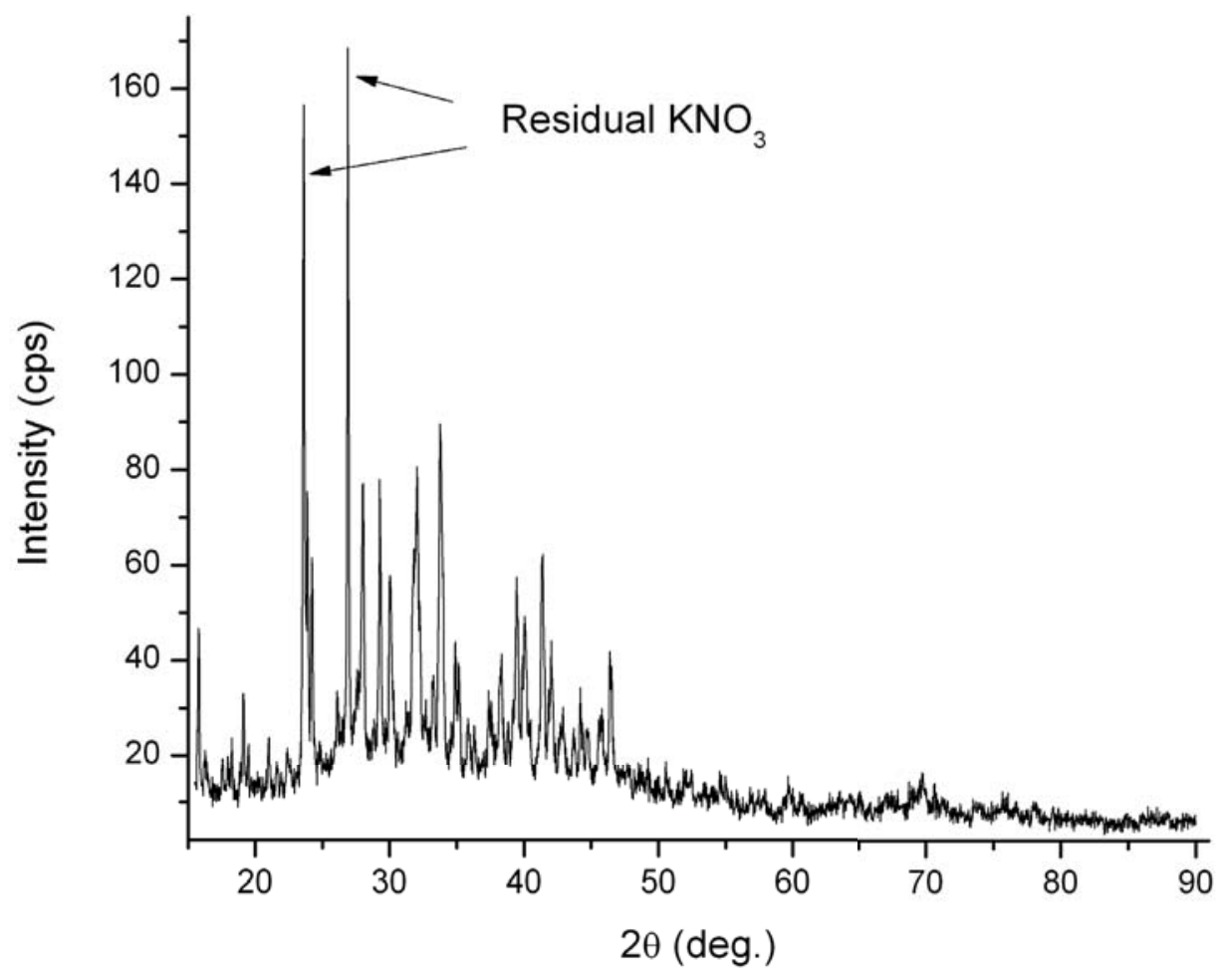

Figure 4.1 X-ray diffraction pattern of product of BPN reaction 


\section{2 $\mathrm{TiB}_{2}$ Synthesis for Technique Validation}

\subsubsection{Process Variable Screening}

The significance or non-significance of the factors (shown previously in Table 3.4) in the DOE matrix, is displayed in a normal plot in Figure 4.3.

The line in Figure 4.3 is Lenth's Pseudo Standard Error (PSE), which assumes the variation in the smallest effects is a measure of random error [41]. Factors that have a large influence on the data will deviate from this line and are considered significant. The normal plot in Figure 4.3 shows that at an error threshold $\alpha=0.05$, only the total initiation aid fraction and the $\mathrm{KNO}_{3}$ fraction of the initiation aid are significant.

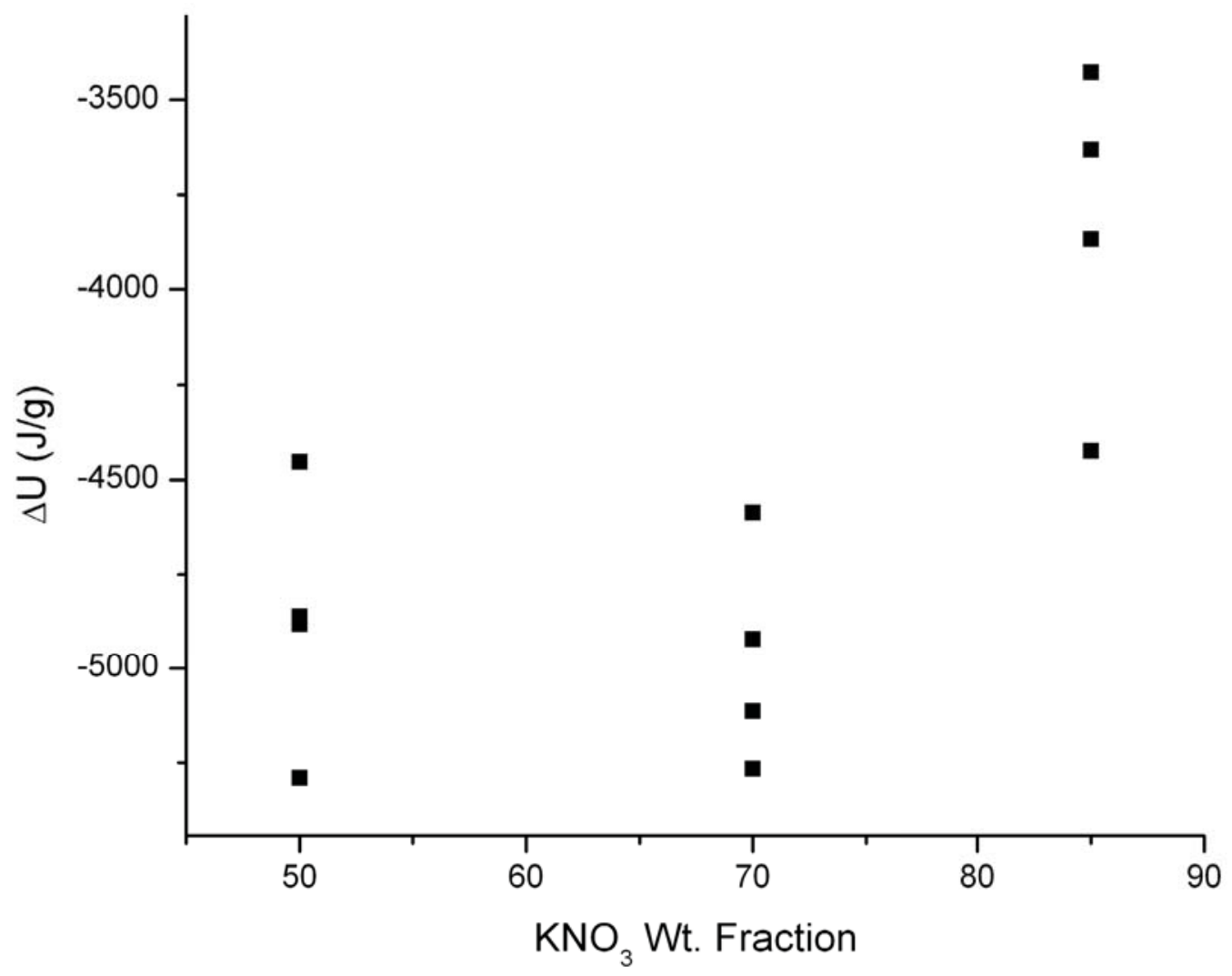

Figure 4.2 Internal energy vs. $\mathrm{KNO}_{3}$ wt. fraction for the $\mathrm{BPN}$ reaction 


\subsubsection{Calorimetry Regression Development}

Figure 4.4 shows the regression of the significant factors to estimate the enthalpy of reaction for the Ti-B system.

The equations for the regressions can be compared in the equations below:

$0.85 \mathrm{KNO}_{3}: \Delta U_{r}(\mathrm{~J} / \mathrm{g})=-4255-3127$ IA Frac, $S=117, \mathrm{R}-\mathrm{sq}(\operatorname{adj})=93.6 \%$

$0.70 \mathrm{KNO}_{3}: \Delta U_{r}(\mathrm{~J} / \mathrm{g})=-4183-2803 \mathrm{IA} \mathrm{Frac}, S=110, R$-sq(adj $)=92.5 \%$

where $\mathrm{S}$ is the square root of the mean squared error and R-sq(adj) is the adjusted coefficient of determination.

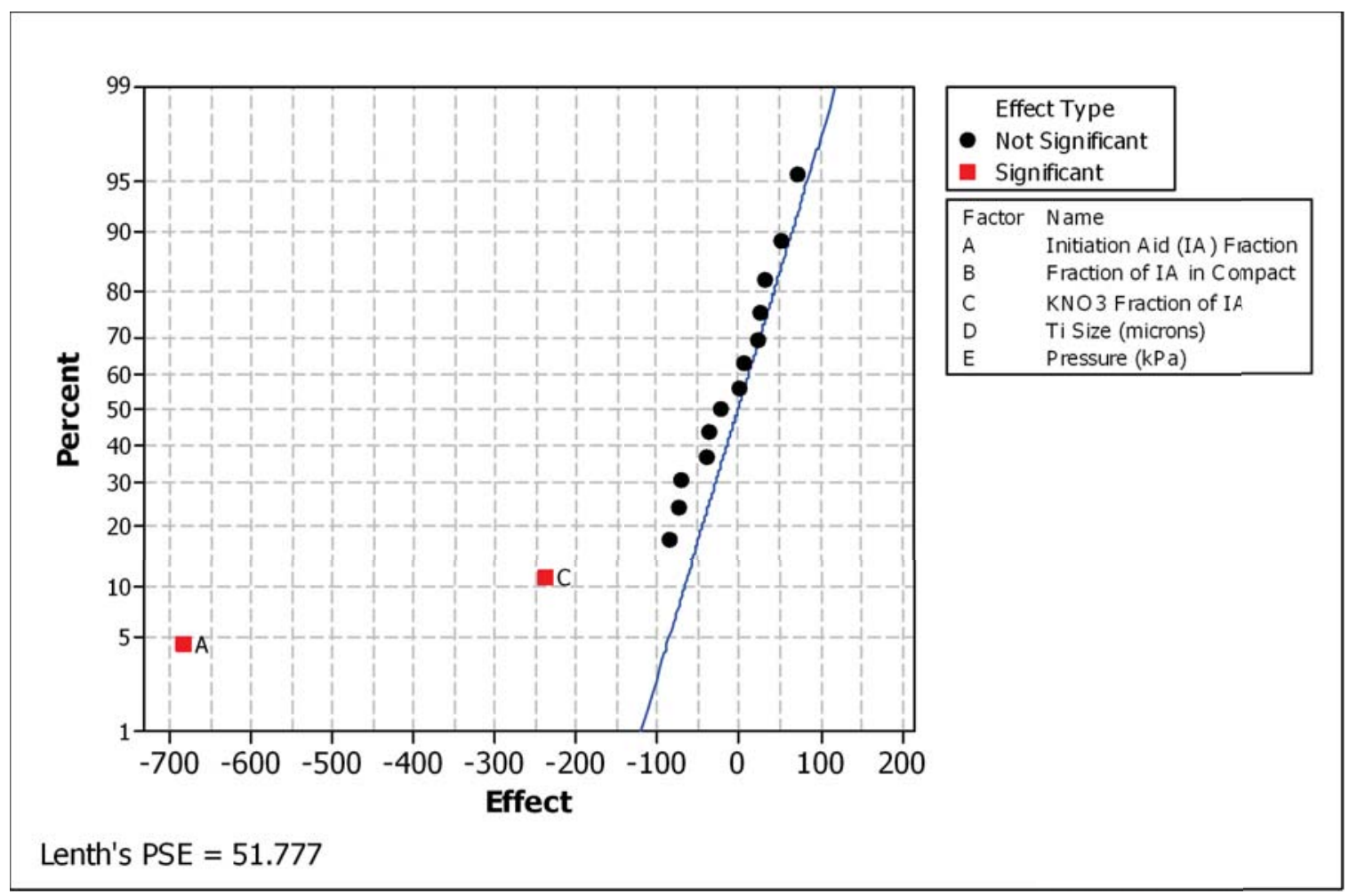

Figure 4.3 Normal plot displaying significance or non-significance of screening variables for $\mathrm{TiB}_{2}$ validation study 
The interactive effect does not appear to be statistically significant according to the analysis of variance (ANOVA) in Table 4.1 even with additional levels added to the regression. 'DF' refers to the degrees of freedom for the factor, 'Seq SS' and 'Adj SS' refer to the sequential and adjusted sum of squares that indicate the magnitude of the effect. The 'Adj MS,' or adjusted mean squared value, of the effect is divided by the MS of the error which results in the ' $F$ ' term which is a measure of whether the effect is significant or not. The significance will be indicated by the ' $\mathrm{P}$ ' value with values $<0.05$ $(\alpha=0.05)$ being significant. The interaction plot in Figure 4.5 indicates the possibility of an interactive effect at lower levels of initiation aid as the lines almost cross.

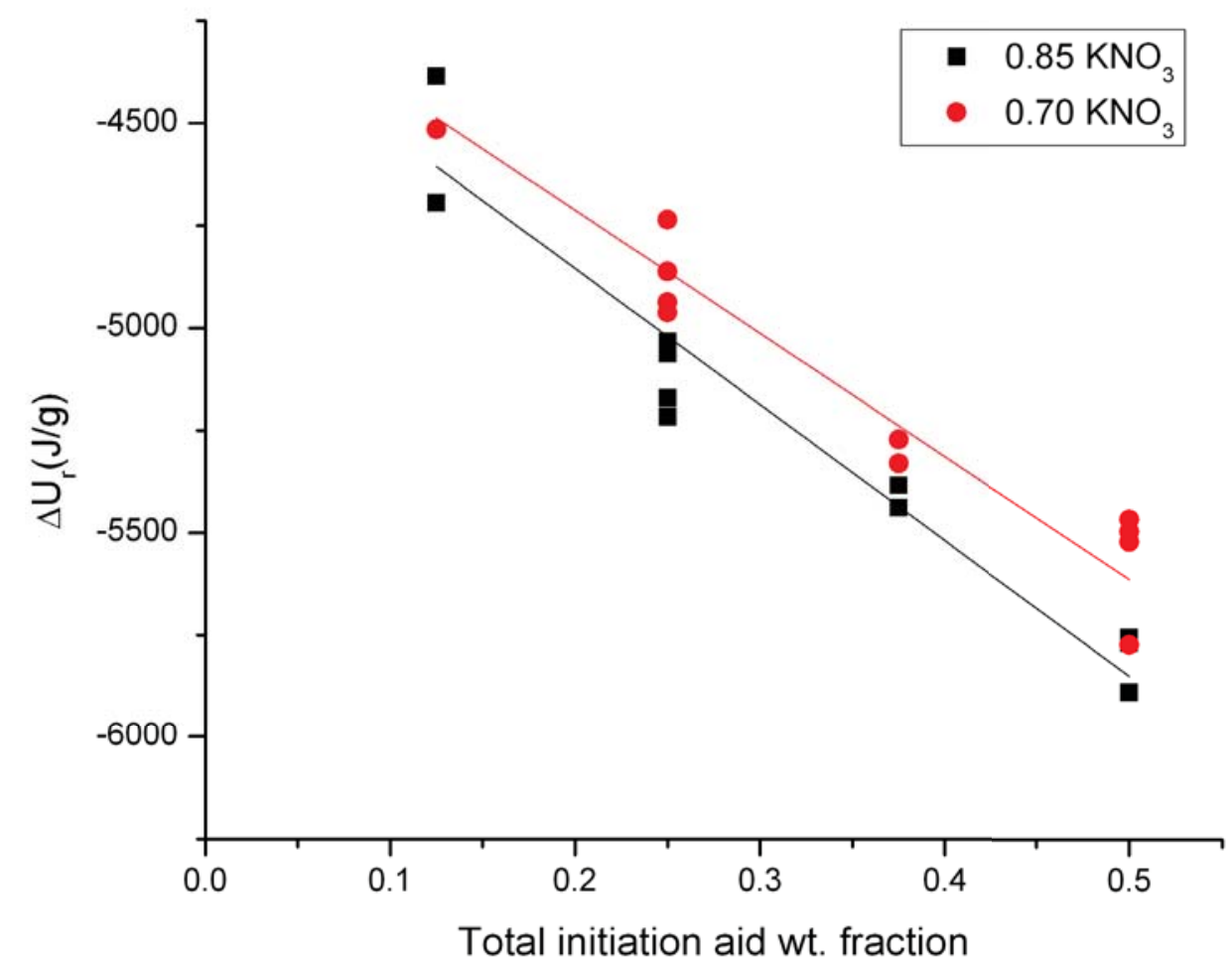

Figure 4.4 Internal energy change of reaction vs. total initiation aid wt. fraction with respect to fraction of $\mathrm{KNO}_{3}$ in the $\mathrm{B} / \mathrm{KNO}_{3}$ blend for the $\mathrm{TiB}_{2}$ validation study. 
Table 4.1

ANOVA table for $\mathrm{TiB}_{2}$ validation study with relevant factors

\begin{tabular}{crrrrrr}
\hline Source & DF & \multicolumn{1}{c}{ Seq SS } & \multicolumn{1}{c}{ Adj SS } & Adj MS & \multicolumn{1}{c}{ F } & \multicolumn{1}{c}{ P } \\
\hline IA Frac & 3 & 3585620 & 3432883 & 1144294 & 97.49 & 0.000 \\
$\mathrm{KNO}_{3}$ Frac & 1 & 206344 & 107188 & 107188 & 9.13 & 0.009 \\
IA Frac* $\mathrm{KNO}_{3}$ Frac & 3 & 34179 & 34179 & 11393 & 0.97 & 0.432 \\
Error & 15 & 176068 & 176068 & 11738 & & \\
Total & 22 & 4002211 & & & & \\
\hline
\end{tabular}

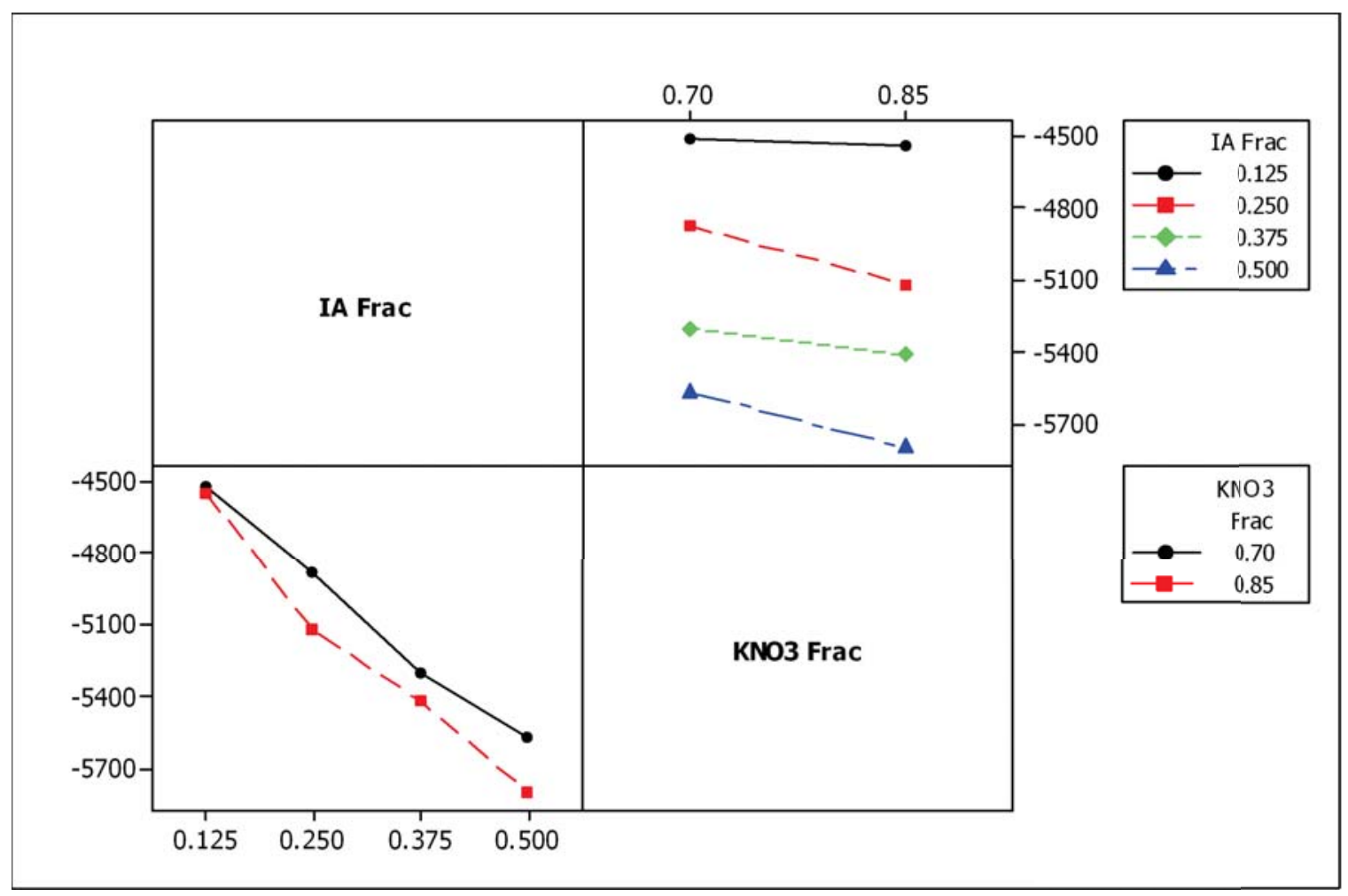

Figure 4.5 Interaction plot between IA fraction and $\mathrm{KNO}_{3}$ fraction. Interaction is indicated by lack of a parallel nature between lines 
The $\mathrm{J} / \mathrm{g}$ output of the regression is multiplied by the appropriate molar conversion factor as if the result of the reaction was monolithic $\mathrm{TiB}_{2}$ for the purposes of comparing with the literature values (the literature values hereafter referred to as Barin [14] and Frankhouser [15]). The resultant values as compared with the literature values are compared in Table 4.2. The enthalpy values of the regression are in good agreement with the literature values if data for crystalline boron as the reactant is used in the prediction.

\subsubsection{Qualitative X-Ray Diffraction}

Figure 4.6 displays an XRD pattern of the reacted product with characteristic peaks of $\mathrm{TiB}_{2}$ and TiN with a metastable composition of $\sim \mathrm{TiN}_{0.5}$. A few unidentified peaks are present in the broad scan range, but are barely above background and are assumed to be from one of the products of the BPN reaction.

X-ray diffraction analysis (Figure 4.7) in of the product residue on the sides of the bomb and crucible indicate the presence of some unidentified low-symmetry phases that are likely a potassium borate as described in the BPN characterization section. However, peaks can be identified that correspond to either metastable $\beta$-Ti or scattering from the $\mathrm{Al}$ holder that the sample rests in.

Table 4.2

Experimental and literature enthalpy of reaction values for $\mathrm{TiB}_{2}$ in the $\mathrm{TiB}_{2}$ validation study (amorphous boron enthalpy contribution from Barin[14] in both values)

\begin{tabular}{cc}
\hline Experimental $\Delta \mathbf{H}_{\mathbf{r}}(\mathbf{k J} / \mathbf{m o l})$ & Literature $\Delta \mathbf{H}_{\mathbf{r}}(\mathbf{k J} / \mathbf{m o l})$ \\
\hline$-291 \pm 7\left(0.85 \mathrm{KNO}_{3}\right)$ & $-281($ Crystalline B)[15] \\
$-296 \pm 6\left(0.70 \mathrm{KNO}_{3}\right)$ & $-324($ Crystalline B)[14] \\
& -379 (Amorphous B)[15] \\
& -422 (Amorphous B)[14] \\
\hline
\end{tabular}




\subsubsection{Quantitative X-Ray Diffraction}

Volume fraction analysis w/respect to unresolved BPN product is shown in Table 4.3. As seen in Figures 4.8 and 4.9, the sample is primarily $\mathrm{TiB}_{2}$, but a regression cannot be developed with the available data.

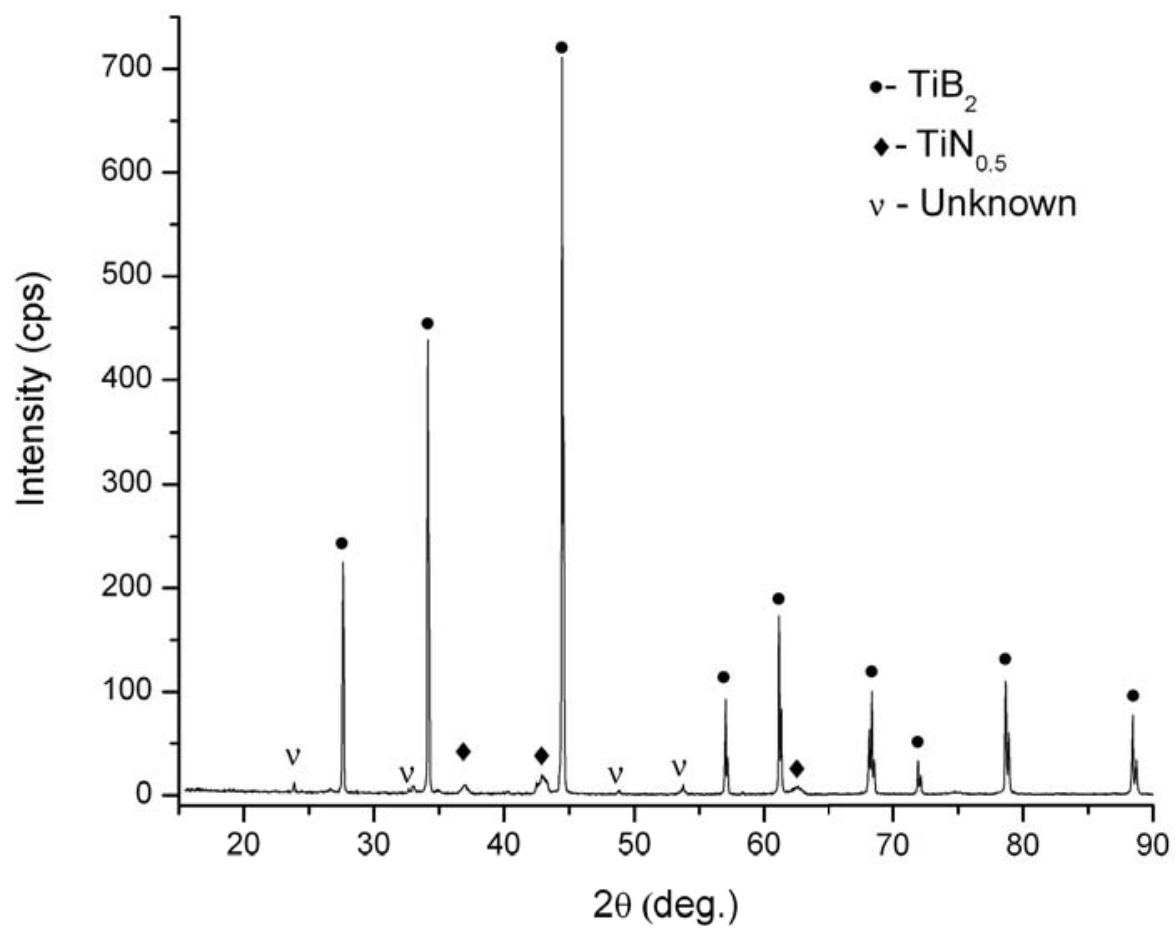

Figure 4.6 X-ray diffraction pattern of a sample with 0.25 initiation aid level, 0.80 internal initiation aid fraction, and $0.85 \mathrm{KNO}_{3}$ initiation aid fraction for the $\mathrm{TiB}_{2}$ validation study. 


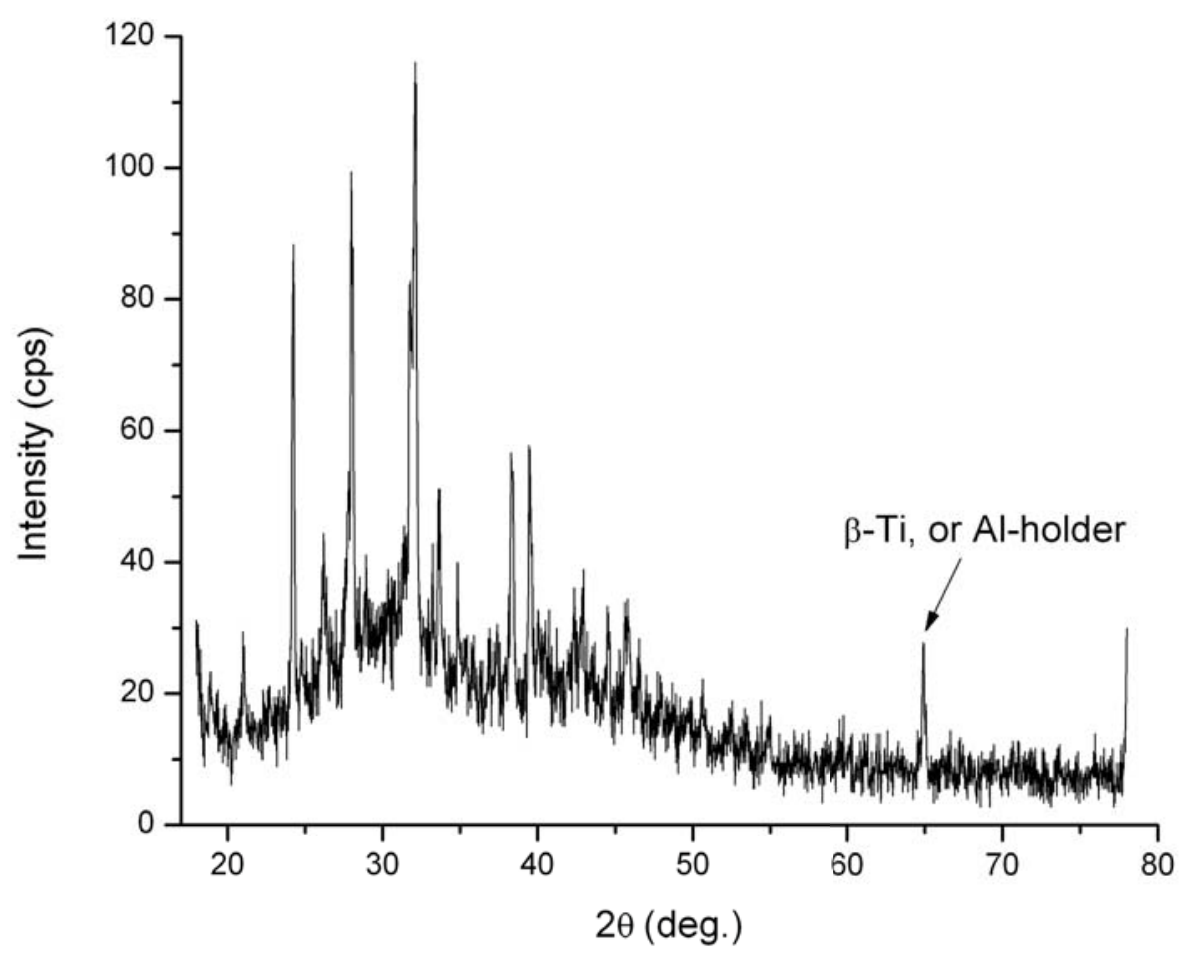

Figure 4.7 X-ray diffraction pattern of residue of a 0.25 initiation aid fraction, 0.80 internal initiation aid fraction, $0.85 \mathrm{KNO}_{3}$ initiation aid fraction sample for the $\mathrm{TiB}_{2}$ validation study

Table 4.3

Volume percents of products for the $\mathrm{TiB}_{2}$ validation study (w/respect to the unknown BPN volume)

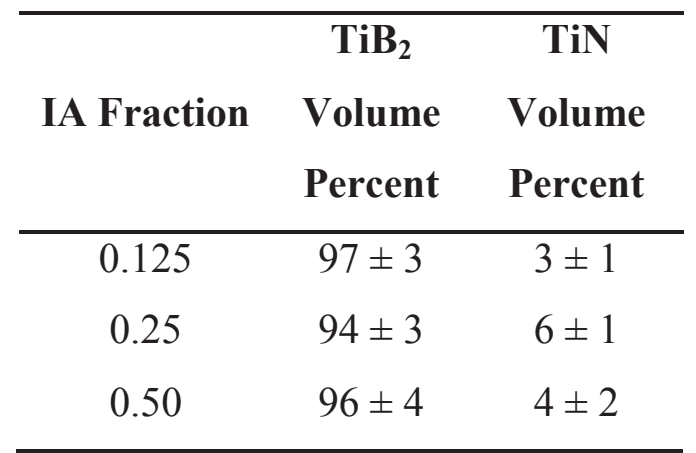




\subsubsection{Summary of Results: $\mathrm{TiB}_{2}$ Validation Study}

The results of the $\mathrm{TiB}_{2}$ validation study indicate that:

1) A statistically significant model could be developed for varying levels of initiation aid with Ti-B blends, which is in good agreement with the literature values for the formation of $\mathrm{TiB}_{2}$. The model satisfies condition (a) of the hypothesis for the Ti-B blends.

2) Post-reaction quantitative $\mathrm{x}$-ray diffraction indicates the presence of approximately $3 \pm 1$ vol. \% $\mathrm{TiN}_{0.5}$ at the lowest recorded initiation aid fraction, presumably an artifact of the BPN reaction. This finding does not explicitly confirm condition (b) of the hypothesis for the Ti-B blends, but the amount of TiN formed is very small, and must be explored further in the discussion section to determine if this amount is negligible and condition (b) is fully satisfied.

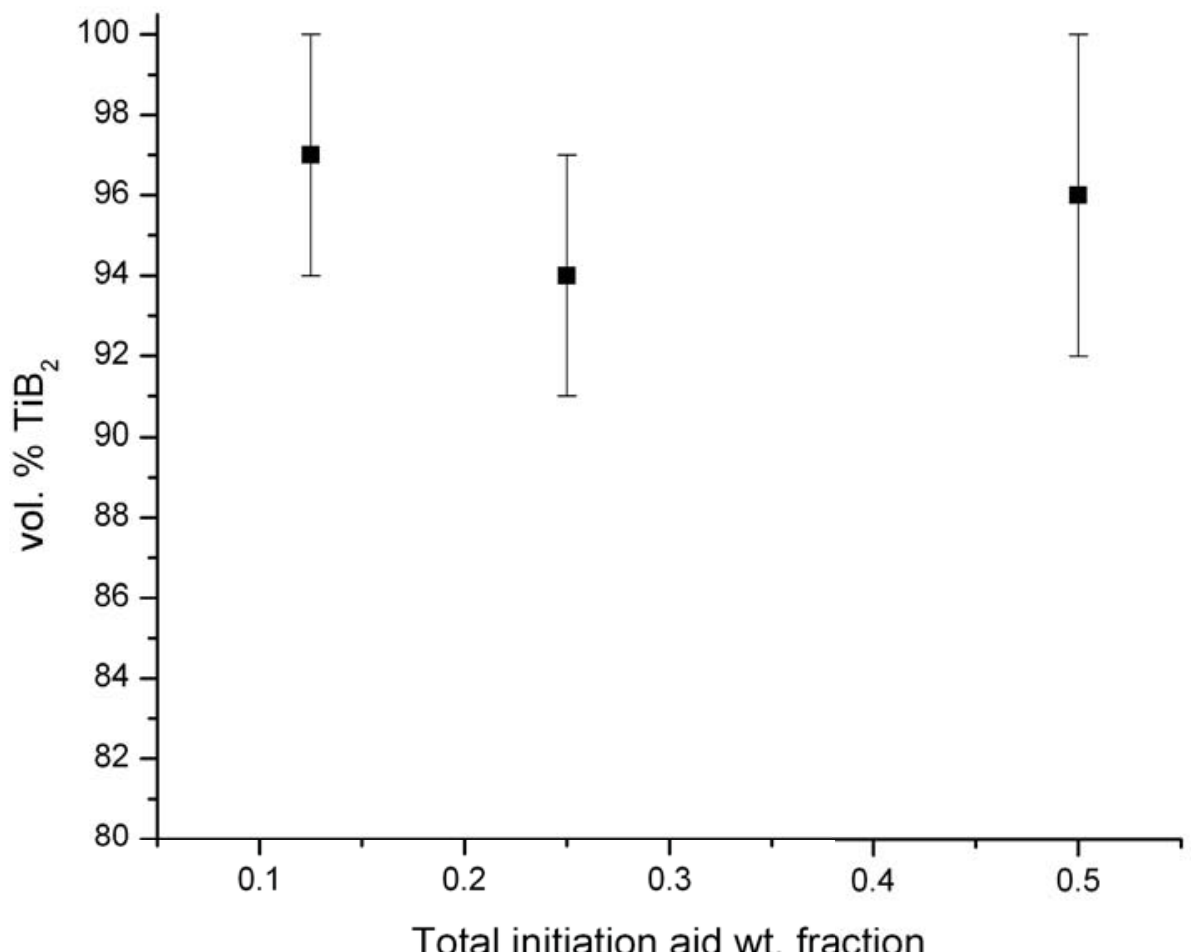

Figure 4.8 Volume percents of $\mathrm{TiB}_{2}$ vs. total initiation aid wt. fraction for $\mathrm{TiB}_{2}$ validation study (w/respect to unknown BPN product) 


\subsection{Application of Technique to Al-Ti-B}

\subsubsection{Process Variable Screening}

The normal plot (Figure 4.10) estimates the significance of the variables in Table 4.4.

The total initiation aid fraction (IA Frac), the fraction of the IA in the compact (IntFrac), the $\mathrm{KNO}_{3}$ fraction of the initiation aid, the formulated volume fraction of $\mathrm{TiB}_{2}$ in the product $\left(\mathrm{TiB}_{2} \mathrm{Frac}\right)$, and an interactive effect between the IA Frac and the $\mathrm{KNO}_{3}$ Frac are significant.

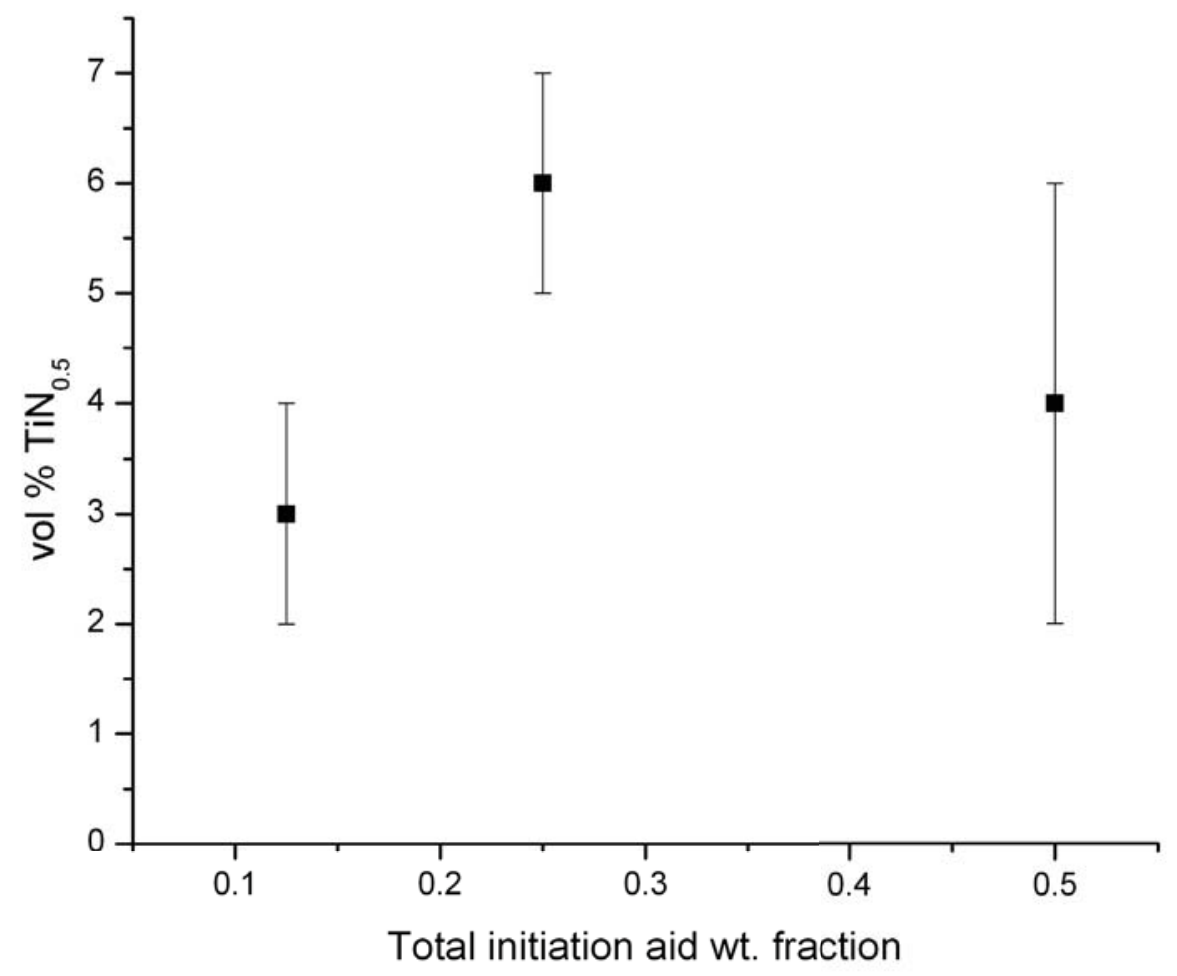

Figure 4.9 Volume percents of $\mathrm{TiN}_{0.5}$ vs. total initiation aid wt. fraction for $\mathrm{TiB}_{2}$ validation study (w/respect to unknown BPN product) 


\subsubsection{Calorimetry Regression Development}

Using the newly created terms and the $\mathrm{TiB}_{2}$ factor, the reduced regression model is determined to be the equation:

$\Delta \mathrm{H}(\mathrm{kJ} / \mathrm{g})=-2.03-2.94$ Ext Contrib -6.96 Int Contrib $-3.05 \mathrm{TiB}_{2} \mathrm{Frac}+7.23$ $\mathrm{Int}^{*} \mathrm{TiB}_{2}^{2}$

Statistical information displaying the significance of each term is provided in Table XII.

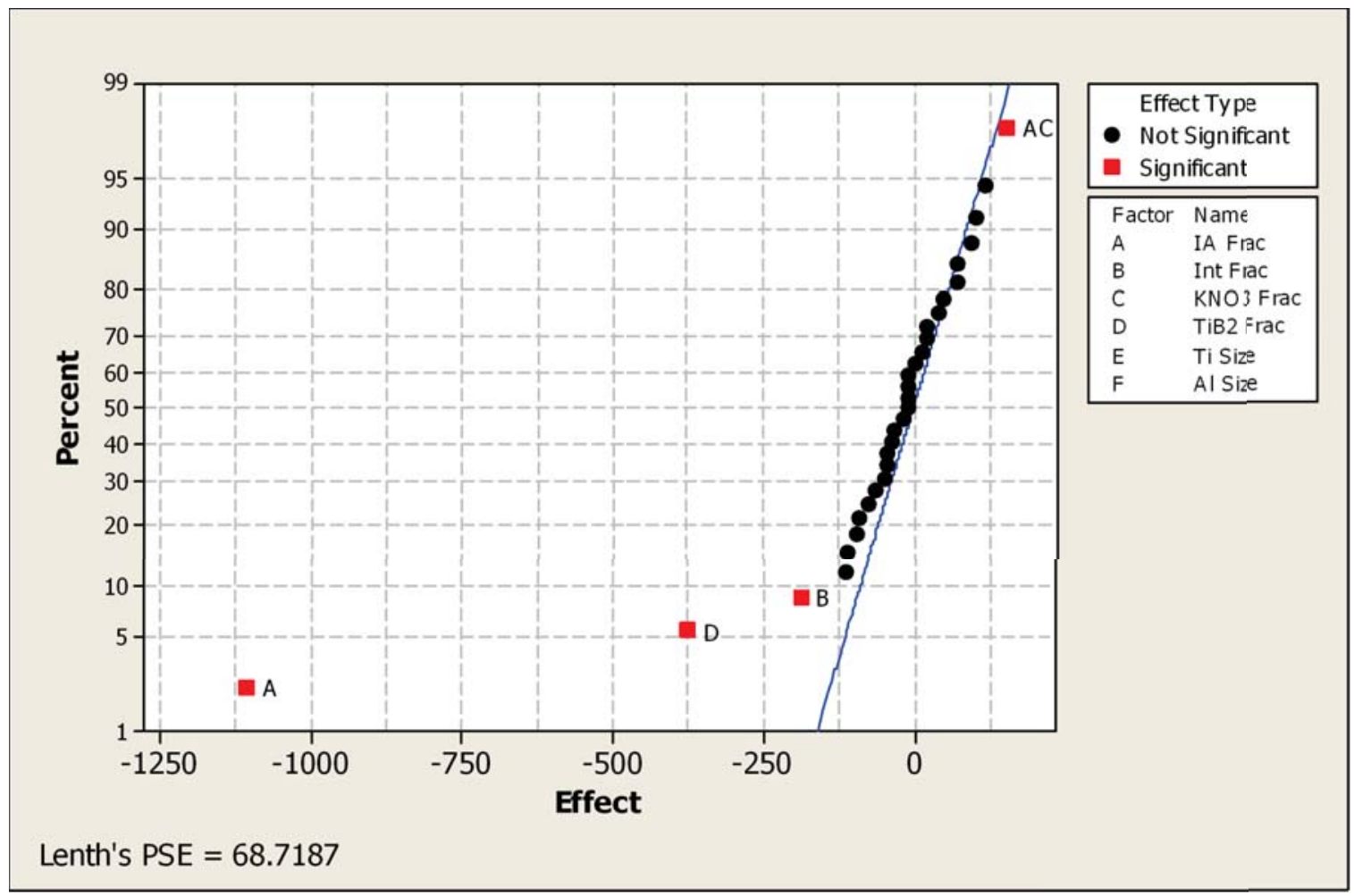

Figure 4.10 Normal effects plot showing significance and non-significance of factors for $\alpha=0.05$ in the Al-Ti-B study 
'Ext Contrib' is the external initiation aid component, 'Int Contrib' is the internal initiation component, ' $\mathrm{TiB}_{2} \mathrm{Frac}$ ' is the formulated $\mathrm{TiB}_{2}$ product volume fraction, and 'Int* $\mathrm{TiB}_{2}$ ' is the interactive effect between the internal initiation component and the formulated $\mathrm{TiB}_{2}$ product volume fraction. The column 'Coef' designates the coefficient for the factor and the column 'SE Coef' the standard error of the coefficient. The ' $\mathrm{T}$ ' value is the resultant of the coefficient being divided by its standard error to determine if the value is significant. This significance is indicated by the P column, where $\mathrm{P}$ values $<0.05(\alpha=0.05)$ are significant. The adequacy of the model was determined to be sufficient with an R-sq (adj) value of 93.3\%.

Figure 4.11 displays the experimental and predicted values from the regression model next to the predicted values from the literature. The enthalpy is converted to $\mathrm{kJ} / \mathrm{mol}$ from $\mathrm{kJ} / \mathrm{g}$ assuming the correction proportions of products were formed in order to evaluate the regression values versus the literature values. The Barin data utilizes enthalpy data for both $\mathrm{TiB}_{2}$ and $\mathrm{Al}_{3} \mathrm{Ti}$ from [14], while the (Frankhouser + Barin) data utilizes enthalpy data for $\mathrm{TiB}_{2}$ from [15] and for $\mathrm{Al}_{3} \mathrm{Ti}$ from [14]. In both cases, the enthalpy change associated with the amorphous to crystalline change in boron is from Barin[14].

Table 4.4

Statistical information for the terms of the enthalpy regression model for the Al-Ti-B study

\begin{tabular}{ccccc}
\hline Predictor & Coef & SE Coef & T & P \\
\hline Constant & -2.0323 & 0.1878 & -10.82 & 0.000 \\
Ext Contrib & -2.9401 & 0.4716 & -6.23 & 0.000 \\
IntContrib & -6.9580 & 0.4325 & -16.09 & 0.000 \\
$\mathrm{TiB}_{2} \mathrm{Frac}$ & -3.0547 & 0.3926 & -7.78 & 0.000 \\
$\mathrm{Int}^{*} \mathrm{TiB}_{2}{ }^{2}$ & 7.230 & 1.422 & 5.08 & 0.000 \\
\hline
\end{tabular}


The experimental model diverges from the predicted thermodynamic models. Error values were determined for the $\mathrm{TiB}_{2}$ values of $0,20,40,60$, and 80 vol $\% \mathrm{TiB}_{2}$ (formulated) to provide a sense of scatter of the data as a function of the $\mathrm{TiB}_{2}$ formulation. Furthermore, the enthalpy result for the monolithic $\mathrm{TiB}_{2}$ study differs greatly from the trend of the Al-Ti-B study.

\subsubsection{Qualitative X-Ray Diffraction}

X-ray diffraction of selected samples at 0.40 (Figure 4.12) and 0.20 revealed formation of the intended equilibrium products $\mathrm{TiB}_{2}$ and $\mathrm{Al}_{3} \mathrm{Ti}$. Additional byproducts of $\mathrm{Al}_{2} \mathrm{O}_{3}, \mathrm{TiN}$, and Al were also identified.

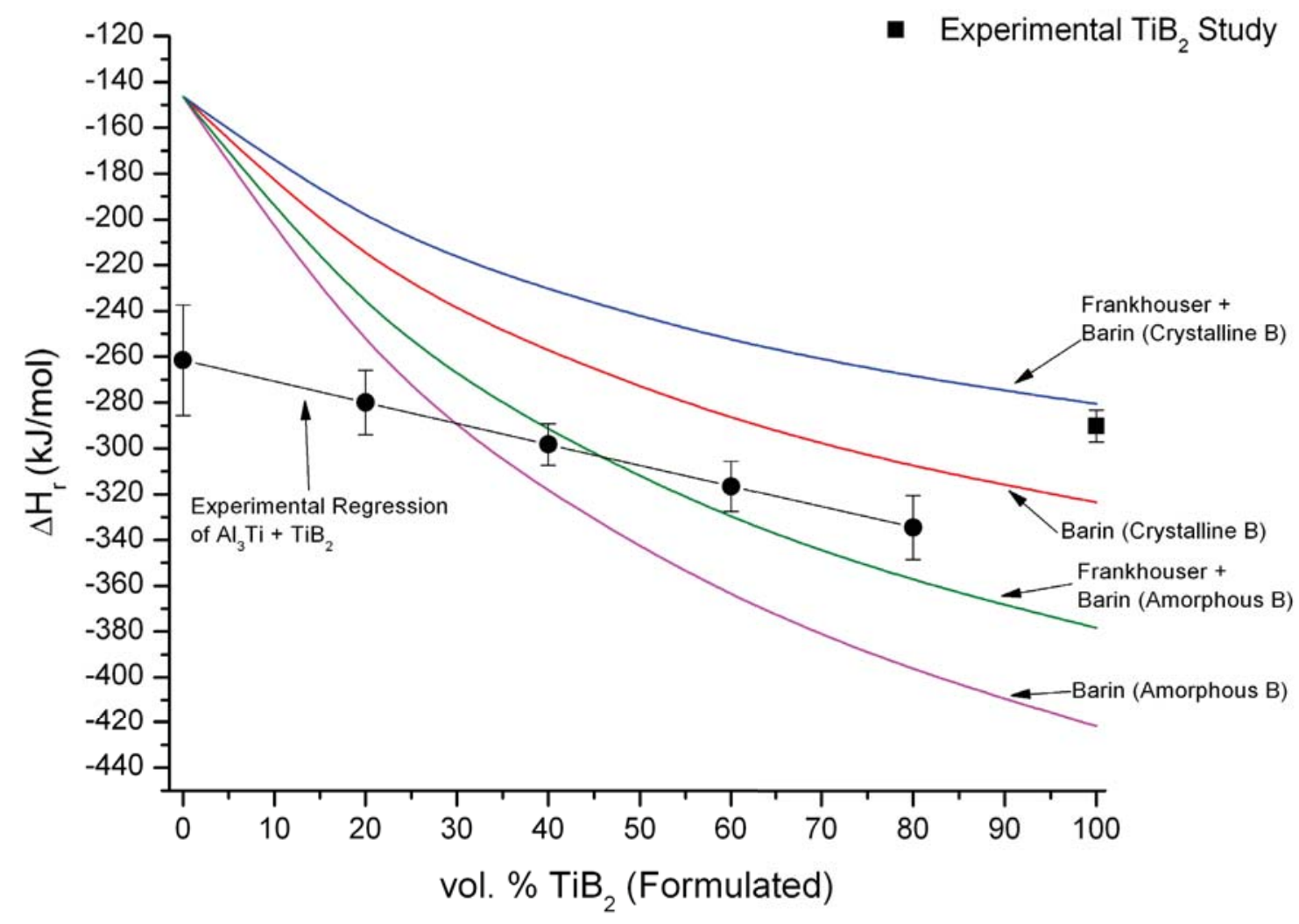

Figure 4.11 Experimental and predicted reaction enthalpy change vs. vol. $\% \mathrm{TiB}_{2}$ (formulated) for the $\mathrm{Al}_{3} \mathrm{Ti} / \mathrm{TiB}_{2}$ study. 
X-ray diffraction on residues from samples at 0.20 and 0.40 formulated $\mathrm{TiB}_{2}$ volume fractions are shown in Figures 4.13 and 4.14 respectively. The presence of $\gamma-\mathrm{Al}_{2} \mathrm{O}_{3}$ can be detected in the diffraction patterns along with unidentified low symmetry phases similar to those in the raw BPN product.

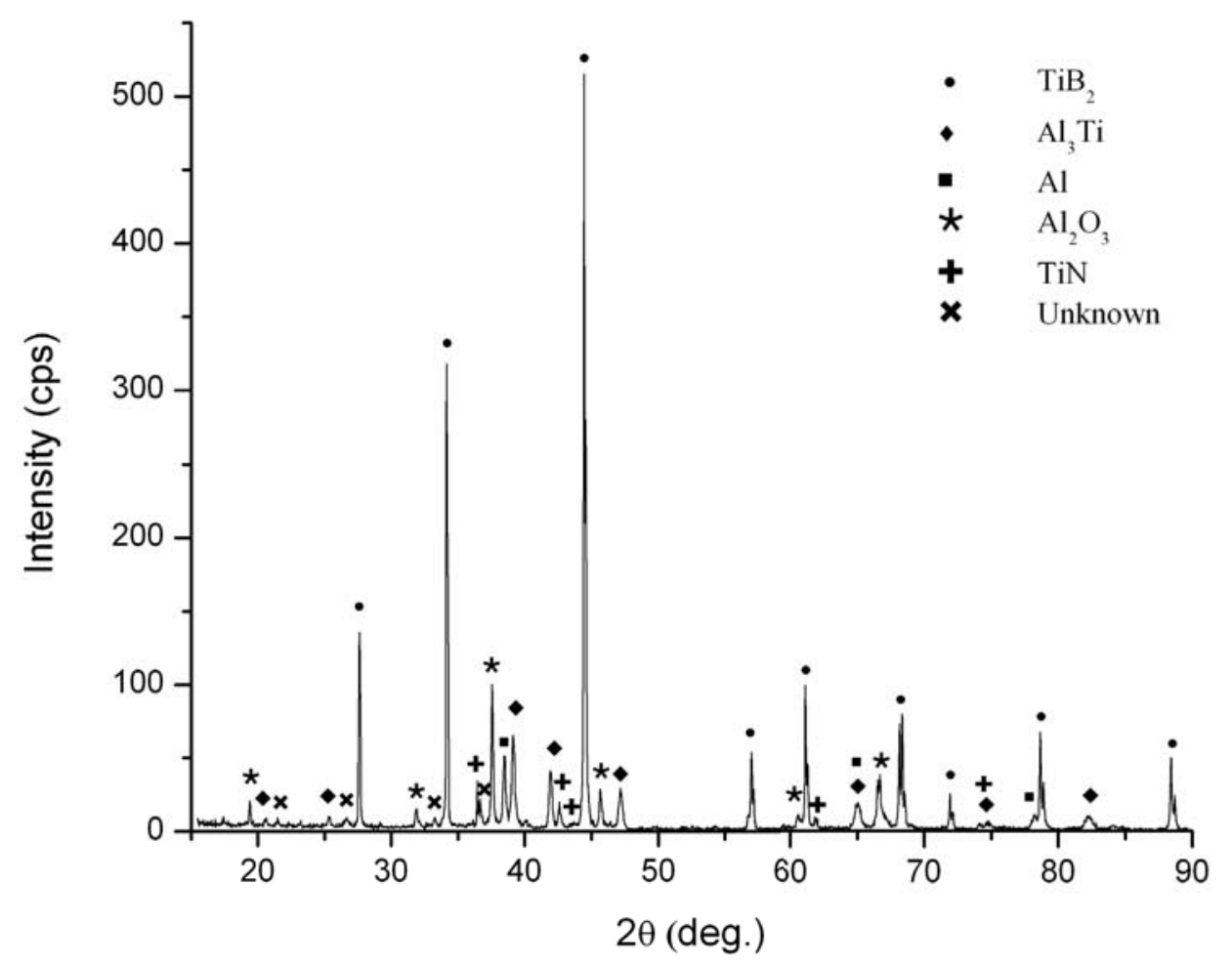

Figure 4.12 X-ray diffraction pattern of a product with formulation factor levels: 0.50 IA Frac, 0.80 Int Frac, 0.4 $\mathrm{TiB}_{2}$ Frac for the Al-Ti-B study 


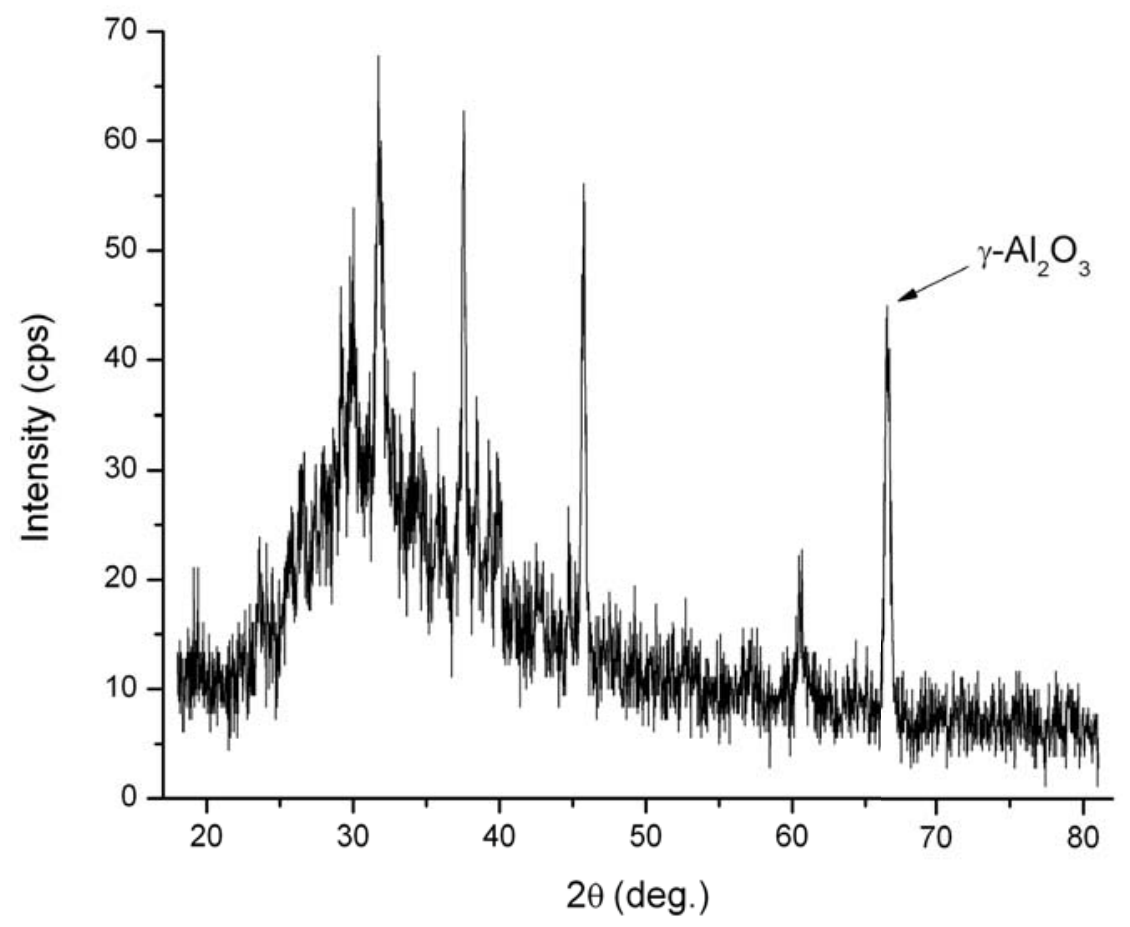

Figure 4.13 X-ray diffraction pattern of residue of a 0.50 initiation aid, 0.80 internal initiation aid, $0.70 \mathrm{KNO}_{3}$ initiation aid fraction sample at 0.20 vol. fraction $\mathrm{TiB}_{2}$ (formulated) for the Al-Ti-B study

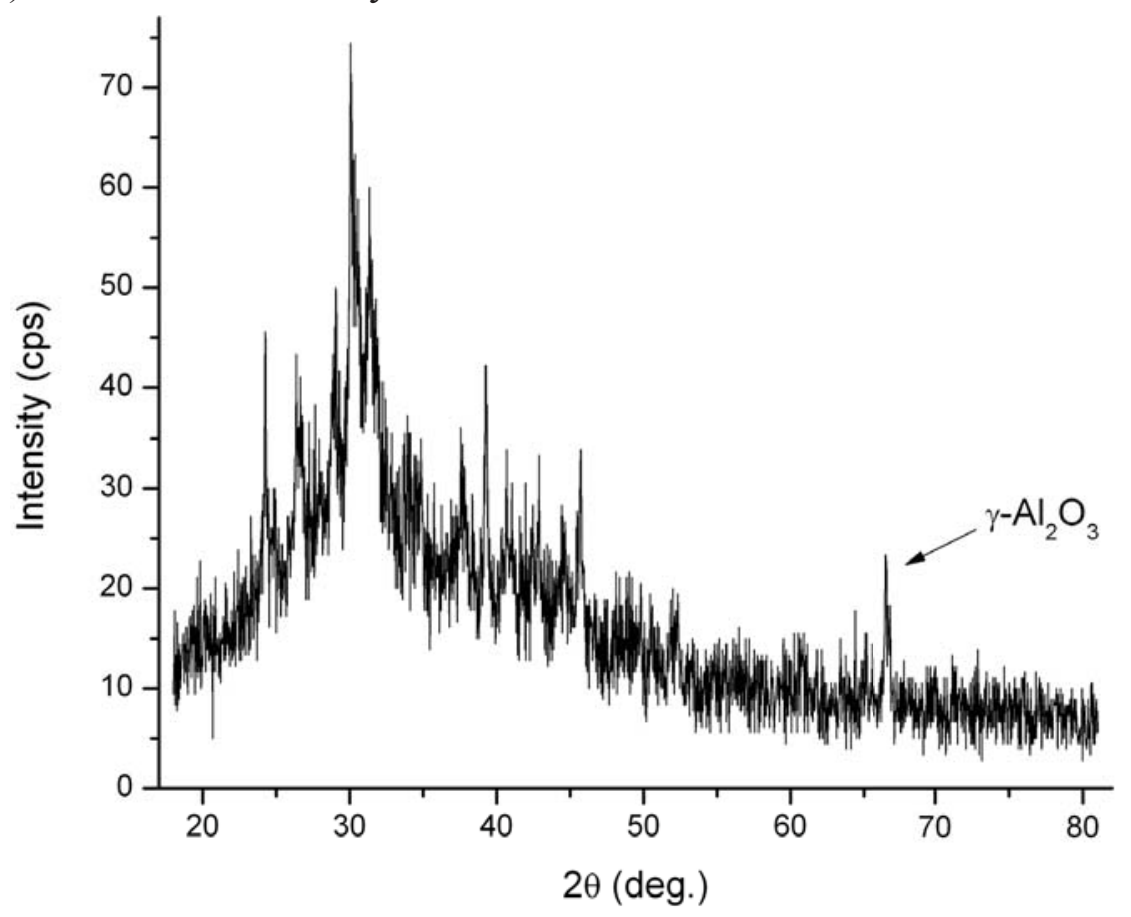

Figure 4.14 X-ray diffraction pattern of residue of a 0.50 initiation aid, 0.80 internal initiation aid, $0.70 \mathrm{KNO}_{3}$ initiation aid fraction sample at 0.40 vol. fraction $\mathrm{TiB}_{2}$ (formulated) for the $\mathrm{Al}_{3} \mathrm{Ti} / \mathrm{TiB}_{2}$ study 


\subsubsection{Quantitative X-ray Diffraction}

The summary of the volume fractions as determined through analysis of the x-ray diffraction pattern of the samples are displayed in Table 4.5.

The volume fractions of $\mathrm{TiB}_{2}$ derived with respect to the unknown BPN volume fractions are shown in Figure 4.15.

The volume fraction of $\mathrm{TiB}_{2}$ appears to be linearly proportional to initiation aid for each $\mathrm{TiB}_{2}$ formulation. The result of the weighted least squares regression is shown in the equation:

Vol. Percent $\mathrm{TiB}_{2}=5.85+53.2 *$ Initiation Aid Fraction $+80.2 * \mathrm{TiB}_{2}$ Vol. Fraction

(Formulated)

Table 4.5

Volume percents of products from the Al-Ti-B study samples (w/ respect to the BPN product volumes)

\begin{tabular}{|c|c|c|c|c|c|c|}
\hline $\begin{array}{c}\text { IA wt. } \\
\text { Fraction }\end{array}$ & $\begin{array}{c}\mathrm{TiB}_{2} \\
\text { vol. \% } \\
\text { (form.) }\end{array}$ & $\begin{array}{c}\mathrm{TiB}_{2} \\
\text { vol. \% }\end{array}$ & $\begin{array}{c}\mathrm{Al}_{3} \mathrm{Ti} \\
\text { vol. } \%\end{array}$ & $\begin{array}{c}\text { Al } \\
\text { vol. \% }\end{array}$ & $\begin{array}{c}\gamma-\mathrm{Al}_{2} \mathrm{O}_{3} \\
\text { vol. } \%\end{array}$ & $\begin{array}{c}\text { TiN } \\
\text { vol. \% }\end{array}$ \\
\hline 0.375 & 0 & $24 \pm 5$ & $36 \pm 2$ & $22 \pm 2$ & $16 \pm 5$ & $1 \pm<0.5$ \\
\hline 0.50 & 0 & $34 \pm 3$ & $4 \pm 1$ & $30 \pm 3$ & $32 \pm 5$ & Trace \\
\hline 0.625 & 0 & $35 \pm 5$ & Trace & $32 \pm 2$ & $34 \pm 4$ & Trace \\
\hline 0.25 & 20 & $36 \pm 5$ & $24 \pm 3$ & $19 \pm 2$ & $18 \pm 6$ & $2 \pm 1$ \\
\hline 0.375 & 20 & $40 \pm 6$ & $17 \pm 2$ & $16 \pm 3$ & $26 \pm 5$ & $2 \pm<0.5$ \\
\hline 0.50 & 20 & $52 \pm 5$ & Trace & $25 \pm 3$ & $23 \pm 6$ & Trace \\
\hline 0.25 & 40 & $51 \pm 3$ & $14 \pm 2$ & $23 \pm 3$ & $11 \pm 3$ & $2 \pm<0.5$ \\
\hline 0.375 & 40 & $57 \pm 4$ & $4 \pm 1$ & $15 \pm 1$ & $24 \pm 3$ & Trace \\
\hline 0.50 & 40 & $65 \pm 5$ & Trace & $11 \pm 1$ & $24 \pm 6$ & Trace \\
\hline
\end{tabular}


The final estimates of the volume fractions of $\mathrm{TiB}_{2}$ are presented in Table 4.6.

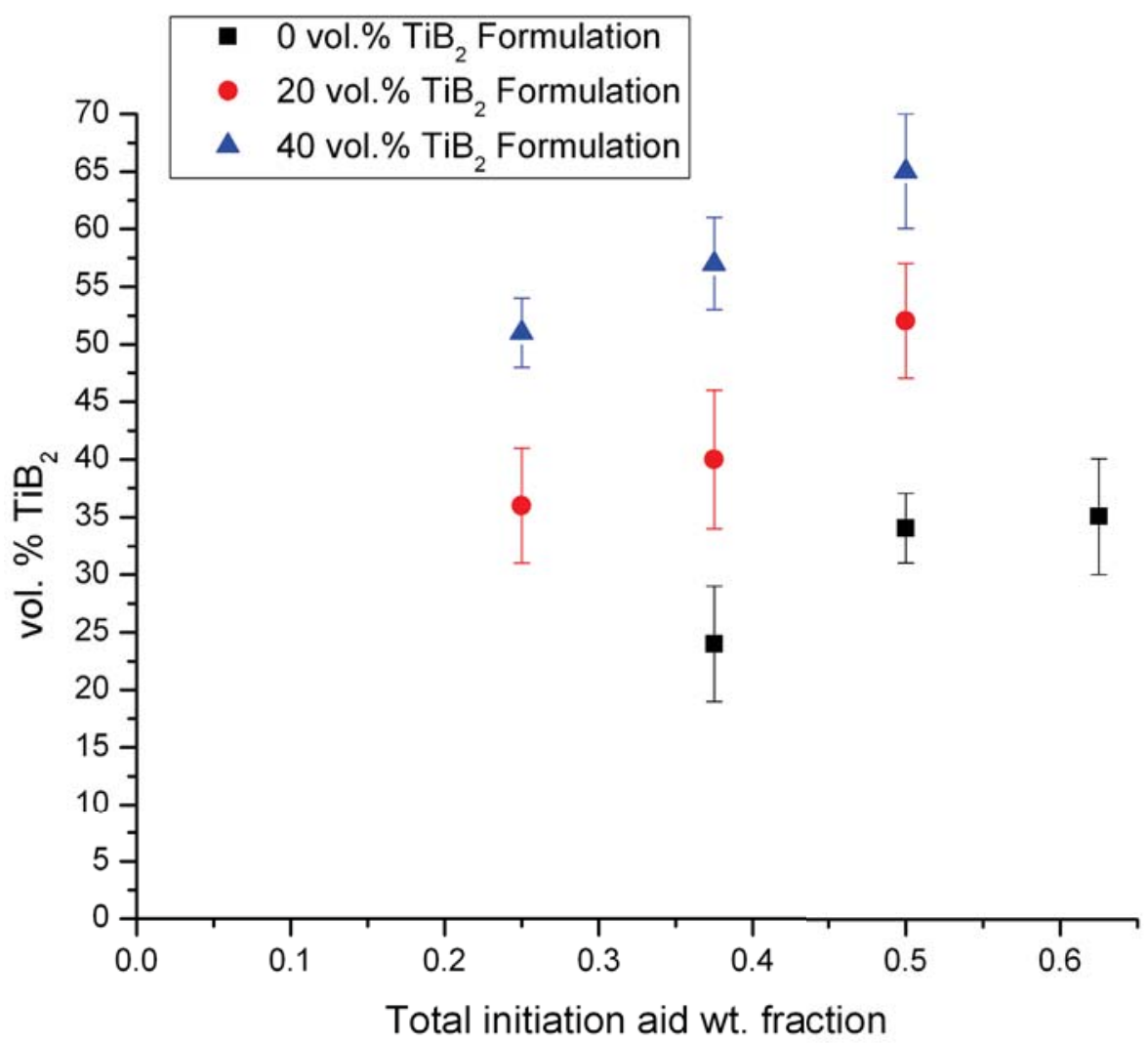

Figure 4.15 Volume percents of $\mathrm{TiB}_{2}$ vs. total initiation aid for the Al-Ti-B study (w/respect to the BPN product volumes)

Table 4.6

Formulated $\mathrm{TiB}_{2}$ vol. $\%$ vs. experimental $\mathrm{TiB}_{2}$ vol. $\%$ as a result of a regression of the volume percents derived from $\mathrm{x}$-ray diffraction (for the Al-Ti-B study)

\begin{tabular}{cc}
\hline Formulated Vol. \% TiB $_{\mathbf{2}}$ & Experimental TiB $_{\mathbf{2}}$ Vol. \% \\
\hline 0 & $6 \pm 6$ \\
20 & $22 \pm 6$ \\
40 & $38 \pm 5$ \\
\hline
\end{tabular}


A regression could not be developed for the volume fraction of $\mathrm{Al}_{3} \mathrm{Ti}$ given the limited amount of data, and therefore the nominal amount of $\mathrm{Al}_{3} \mathrm{Ti}$ being formed for each formulation cannot be determined. However, a general trend of increasing $\mathrm{Al}_{3} \mathrm{Ti}$ with decreasing initiation aid can be observed (Figure 4.16).

No consistent trend for the volume fraction of Al could be determined as observable in Figure 4.17. Implicitly, no regression could be developed for the volume fraction of Al.

The volume fractions of $\mathrm{Al}_{2} \mathrm{O}_{3}$ show a general decrease with decreasing initiation aid (Figure 4.18). However, a reliable regression could not be developed at this time.

Volume fractions of TiN were only detectable at the lower initiation aid fractions (Figure 4.19). A regression could not be developed for this set of data.

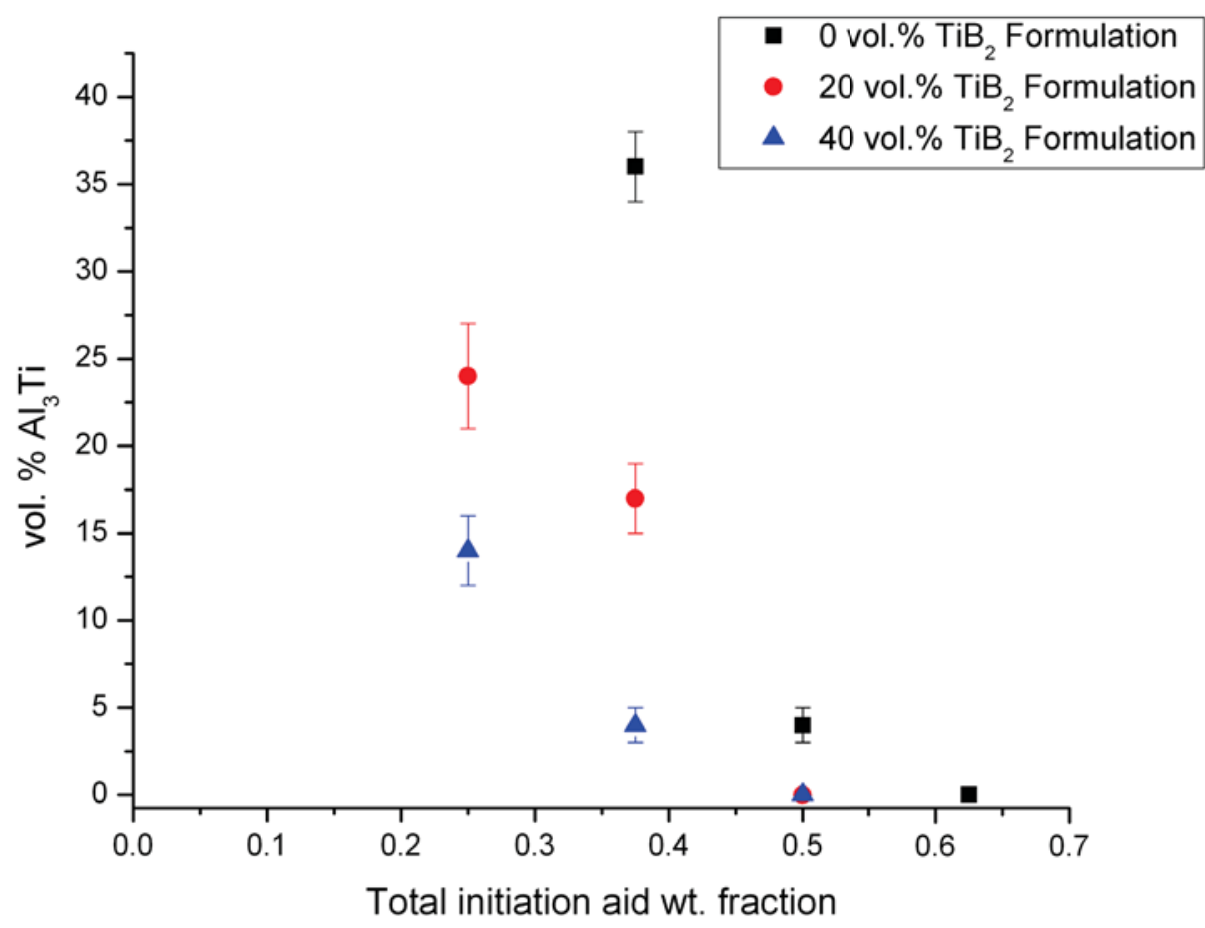

Figure 4.16 Volume percents of $\mathrm{Al}_{3} \mathrm{Ti}$ vs. total initiation aid for the Al-Ti-B study (w/respect to the BPN product volumes) 


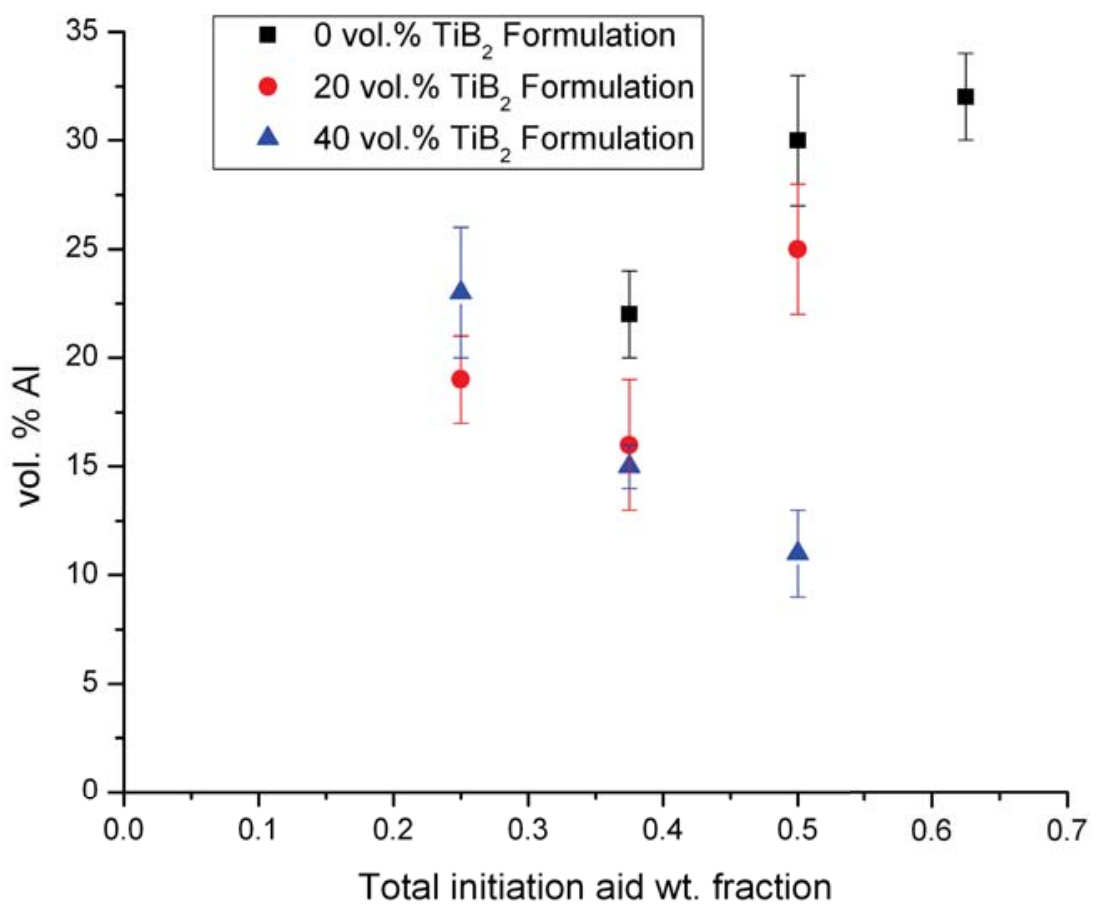

Figure 4.17 Volume percents of Al vs. total initiation aid for the Al-Ti-B study (w/respect to the BPN product volumes)

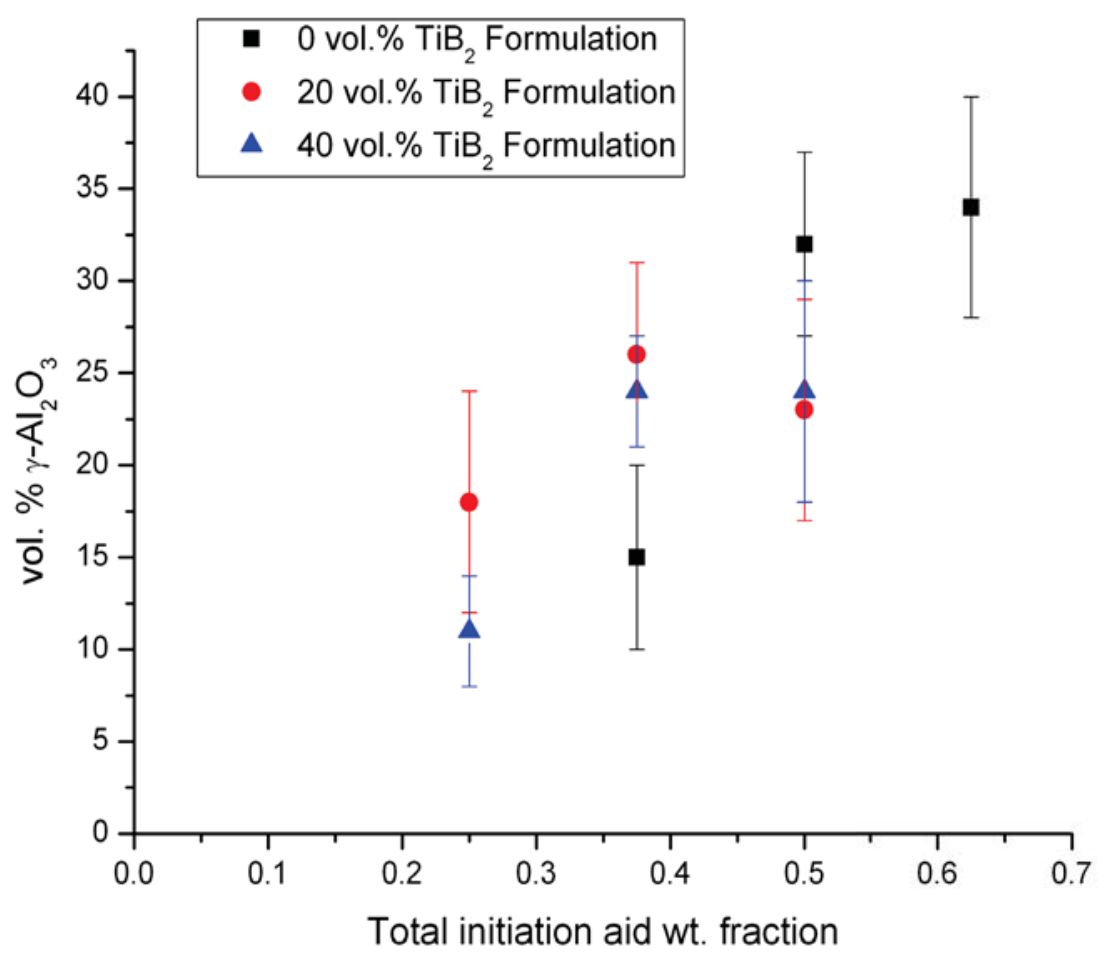

Figure 4.18 Volume percents of $\gamma-\mathrm{Al}_{2} \mathrm{O}_{3}$ vs. total initiation aid for the Al-Ti-B study (w/respect to the BPN product volumes) 


\subsubsection{Summary of Results: Al-Ti-B Reactant System}

The results of the Al-Ti-B reactant system study indicate that:

1) A statistically significant regression model for enthalpy was developed for varying levels of initiation aid and formulated volume fraction of $\mathrm{TiB}_{2} / \mathrm{Al}_{3} \mathrm{Ti}$ of the products with Al-Ti-B blends. This model satisfies condition (a) of the hypothesis for the Al-Ti-B blends.

2) Post-reaction qualitative $x$-ray diffraction indicates the presence of the presumptive products of $\mathrm{TiB}_{2}$ and $\mathrm{Al}_{3} \mathrm{Ti}$, as well as byproducts of $\mathrm{Al}$, TiN, and $\gamma$ $\mathrm{Al}_{2} \mathrm{O}_{3}$. Regression of post-reaction quantitative $\mathrm{x}$-ray diffraction shows experimental $\mathrm{TiB}_{2}$ vol. fractions in good agreement with formulated $\mathrm{TiB}_{2}$ vol. fractions. Post-reaction quantitative $\mathrm{x}$-ray diffraction indicates actual volume fractions of $\mathrm{Al}_{3} \mathrm{Ti}$ appear to increase with decreasing initiation aid. Volume fractions of $\gamma-\mathrm{Al}_{2} \mathrm{O}_{3}$ appear to decrease with decreasing initiation aid, but not to zero. While general trends can be observed for the $\mathrm{Al}_{3} \mathrm{Ti}$ and $\gamma-\mathrm{Al}_{2} \mathrm{O}_{3}$ products, they cannot be precisely quantified and therefore do not satisfy condition (b) of the hypothesis for the Al-Ti-B blends.



Figure 4.19 Volume percents of TiN vs. total initiation aid for the Al-Ti-B study (w/respect to the BPN product volumes) 
3) Since condition (b) of the hypothesis is not met, condition (c) of the hypothesis cannot be addressed at this time.

\subsection{Preliminary Application of Technique to Al-Ti- $\mathrm{B}_{4} \mathrm{C}$ Reactant System}

\subsubsection{Regression Development}

A statistically significant regression that takes into account both initiation aid and formulated $\mathrm{TiB}_{2} / \mathrm{TiC}$ volume percent could not be established. The internal initiation aid weight fraction (Total initiation fraction multiplied by the fraction of initiation aid that is internal) is the only significant predictor of the internal energy. The external initiation aid and the formulated volume percent of $\mathrm{TiB}_{2} / \mathrm{TiC}$ could not be resolved as predictors. The raw internal energy measurements from the bomb calorimeter are shown in Figure 4.20. Each formulated volume percentage appears to have its own unique point of inflection with respect varying internal initiation aid fraction of the total weight, where the slope of the data appears to change in sign. One point, the $0.4 \mathrm{TiB} 2 / \mathrm{TiC}$ formulated volume fraction at 0.5 internal initiation aid weight fraction appears to be an outlier.

\subsubsection{Qualitative X-Ray Diffraction}

$\mathrm{X}$-ray diffraction conducted on a randomly selected sample $\left(0.20 \mathrm{TiB}_{2} / \mathrm{TiC}\right.$ formulated volume fraction, 0.375 initiation aid fraction) can be seen in the diffraction pattern in Figure 4.21. The phases of $\mathrm{TiB}_{2}$ and $\mathrm{Al}_{3} \mathrm{Ti}$ are clearly identified. TiC is present in the sample, but the peak position indicates that it likely exists in a solid solution with TiN. As similarly seen in the Al-Ti-B experiments, residual Al exists in the product as well as $\mathrm{\gamma}-\mathrm{Al}_{2} \mathrm{O}_{3}$, as a byproduct of the reaction. 


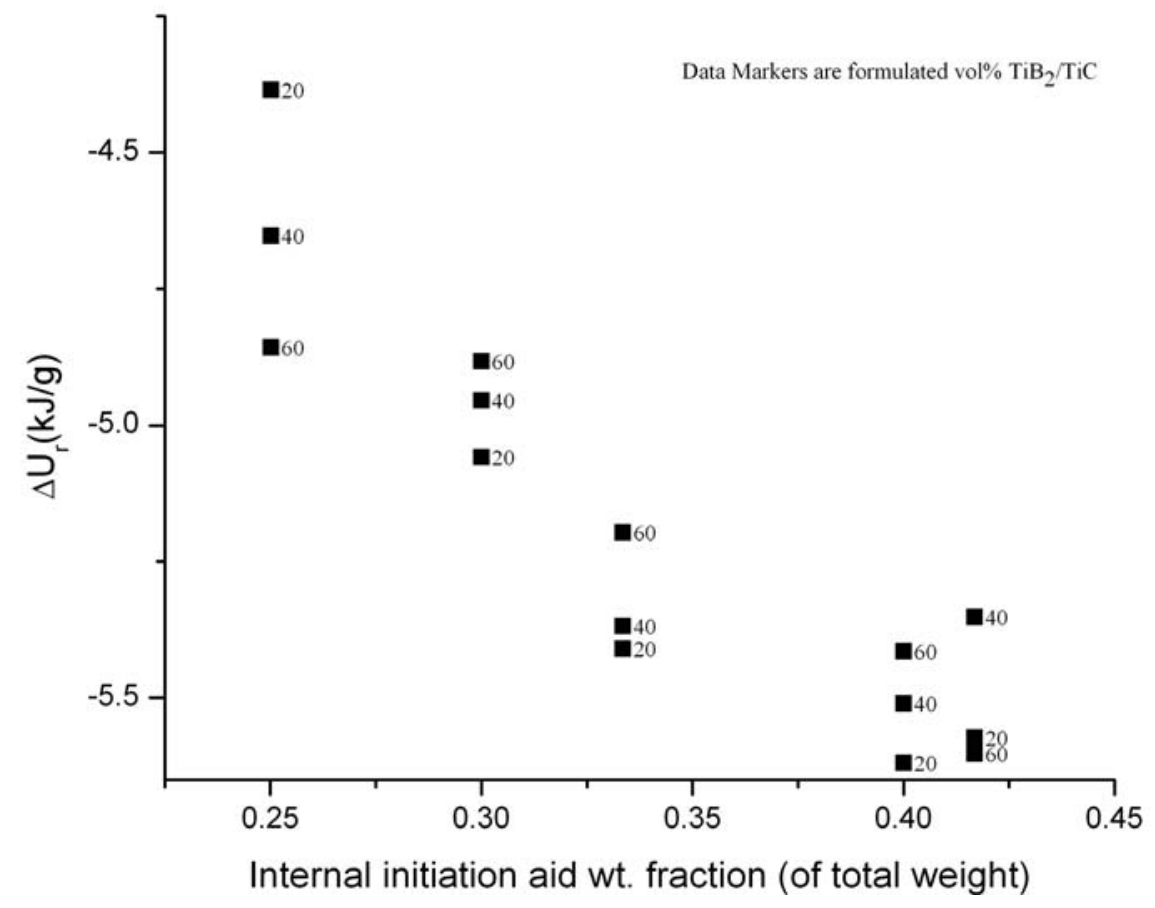

Figure 4.20 Experimental reaction energies vs. weight fraction of the internally added initiation aid

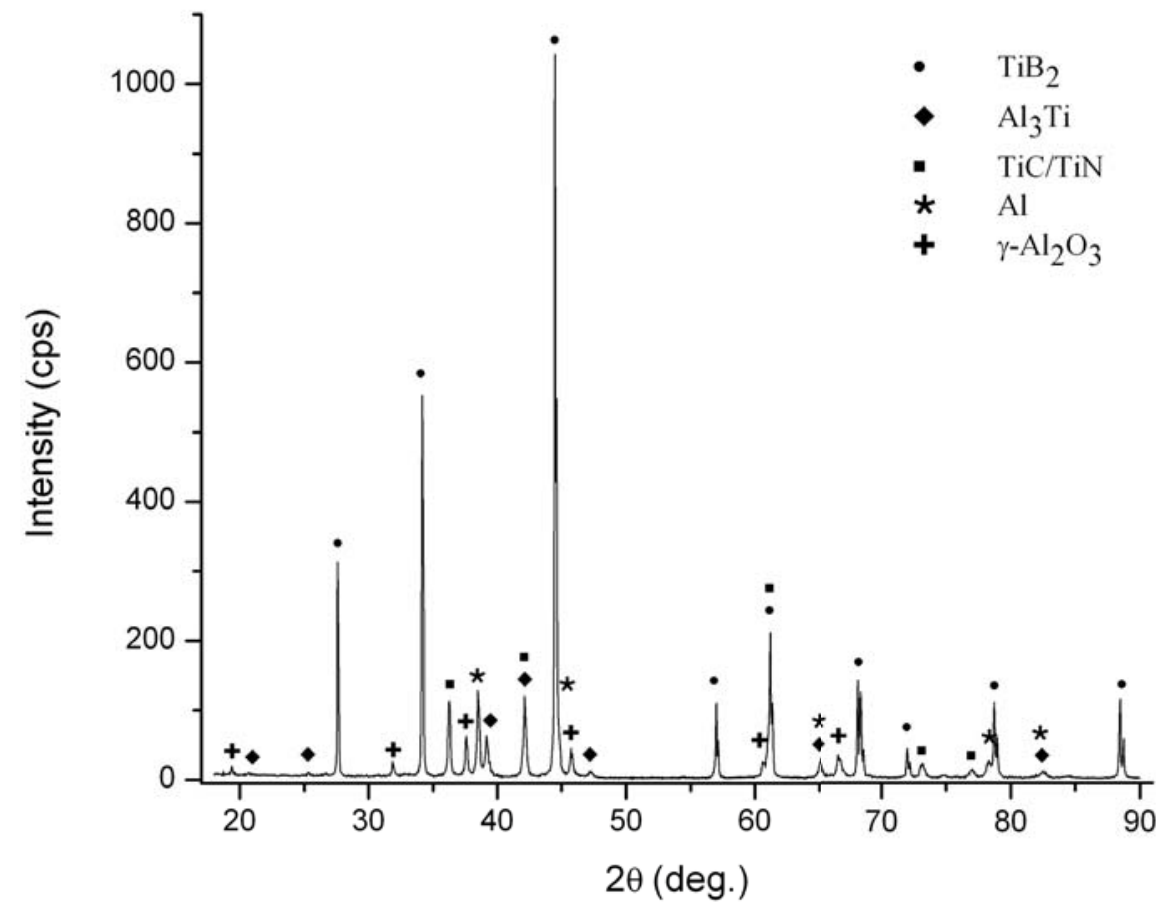

Figure 4.21 X-ray diffraction pattern of a product with formulation factor levels: 0.25 initiation aid, 0.80 internal initiation aid fraction, $0.70 \mathrm{KNO}_{3}$ initiation aid fraction, and 0.20 vol. fraction $\mathrm{TiB}_{2}+\mathrm{TiC}$ (formulated) for the $\mathrm{Al}-\mathrm{Ti}-\mathrm{B}_{4} \mathrm{C}$ study 


\subsubsection{Summary of Results: Al-Ti-B ${ }_{4}$ C Reactant System}

The results of the $\mathrm{Al}-\mathrm{Ti}-\mathrm{B}_{4} \mathrm{C}$ reactant system study indicate that:

1) A significant regression model for enthalpy could not be developed for varying levels of initiation aid and formulated volume fraction of $\mathrm{TiB}_{2} / \mathrm{TiC} / \mathrm{Al}_{3} \mathrm{Ti}$ of the products with $\mathrm{Al}-\mathrm{Ti}-\mathrm{B}_{4} \mathrm{C}$ blends. A general trend of decreasing magnitude of enthalpy of the reaction with decreasing initiation aid can be observed. This model does not satisfy condition (a) of the hypothesis for the Al-Ti-B ${ }_{4} \mathrm{C}$ blends.

2) Post-reaction qualitative $x$-ray diffraction indicates the presence of the presumptive products of $\mathrm{TiB}_{2}$, $\mathrm{TiC}$ (in a solid solution with $\mathrm{TiN}$ ) and $\mathrm{Al}_{3} \mathrm{Ti}$, as well as byproducts of $\mathrm{Al}$, TiN (in a solid solution with $\mathrm{TiC}$ ), and $\gamma-\mathrm{Al}_{2} \mathrm{O}_{3}$. Because a significant model for heat of reaction could not be attained, quantitative $\mathrm{x}$-ray diffraction was not performed, and therefore conditions (b) and (c) of the hypothesis are not addressed. 


\section{Discussion}

\subsection{BPN Characterization}

The initiation aid chosen to help ignite the samples is a mixture of boron (B) and potassium nitrate $\left(\mathrm{KNO}_{3}\right)$, also known as BPN. BPN is a common igniter blend in the propellant industry. BPN was selected as an igniter for these SHS blends since it: (1) does not introduce a new metallic element to the blend, (2) is highly exothermic upon reaction, and (3) sensitive enough to be ignited by the heat produced by the current running through a resistive-wire, but still insensitive enough to be handled relatively safely in the laboratory.

BPN igniter mixtures have generally consisted of $50 / 50,70 / 30$, or $80 / 20\left(\mathrm{KNO}_{3}\right.$ to $\left.\mathrm{B}\right)$ weight mixtures[42]. Trying to formulate stoichiometrically is difficult because of the uncertainty of the degree of reaction that will occur. In the literature, the BPN reaction has been characterized as 3 step process where most of the heat is produced in the first stage in the formation of $\mathrm{KBO}_{2}$ and $\mathrm{NO}$, the second stage decomposes the remaining $\mathrm{KNO}_{3}$, and the final stage being a decomposition of the $\mathrm{KBO}_{2}$ compound to $\mathrm{B}_{2} \mathrm{O}_{3}$ and $\mathrm{K}_{2} \mathrm{O}[43]$.

The particular unidentified phases in the x-ray diffraction analysis are not of particular consequence to the study since the amount of product is being regressed to zero and the structure will likely change based on the heat applied from the $\mathrm{TiB}_{2}$ and $\mathrm{Al}_{3} \mathrm{Ti}$ reactions.

In selection of a $\mathrm{B} / \mathrm{KNO}_{3}$ relative fraction for subsequent experiments, maximization of energy output but retaining sensitivity is of importance. It appears a greater degree of reaction occurs with the 50/50 and 70/30 compositions since they have a larger internal energy output. In the $\mathrm{TiB}_{2}$ validation study, both the 70/30 and 85/15 compositions are utilized to investigate any interactive effects with processing variables. However, for the Al-Ti-B and Al-Ti-B ${ }_{4} \mathrm{C}$ systems, the 70/30 composition is used since it provides both a higher energy output and good sensitivity. 


\subsection{Ti-B Reactant System}

\subsubsection{Process Variable Screening}

The initiation aid is expected to have a significant main effect contribution as the reaction between $\mathrm{B}$ and $\mathrm{KNO}_{3}$ is more energetic than the reaction between Ti and $\mathrm{B}$. Furthermore, the initiation aid having a significant effect is the basis for modeling the regression. However, a $\mathrm{KNO}_{3}$ interaction with $\mathrm{IA}$ fraction was expected rather than a $\mathrm{KNO}_{3}$ effect alone. Since more $\mathrm{KNO}_{3}$ particles will be in contact with $\mathrm{B}$ particles inside the compact, there should be a higher contribution to the enthalpy from the $\mathrm{B} / \mathrm{KNO}_{3}$ reaction.

\subsubsection{Regression Analysis}

The regression with additional IA fraction values reveals that the interactive effect may have indeed been missed since at the 0.125 IA fraction level the enthalpy values seem to overlap. This convergence is more consistent with what is expected as both regressions should produce the same enthalpy at the estimated zero point of IA fraction.

The interaction plot matrix in Figure 5.1 shows the presence of an interaction effect toward the 0.125 IA fraction since the lines no longer exhibit roughly parallel slopes and almost overlap.

The final regressed enthalpy value show close agreement with enthalpy values using crystalline boron. The reactant boron is commercially labeled as amorphous, so this result is somewhat unexpected. Further analysis of the boron is discussed later.

\subsubsection{Qualitative X-Ray Diffraction}

The diffraction pattern of the compact indicates the presence of $\mathrm{TiB}_{2}$ and $\mathrm{TiN}$ in a metastable composition of $\mathrm{TiN}_{0.5}$. The possibility of this metastable composition is confirmed in the TiN binary phase diagram where the solubility range of $\mathrm{N}$ is larger at high temperatures. The reaction temperatures with rapid cooling could possibly give rise to this metastable state. 
The residue is likely mostly made up of low electron density elements $(\mathrm{B}, \mathrm{O})$ and would not scatter significantly which may allow the x-rays to penetrate down to the holder. During quantitative $\mathrm{x}$-ray analysis with the combined compact and residue in a single powder sample, x-rays will not penetrate through to the holder and a determination can be made if there is any significant $\beta$-Ti.

\subsubsection{Quantitative X-Ray Diffraction}

The small sample size may be the primary reason that a $\mathrm{TiN}_{0.5}$ regression was not able to be achieved. It is possible that the $\mathrm{TiN}_{0.5}$ regresses to zero and $\mathrm{TiB}_{2}$ is the only product at zero initiation aid, but higher resolution and replicates of samples at each initiation aid level are needed to verify this predicted regression.

If residual TiN exists however, this would not significantly affect the outcome of the experimental heats of reaction. The heat of formation as specified in the literature is -338 $\mathrm{kJ} / \mathrm{mol}$. If the maximum recorded value of $6 \mathrm{vol}$. $\%$ for TiN is taken, the predicted heat of formation change would be $-1 \mathrm{~kJ} / \mathrm{mol}$ to the Barin $\mathrm{TiB}_{2}$ prediction value and $-4 \mathrm{~kJ} / \mathrm{mol}$ to the Frankhouser $\mathrm{TiB}_{2}$ prediction value. Therefore, the effect of having $6 \% \mathrm{TiN}$ is below the level of resolution of the technique and the technique for this particular system remains valid.

\subsubsection{Boron Analysis}

Since the volume percent of the $\mathrm{TiB}_{2}$ is near $100 \%$, and the residual TiN would not account for any appreciable difference in enthalpy values, it would leave the degree of crystallinity of the boron as possible answer to why the experimental enthalpy values match those of crystalline boron rather than amorphous boron.

As seen in the x-ray diffraction pattern of the commercially labeled 'amorphous' boron in Figure 28, there are distinct and unbroadened peaks in the pattern. Some of the peaks roughly match a crystalline state of boron. These distinct peaks are indicative of strong crystallinity of the boron. If the boron were completely amorphous, a wide broadened peak would be expected instead of distinct peaks [23]. This evidence suggests that the 
boron is semi-crystalline. Boron hydroxide was also determined to be present in the sample, likely due to reaction with the boron with oxygen and water in the air.

\subsection{Al-Ti-B Reactant System}

\subsubsection{Process Variable Screening}

The significant effects determined from the normal plot are all expected and pose no problems for developing a regression. The initiation aid and $\mathrm{TiB}_{2}$ volume fraction are the basis of the regression, and therefore would be expected to have a large effect. The fraction of the IA in the compact (IntFrac) being significant implies an interaction between the constituents in the compact and the initiation aid added to the compact. The presence of the $\mathrm{KNO}_{3}$ effect and interaction between $\mathrm{KNO}_{3}$ and IA Frac is expected because in previous work it is shown that the levels chosen will have a different external initiation aid enthalpy value. Keeping the $\mathrm{KNO}_{3}$ fraction constant will negate this effect as the enthalpy will then depend only on the total level of initiation aid and the internal fraction of the initiation aid.

\subsubsection{Regression Analysis}

If the reactant boron is crystalline, more heat is being generated in the experiment than the nominal prediction for all formulated $\mathrm{TiB}_{2}$ levels. This would indicate that an unintended reaction is taking place or the heat contribution of the BPN reaction is not being fully regressed out and an oversaturation of igniter is present.

Possible unintended side-reactions may include the reduction of the $\mathrm{SiO}_{2}$ crucible by $\mathrm{Al}$, or reduction of boron oxides in the boron powder unidentified by x-ray diffraction. The reaction of $\mathrm{Al}$ and $\mathrm{SiO}_{2}$ occurs according to the equation (for $\gamma-\mathrm{Al}_{2} \mathrm{O}_{3}$ ):

$$
3 \mathrm{SiO}_{2}+2 \mathrm{Al} \rightarrow 2 \mathrm{Al}_{2} \mathrm{O}_{3}+3 \mathrm{Si}, \Delta \mathrm{H}_{r}=-590 \mathrm{~kJ}[14]
$$




\subsubsection{Qualitative X-Ray Diffraction}

The products of $\mathrm{TiB}_{2}$ and $\mathrm{Al}_{3} \mathrm{Ti}$ are present in the x-ray diffraction pattern as expected. $\mathrm{Al}_{2} \mathrm{O}_{3}$ likely forms from the oxidation of $\mathrm{Al}$ with oxygen liberated from $\mathrm{KNO}_{3}$ or from the two side reactions of $\mathrm{Al}$ interaction with the $\mathrm{SiO}_{2}$ crucible or boron oxide contamination. TiN is likely formed from titanium absorbing nitrogen gas, which is a byproduct of the reaction of $\mathrm{KNO}_{3}$ and $\mathrm{B}$ [43]. If the $\mathrm{KNO}_{3}$ is the only source of oxygen and nitrogen in the formation of $\mathrm{Al}_{2} \mathrm{O}_{3}$ and $\mathrm{TiN}$, as the initiation aid is regressed to zero, these byproducts should disappear.

The presence of $\mathrm{Al}$ in the $\mathrm{x}$-ray diffraction spectrum is likely due to the stoichiometric imbalance of the formulation when the initiation aid is added. If the prevalent reaction is the formation of $\mathrm{TiB}_{2}$, the $\mathrm{TiB}_{2}$ reaction would abscond $\mathrm{Ti}$ from the formation of $\mathrm{Al}_{3} \mathrm{Ti}$, putting the effective formulation titanium deficient and therefore in the phase field of $\mathrm{Al}$ $+\mathrm{Al}_{3} \mathrm{Ti}$. Under this reasoning, in the presence of the initiation aid, Al would be expected to be seen in the x-ray diffraction spectrum of the product.

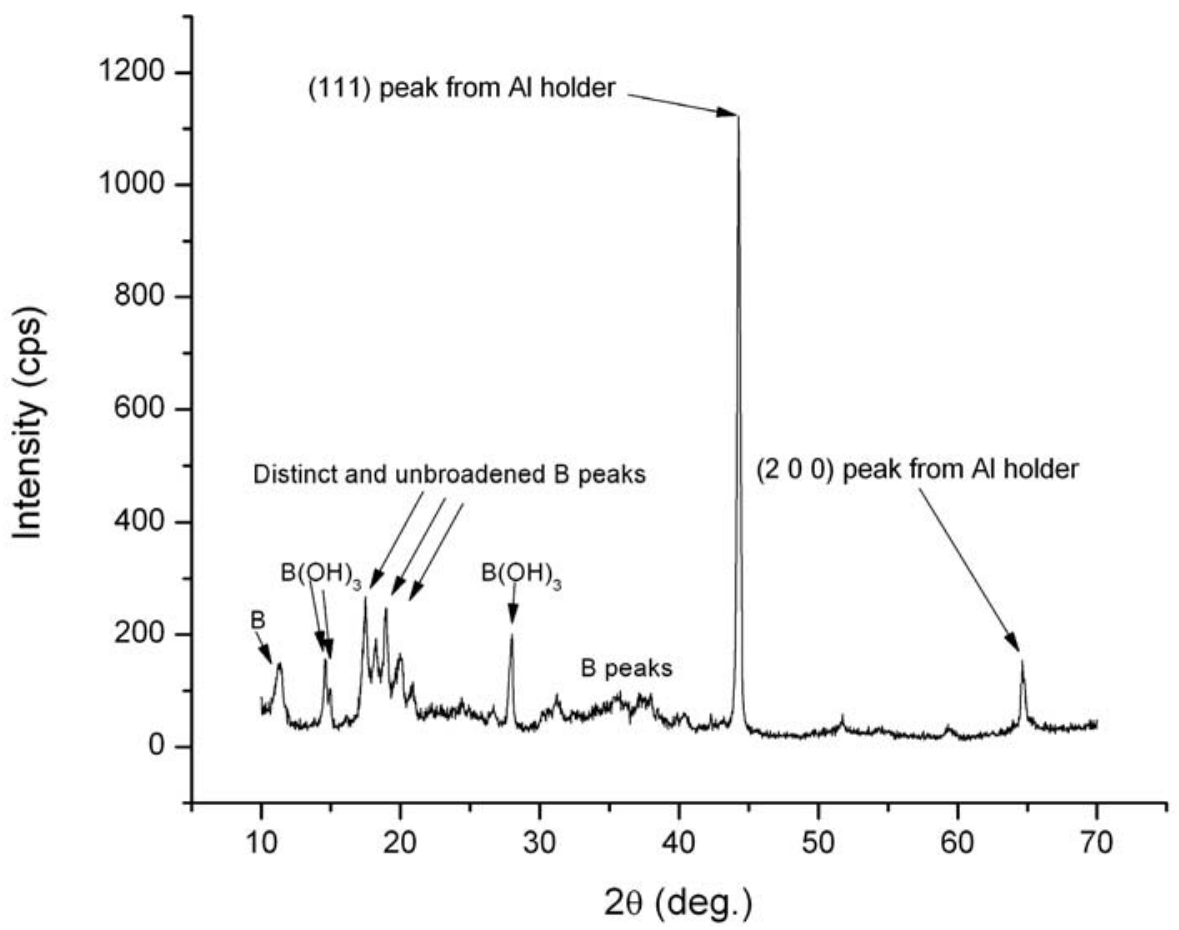

Figure 5.1 X-ray diffraction pattern of 'commercially amorphous' boron showing crystalline nature 


\subsubsection{Quantitative X-Ray Diffraction}

\section{$\mathrm{TiB}_{2}$}

Given the small amount of data, the experimentally regressed $\mathrm{TiB}_{2}$ volumes coincide with the formulated $\mathrm{TiB}_{2}$ volumes fairly well. This would be expected since the $\mathrm{TiB}_{2}$ synthesis study showed the formation of close to monolithic $\mathrm{TiB}_{2}$ and the formation of $\mathrm{Al}_{2} \mathrm{O}_{3}$ should not change the availability of the reactants for $\mathrm{TiB}_{2}$.

\section{$\mathrm{Al}_{3} \mathrm{Ti}$}

The trend of increasing $\mathrm{Al}_{3} \mathrm{Ti}$ with decreasing initiation aid is likely due to the previously stated supposition that as excess boron is introduced to the formulation in the BPN initiation aid, excess $\mathrm{TiB}_{2}$ will be formed, leaving the formulation $\mathrm{Ti}$ deficient and forming less $\mathrm{Al}_{3} \mathrm{Ti}$. It would be expected that as the initiation aid is decreased, more $\mathrm{Al}_{3} \mathrm{Ti}$ would be formed.

\section{Al}

Difficulty was encountered in finding a general trend in the amount of Al present. Explanation of this difficulty in finding a trend may possibly be explained by the reaction of $\mathrm{Al}$ with the $\mathrm{SiO}_{2}$ crucible. As the $\mathrm{Al}$ content increases, a larger reaction with the crucible would be expected. However the degree of this reaction would not controllable. The crucible's silicon content is likely to change reaction to reaction. Furthermore, $\mathrm{Al}_{2} \mathrm{O}_{3}$ or $\mathrm{TiB}_{2}$ forming on the crucible may create a diffusion barrier, further increasing the unpredictability of the amount of $\mathrm{Al}_{2} \mathrm{O}_{3}$ formed, therefore changing the amount of $\mathrm{Al}$ remaining.

Another possible difficulty in determining the amount of Al may be in the regression of initiation aid itself. As the initiation aid is decreased, the formulation will inherently have a larger initial $\mathrm{Al}$ fraction. If the reaction does not go to equilibrium, there would be a larger amount of residual Al. However, decreasing the initiation aid will also push the stoichiometry of the products $\left(\mathrm{Al}_{3} \mathrm{Ti}+\mathrm{Al}\right)$ further towards higher volume fractions of $\mathrm{Al}_{3} \mathrm{Ti}$, decreasing the amount of $\mathrm{Al}$ in the product. 


\begin{abstract}
$\mathrm{Al}_{2} \mathrm{O}_{3}$
The trend of decreasing $\mathrm{Al}_{2} \mathrm{O}_{3}$ with decreasing initiation aid would imply that at least some of the $\mathrm{Al}_{2} \mathrm{O}_{3}$ formation is proportionally related to the subtraction of the initiation aid. This correlation and the presence of residual Al provide some evidence that the initiation aid formulations do not create a state of 'oversaturation' with $\mathrm{KNO}_{3}$.

In addition to the considerations addressed earlier, if a reaction with the $\mathrm{SiO}_{2}$ crucible is occurring, it is also possible that the entire $\mathrm{Al}_{2} \mathrm{O}_{3}$ product has not been collected. The inability to develop a correlation with respect to the amount of formulated $\mathrm{TiB}_{2} / \mathrm{Al}_{3} \mathrm{Ti}$ fraction is still unexplained.
\end{abstract}

\title{
TiN
}

The presence of TiN only at higher levels of initiation aid may imply that the TiN is more likely to react with $\mathrm{Ti}$ meant for the $\mathrm{Al}_{3} \mathrm{Ti}$ reaction, or that a certain critical level of boron exists that prevents the formation of TiN. The volume fraction of TiN may regress to zero, but at the current precision level of this analysis, it cannot be determined and must be assumed that $1-3$ vol \%. TiN is residual in each sample.

\subsection{Al-Ti-B ${ }_{4} \mathrm{C}$ Reactant System}

\subsubsection{Calorimetry Regression Development}

The Al-Ti- $\mathrm{B}_{4} \mathrm{C}$ system appears to be a more difficult reaction system to model using the modified initiation aid method. The increased complexity of the system that includes the endothermic breakdown of $\mathrm{B}_{4} \mathrm{C}$ may contribute to this difficulty. The observed inflection points of the individual sets of formulated volume percent of $\mathrm{TiB}_{2} / \mathrm{TiC}$ with respect to altering the internal initiation aid may be due to some local maxima of energy related to what byproducts are formed as a result of adding the initiation aid. This may be further complicated if there is a reaction with the crucible. A higher level of precision is needed to fully ascertain whether a coherent and significant regression can be developed with respect to both initiation aid and the formulated volume fraction of the products. Once 
the precision of the measurements is increased, the external initiation aid contribution should be able to be resolved as well.

\subsubsection{Qualitative X-Ray Diffraction}

The formation of the expected products of $\mathrm{TiB}_{2}, \mathrm{TiC}$, and $\mathrm{Al}_{3} \mathrm{Ti}$ were confirmed, although TiC appears to be in a solid solution with TiN, with the source of nitrogen being $\mathrm{KNO}_{3}$ from the initiation aid. The Ti-C-N ternary phase diagram confirms the possibility of a solid solution of $\mathrm{TiC}$ and $\mathrm{TiN}$, which would create the position of the diffraction peak between the nominal positions of the peaks of TiN and TiC.

The presence of residual Al is likely due to the stoichiometric imbalance created by adding the initiation aid as addressed in previous sections.

The formation of $\mathrm{Al}_{2} \mathrm{O}_{3}$ has less uncertainty from its possible sources, but without volume fraction analysis with respect to initiation aid, remains difficult to resolve. For this particular set of reactions, the number of oxygen sources is fewer since oxygen contamination coming from boron is minimized since the main source of boron (other than the initiation aid) is bound in $\mathrm{B}_{4} \mathrm{C}$. Whether the source of this $\mathrm{Al}_{2} \mathrm{O}_{3}$ is solely from the reaction of $\mathrm{Al}$ with oxygen liberated from the BPN initiation aid or if it is due to reaction with the crucible is unknown. 


\section{Conclusions and Future Work}

\subsection{Ti-B Validation}

The modified bomb calorimetry technique of blending a BPN initiation aid into the primary powder formulation and developing a regression to estimate the nominal heat of reaction appears valid. The primary product of the reaction is $\mathrm{TiB}_{2}$ with small volume percentages of a TiN byproduct. It was proposed that this byproduct would regress to zero as the initiation aid was decreased. However, the current resolution of the volume fraction analysis and the limited number of samples run prevent the acquisition of data to support this conclusion. However, even at the highest residual value of TiN (6 vol. \%), the effect on the net heat of reaction would only be -1 to $-4 \mathrm{~kJ} / \mathrm{mol}$, which is negligible since it is below the resolution of the calorimetry technique, which is 6 and $7 \mathrm{~kJ} / \mathrm{mol}$.

Replicating the samples, running the x-ray diffraction for longer scan times, and applying more rigorous modeling of the diffraction pattern may be steps that can be taken in the future to resolve whether the formation of TiN decreases as a function of initiation aid and can be adequately measured. The formation of TiN should be noted for future reactions using this technique as the residual heat from the formation of small volumes of nitrides may not be negligible for all systems.

\subsection{Al-Ti-B Reactant System}

The modified initiation aid method of blending of a BPN initiation aid into the blend of $\mathrm{Al}, \mathrm{Ti}, \mathrm{B}$ reactants allowed a statistically significant regression with good precision. It was discovered through $\mathrm{x}$-ray diffraction of the commercially amorphous boron that the powder was of crystalline nature rather than amorphous. If assumption that the boron is not amorphous holds, experimental enthalpies of reaction values are larger than the predicated models. These higher than predicated values may be attributed to excess $\gamma$ $\mathrm{Al}_{2} \mathrm{O}_{3}$ forming as a result of interaction with the $\mathrm{SiO}_{2}$ crucible or interaction with boron oxide forming when the fine boron powder was exposed to the atmosphere. While the possibility exists that oxygen from the potassium nitrate may be oversaturating the 
reaction, the presence of residual Al would seem to provide counter evidence to this statement. A new subset of experiments must be conducted with an alumina (or more stable oxide) crucible to determine if this is the source of the excess heat of reaction. Chemical analysis separate from x-ray diffraction of the reactant boron must also be performed in order determine the oxygen content the boron has acquired from being exposed to the atmosphere.

Volume fraction analysis using x-ray diffraction has shown that despite the uncertainties associated with the reactions with $\mathrm{Al}$, the $\mathrm{TiB}_{2}$ fractions are forming close to formulated values. Reliable regressions could not be developed for $\mathrm{Al}_{3} \mathrm{Ti}, \mathrm{Al}, \gamma-\mathrm{Al}_{2} \mathrm{O}_{3}$, or TiN. However, a general increasing trend with a reduction in initiation aid can be seen for $\mathrm{Al}_{3}$ Ti. Furthermore, a general decreasing trend can be observed with a reduction initiation aid for the formation of $\gamma-\mathrm{Al}_{2} \mathrm{O}_{3}$. Particular trends could not be resolved for $\mathrm{Al}$ and TiN. Performing volume fraction analysis on replicates of these samples and on samples with more levels of initiation aid and formulated $\mathrm{TiB}_{2}$ volume fractions would help increase the resolution of these results. However, the possibility of previous sidereactions with the crucible or boron oxides must first be resolved before pursuing additional volume fraction analysis.

\subsection{Al-Ti-B ${ }_{4} \mathrm{C}$ Reactant System}

A valid relationship between the experimental variables and the enthalpy of reaction cannot yet be established to approximate the nominal heat value for these blends using the modified initiation aid method. A general relationship of the internal initiation aid with the internal energy can be observed, this relationship cannot differentiate between formulated volume fractions of $\mathrm{TiB}_{2} / \mathrm{TiC}$. It is possible that the endothermic step to break up the $\mathrm{B}_{4} \mathrm{C}$ combined with forming additional products $(\mathrm{TiC})$ may require much higher resolution to discern a relationship to approximate the nominal values. In order to achieve this, the question of whether interaction with the $\mathrm{SiO}_{2}$ crucible is occurring must first be resolved. To further increase resolution, replicates and additional levels of initiation aid fraction must be added to the experimental design. 


\section{References}

[1] L. Christodoulou, J.D. Venables, JOM, 55 (2003) 39-45.

[2] J.J. Moore, H.J. Feng, Progress in Materials Science, 39 (1995) 243-273.

[3] J.J. Moore, H.J. Feng, Progress in Materials Science, 39 (1995) 275-316.

[4] Z.A. Munir, Ceramic Bulletin, 67 (1988) 342-349.

[5] Z.A. Munir, U. Anselmi-Tamburini, Materials Science Reports, 3 (1989) 277-365.

[6] R.W. Rice, Journal of Materials Science, 26 (1991) 6533-6541.

[7] J. Subrahmanyam, M. Vijayakumar, Journal of Materials Science, 27 (1992) 62496273.

[8] S.C. Tjong, Z.Y. Ma, Materials Science and Engineering, 29 (2000) 49-113.

[9] C.R. Bowen, B. Derby, Acta Metallurgica et. Materialia, 43 (1995) 3903-3913.

[10] B. Rupp, J.B. Holt, J. Wong, CALPHAD, 16 (1992) 377-386.

[11] V.M. Shkiro, V.N. Doroshin, I.P. Borovinskaya, Combustion, Explosion, and Shock Waves, 16 (1981) 370-374.

[12] E.A. Jeffers, in: Materials Science \& Engineering, Virginia Polytechnic Institute and State University, Blacksburg, 2006.

[13] R.W. Rice, G.Y. Richardson, J.M. Kunetz, T. Schroeter, W.J. McDonough, Advanced Ceramic Materials, 2 (1987) 222-227.

[14] I. Barin, Thermochemical Data of Pure Substances, 2nd ed., VCH, Weinheim, 1973.

[15] W.L. Frankhouser, K.W. Brendley, M.C. Kieszek, Gasless Combustion Synthesis of Refractory Compounds, Noyes Publications, Park Ridge, 1985.

[16] F.R. de Boer, R. Boom, W.C.M. Mattens, A.R. Miedema, A.K. Niessen, Cohesion in Metals, North-Holland, Amsterdam, 1988.

[17] R. Martin, S.L. Kampe, J.S. Marte, T.P. Pete, Metallurgical and Materials Transactions A, 33A (2002) 2747-2753.

[18] L.H. Chiu, D.C. Nagle, A.K. Kercher, Metallurgical and Materials Transactions A, (1999).

[19] A.S. Rogachev, A.S. Mukasyan, A.G. Merzhanov, Doklady Physical Chemistry, 297 (1987) $1240-1243$.

[20] P. Atkins, J. de Paula, Physical Chemistry, W.H. Freeman and Company, New York, 2002.

[21] R.J. Silbey, R.A. Alberty, Physical Chemistry, 3rd ed., Jon Wiley \& Sons, Inc., New York, 2001.

[22] P. Villars, K. Cenzual, in, ASM International, 2010.

[23] B.D. Cullity, S.R. Stock, Elements of X-Ray Diffraction, 3rd ed., Prentice Hall, Upper Saddle River, 2001.

[24] J. Payne, in, Michigan Technological University, Houghton, 1992.

[25] D.T. Cromer, J.B. Mann, Acta Crystallographica, A24 (1968) 321-323.

[26] National Bureau of Standards (U.S.), 25 (1981) 73.

[27] National Bureau of Standards (U.S.), 25 (1984) 43.

[28] N.Y. Alekseyevskly, O.S. Ivanov, I.I. Rayevskiy, M.V. Stepanov, Physics of Metals and Metallography, 23 (1967) 1-28.

[29] N.F.M. Henry, K. Lonsdale, in, The Kynoch Press, Birmingham, England, 1952. 
[30] J.R. Holden, C.W. Dickenson, Journal of Physical Chemistry, 79 (1975) 249.

[31] M.V. Karpets, Y.V. Milman, O.M. Barabash, N.P. Korzhova, O.N. Senkov, D.B. Miracle, T.N. Legkaya, I.V. Voskoboynik, Intermetallics, 11 (2003) 241-249.

[32] G. Lobier, J.P. Marcon, C.R. Seances Academy of Science, (1969) 094906-094901.

[33] P.H. Mayrhofer, D. Music, J.M. Schneider, Journal of Applied Physics, 100 (1996).

[34] S. Mohr, B.H.K. Muller, Y. Grin, H.G. Von Schnering, Journal of Inorganic and General Chemistry, 622 (1996) 1035-1037.

[35] C. Qiu, S.M. Opalka, G.B. Olson, D.L. Anton, International Journal of Materials Research, 97 (2006) 1484-1493.

[36] L. Smrcok, V. Langer, J. Krestan, Acta Crystallographica C, 62 (2006) i83-i84.

[37] D.C. Montgomery, Design and Analysis of Experiments, 6th ed., Wiley, Hoboken, 2005.

[38] F.A. Graybill, H.K. Iyer, Regression Analysis: Concepts and Applications, Duxbury Press, Belmont, 1994.

[39] T.P. Ryan, Modern Regression Methods, 2nd ed., Wiley, Hoboken, 2009.

[40] S. Weisberg, Applied Linear Regression, 2nd ed., John Wiley and Sons, New York, 1985.

[41] R.V. Lenth, Technometrics, 31 (1989) 469-473.

[42] B. Roduit, et al., Journal of Thermal Analysis and Calorimetry, 80 (2005) 229-236.

[43] Y. Yano, Propellants, Explosives, Pyrotechnics, 14 (1989) 187-189. 


\section{Appendix: Internal Energies of Reactions}

The following table (Table 8.1) contains the measured internal energy $(\Delta U)$ of reaction for all reactions within this study. Total initiation aid fraction (IA) refers to the total weight fraction of the initiation aid that was reacted. Internal initiation aid fraction in compact refers to the fraction of the initiation aid that is internal (internal IA mass divided by the total IA mass). $\mathrm{KNO}_{3}$ fraction refers to the $\mathrm{KNO}_{3}$ weight fraction of the initiation aid (balance is B). Bomb pressure refers to the pressure the bomb was initially charged (4.8 grade Ar). 


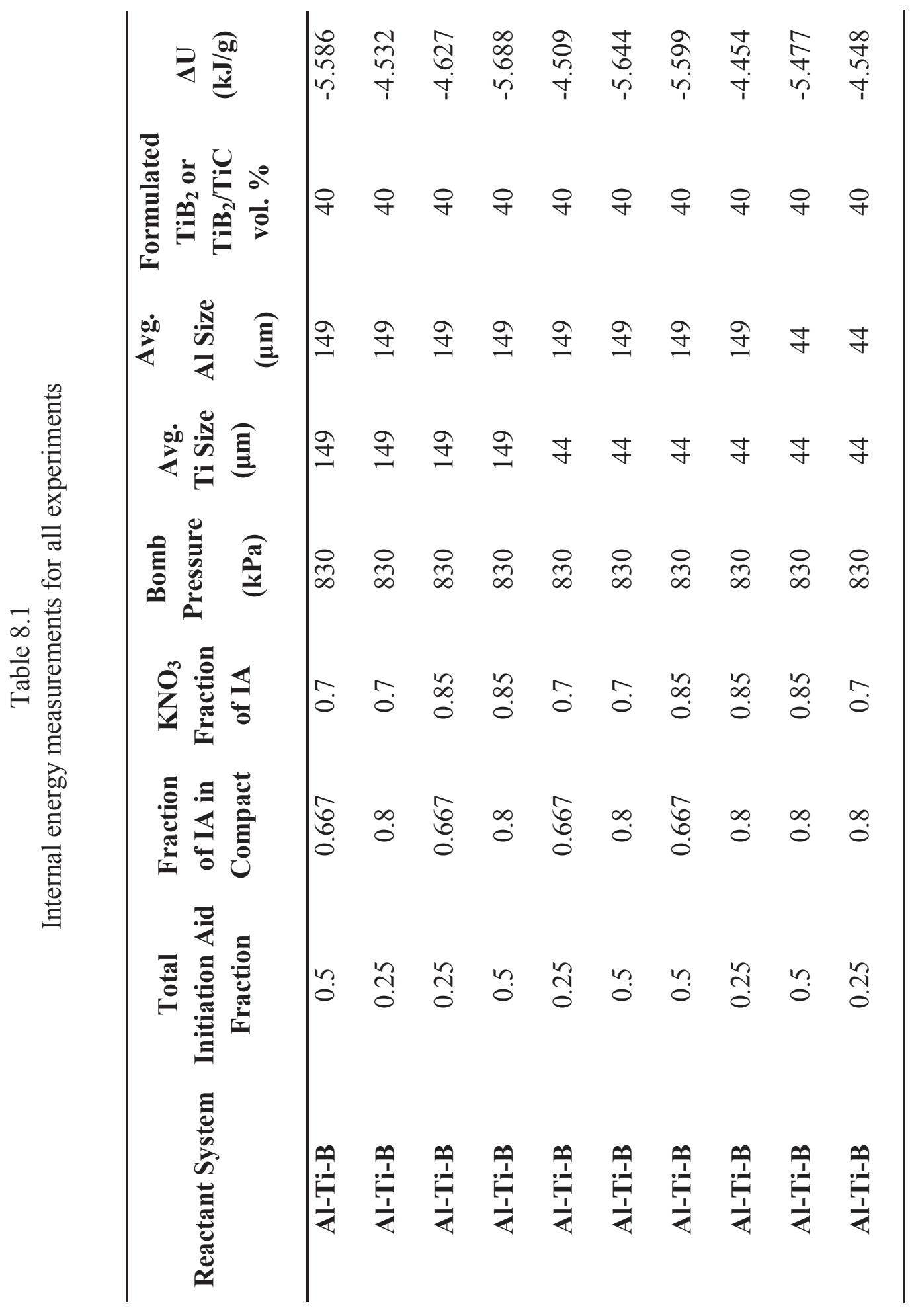




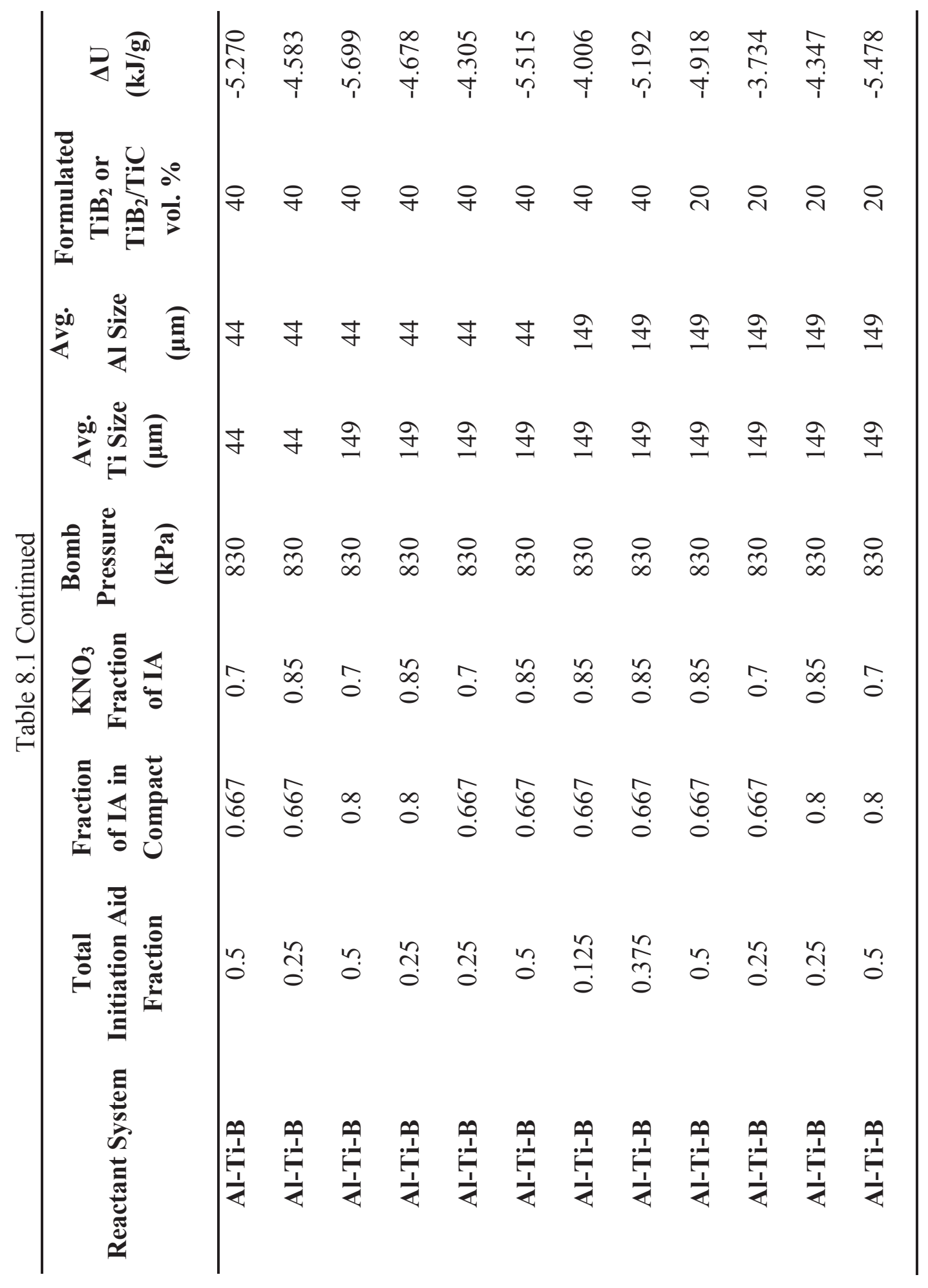




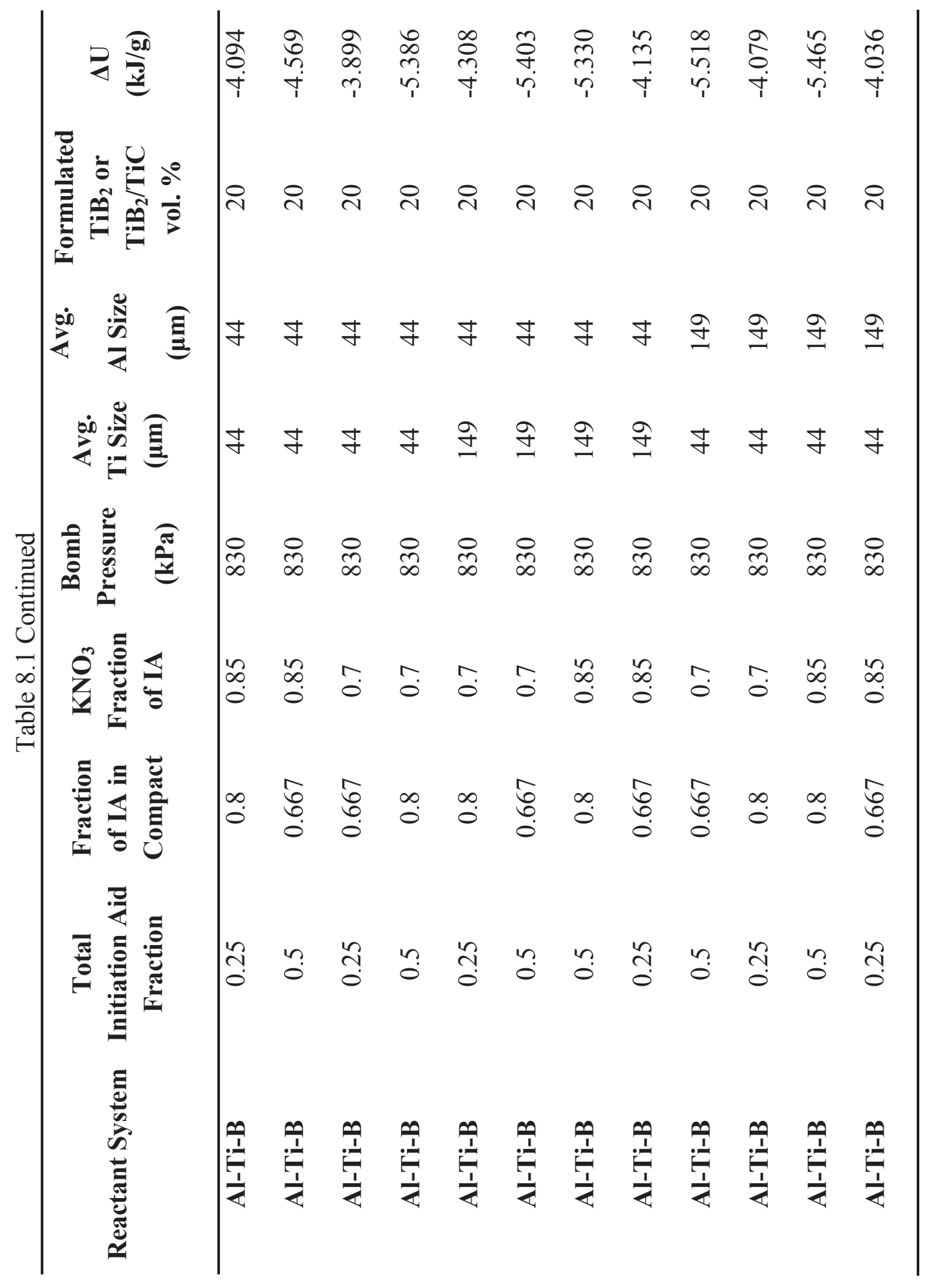




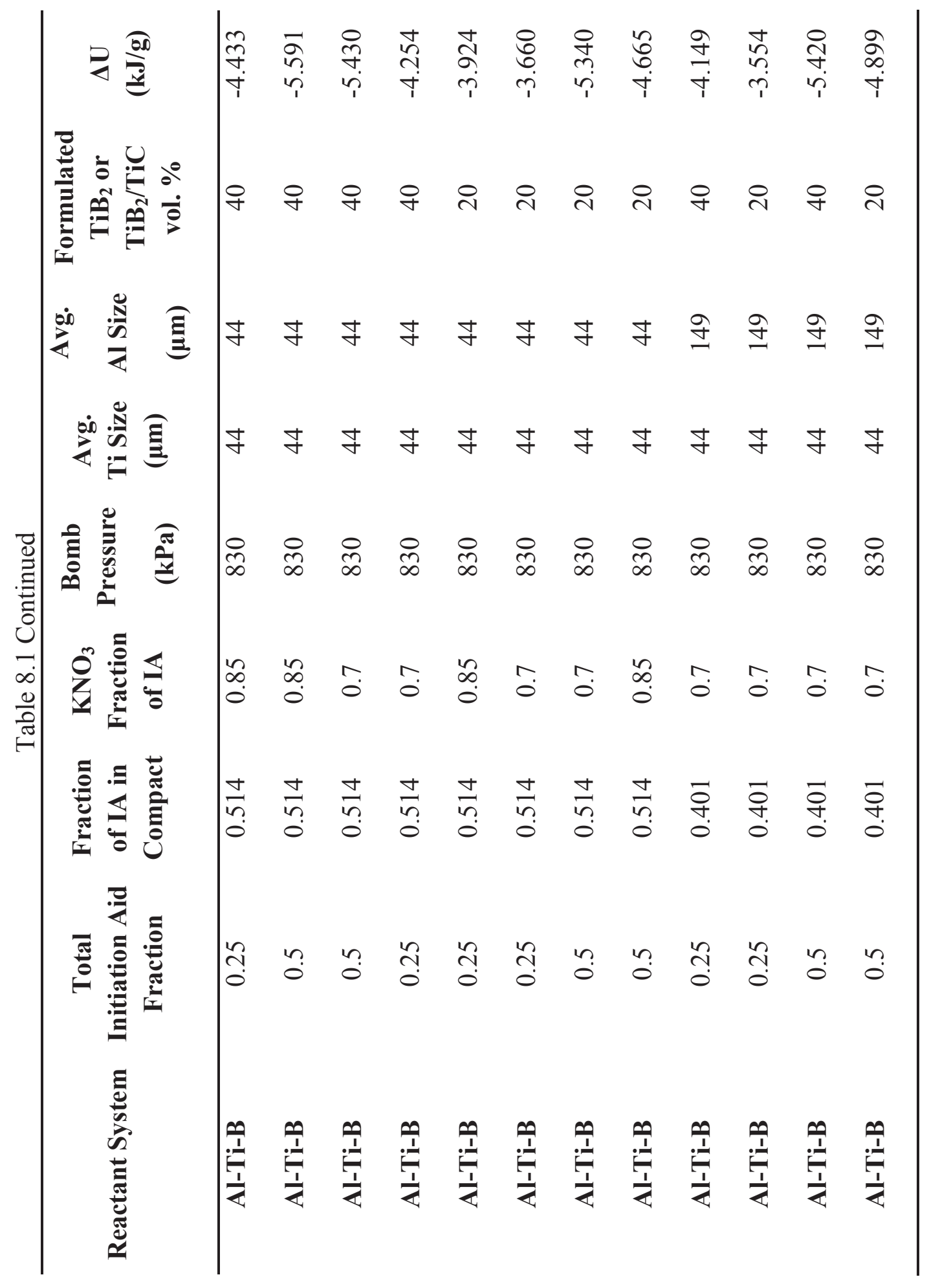




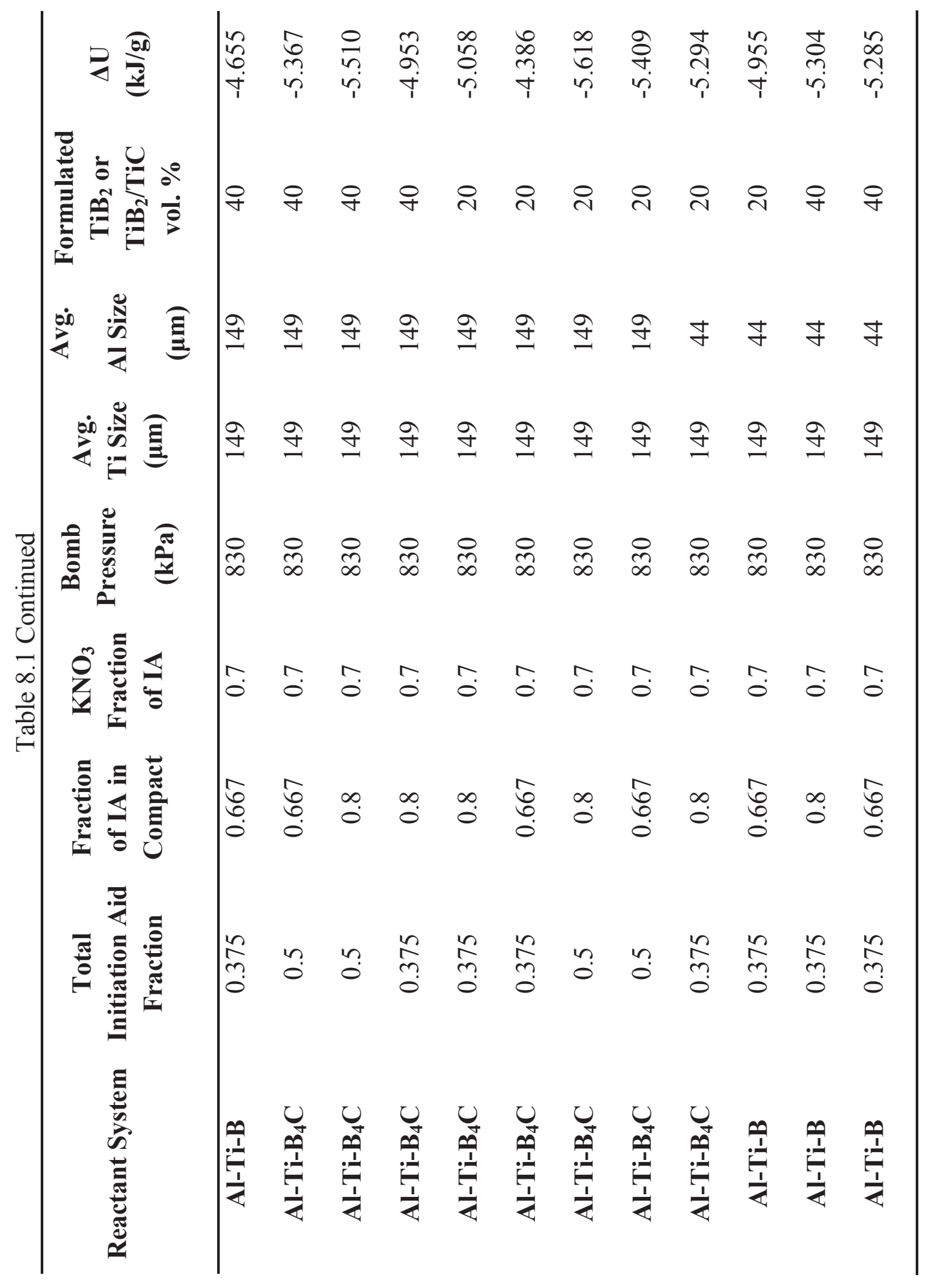




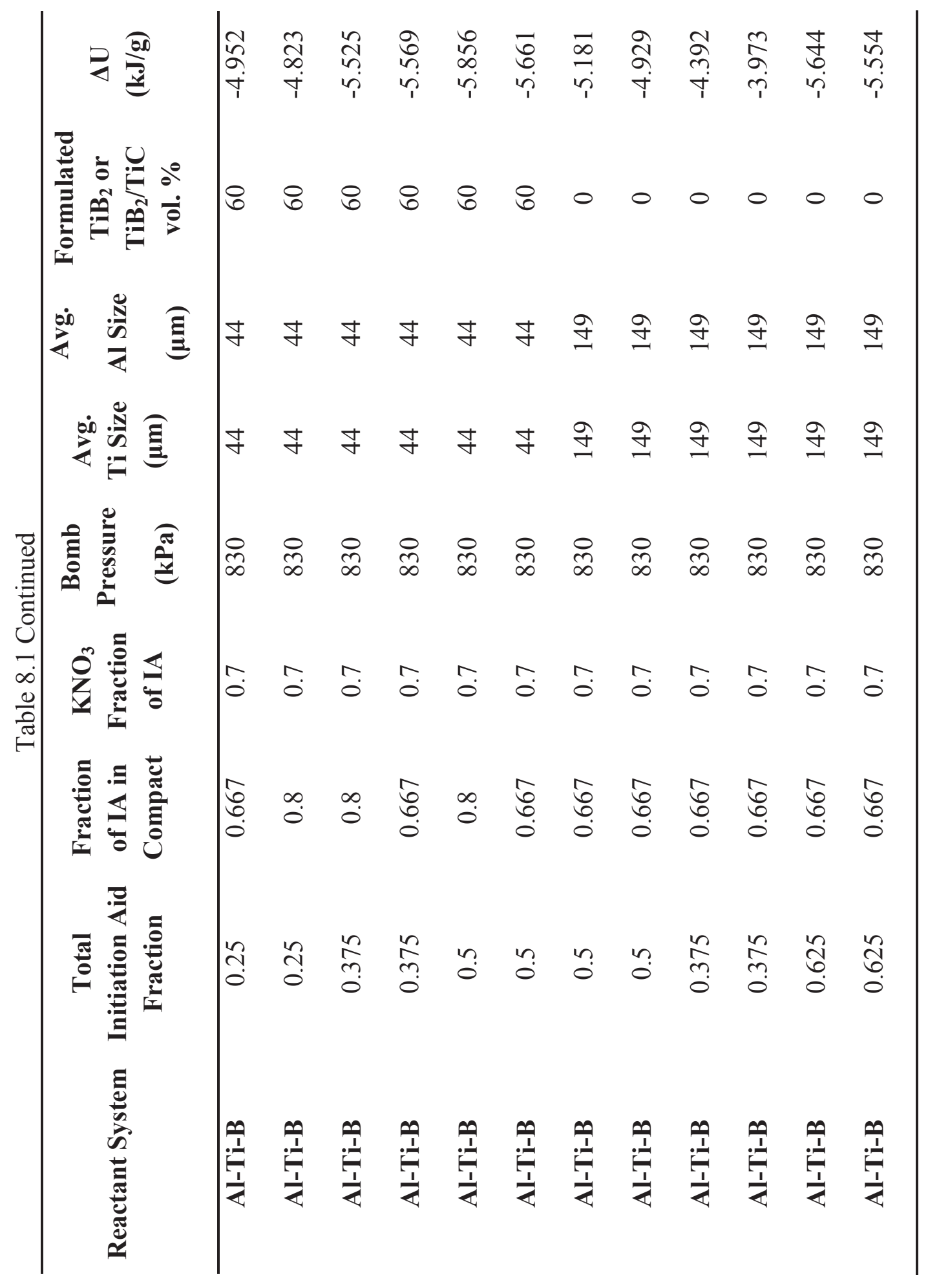




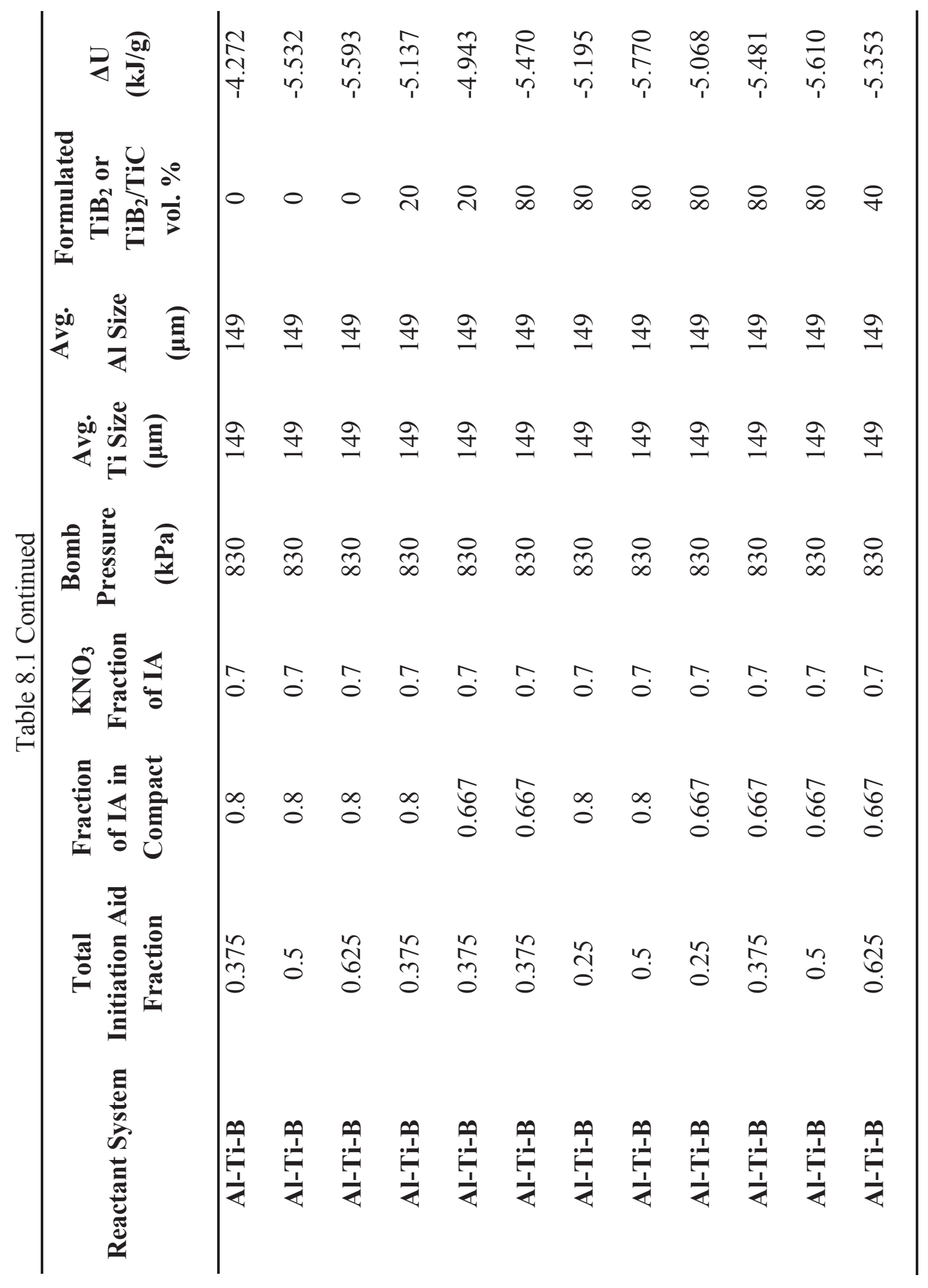




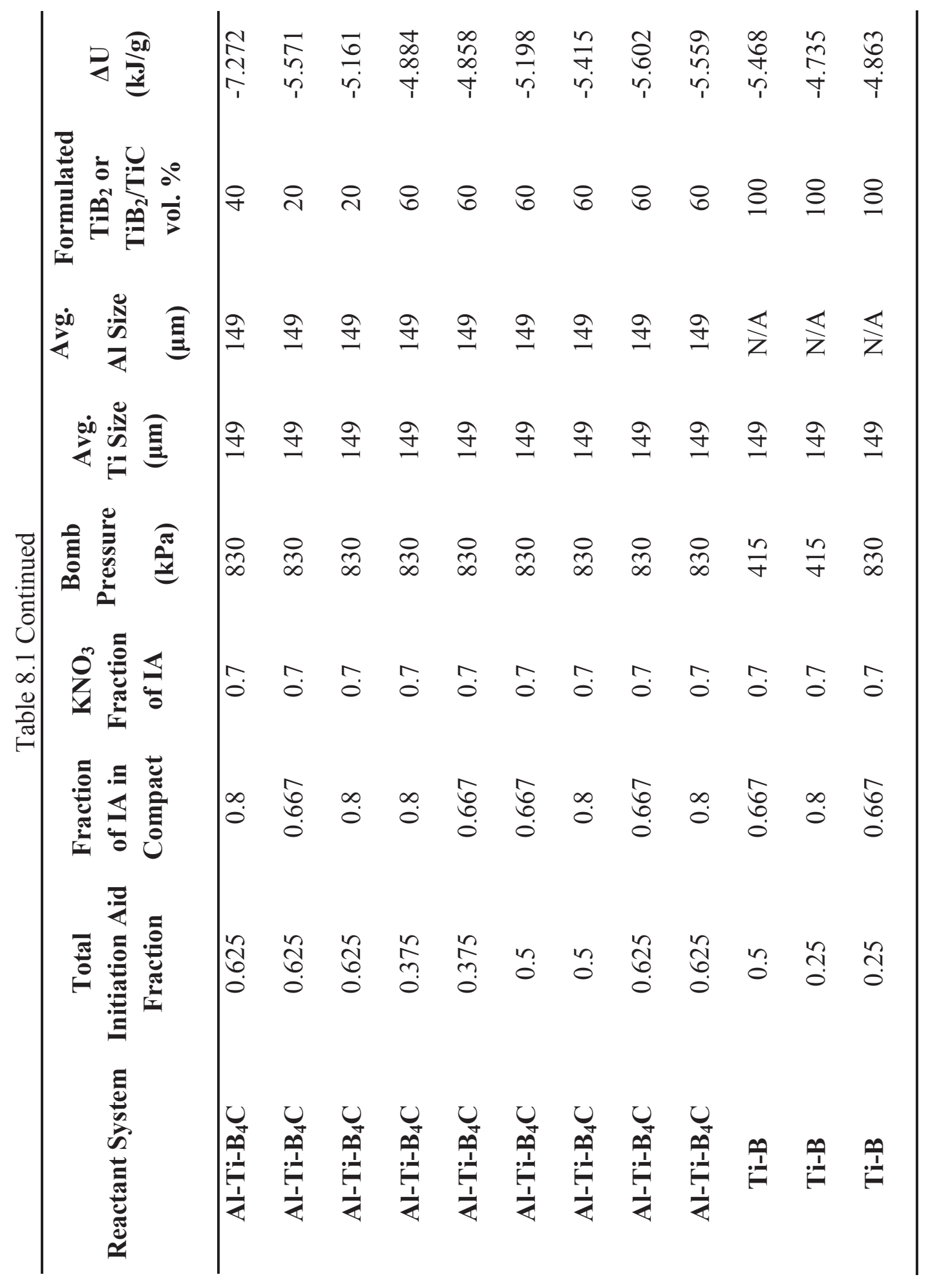




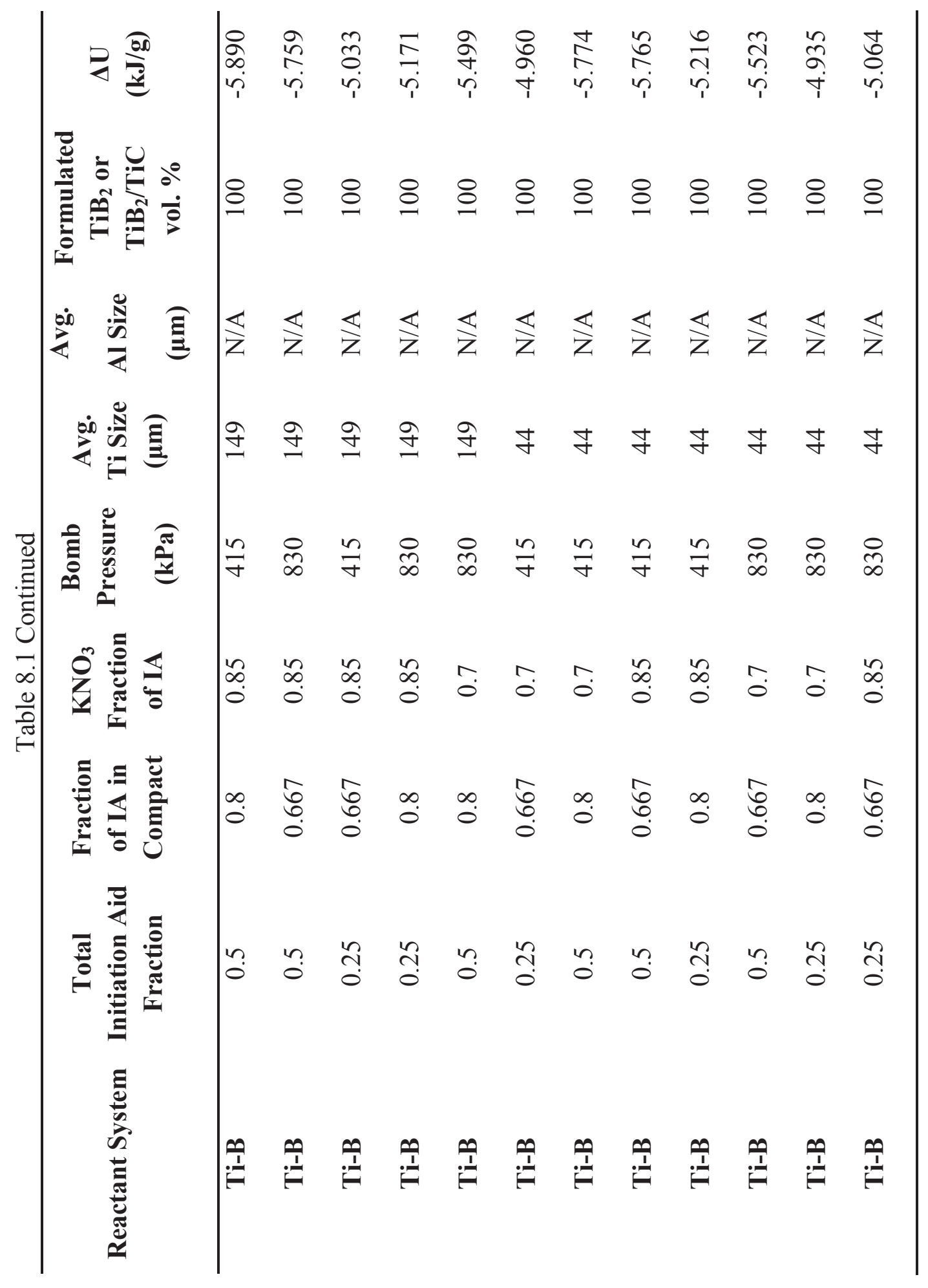




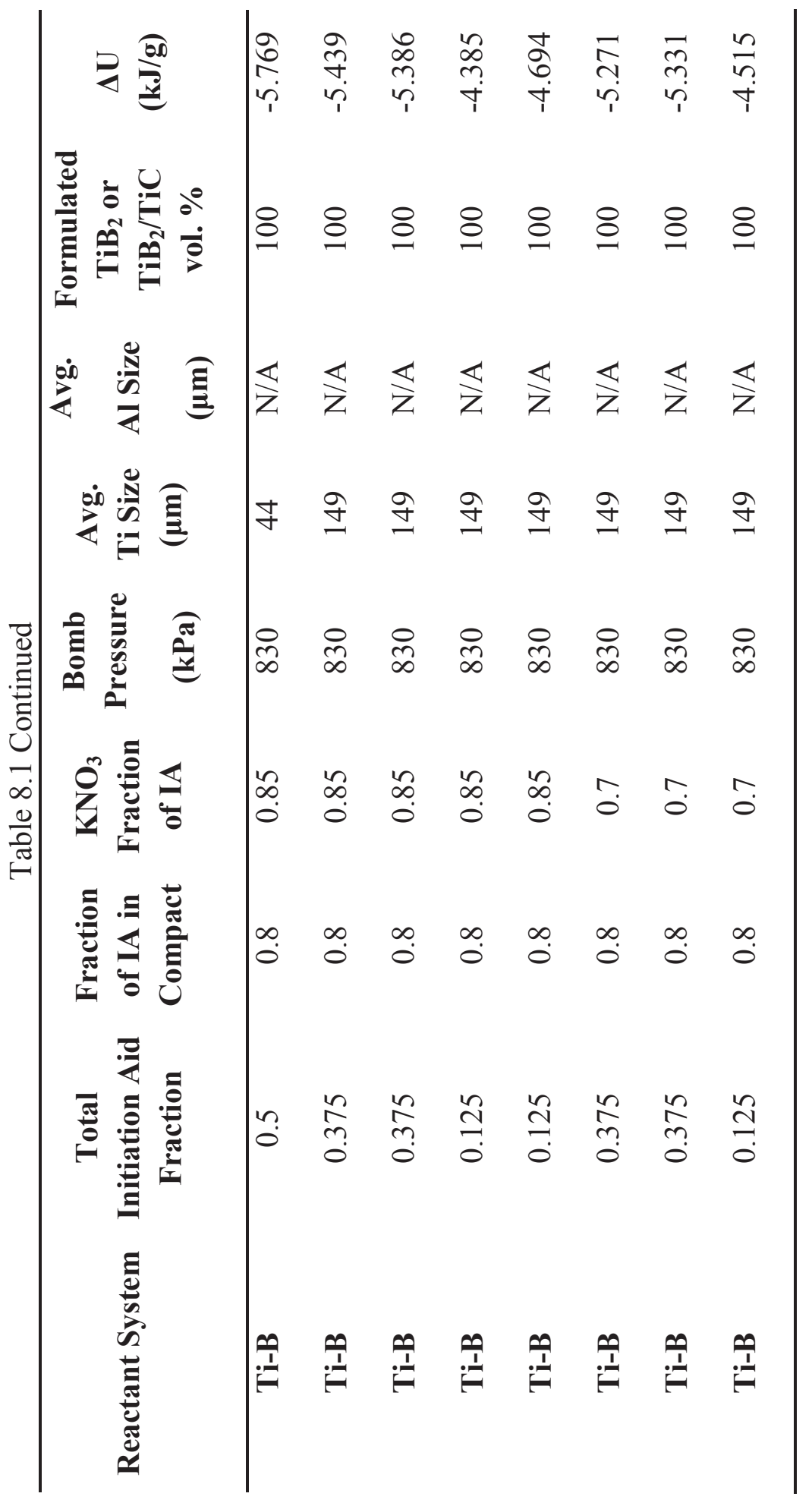




\section{Appendix: X-Ray Diffraction Spectra}

This section contains the x-ray diffraction patterns of the samples used for quantitative volume fraction analysis in this thesis. Designations are given in the captions for the reaction system, total wt. fraction of initiation aid, internal wt. fraction of total initiation aid, and $\mathrm{KNO}_{3}$ wt. fraction of initiation aid. 


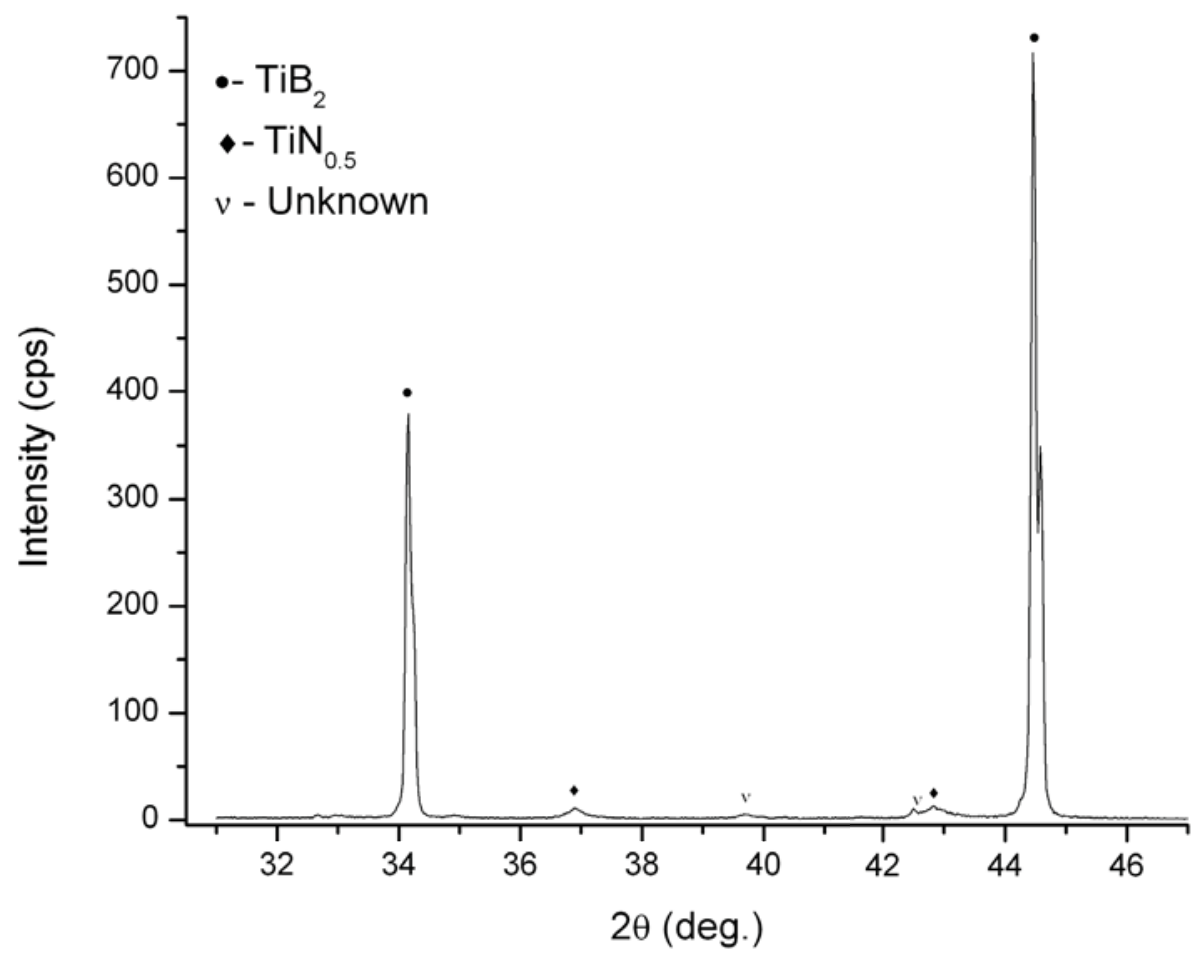

Figure 9.1 Ti-B, 0.125 total initiation aid wt. fraction, 0.80 internal fraction of total initiation aid, 0.85 wt. fraction $\mathrm{KNO}_{3}$ initiation aid

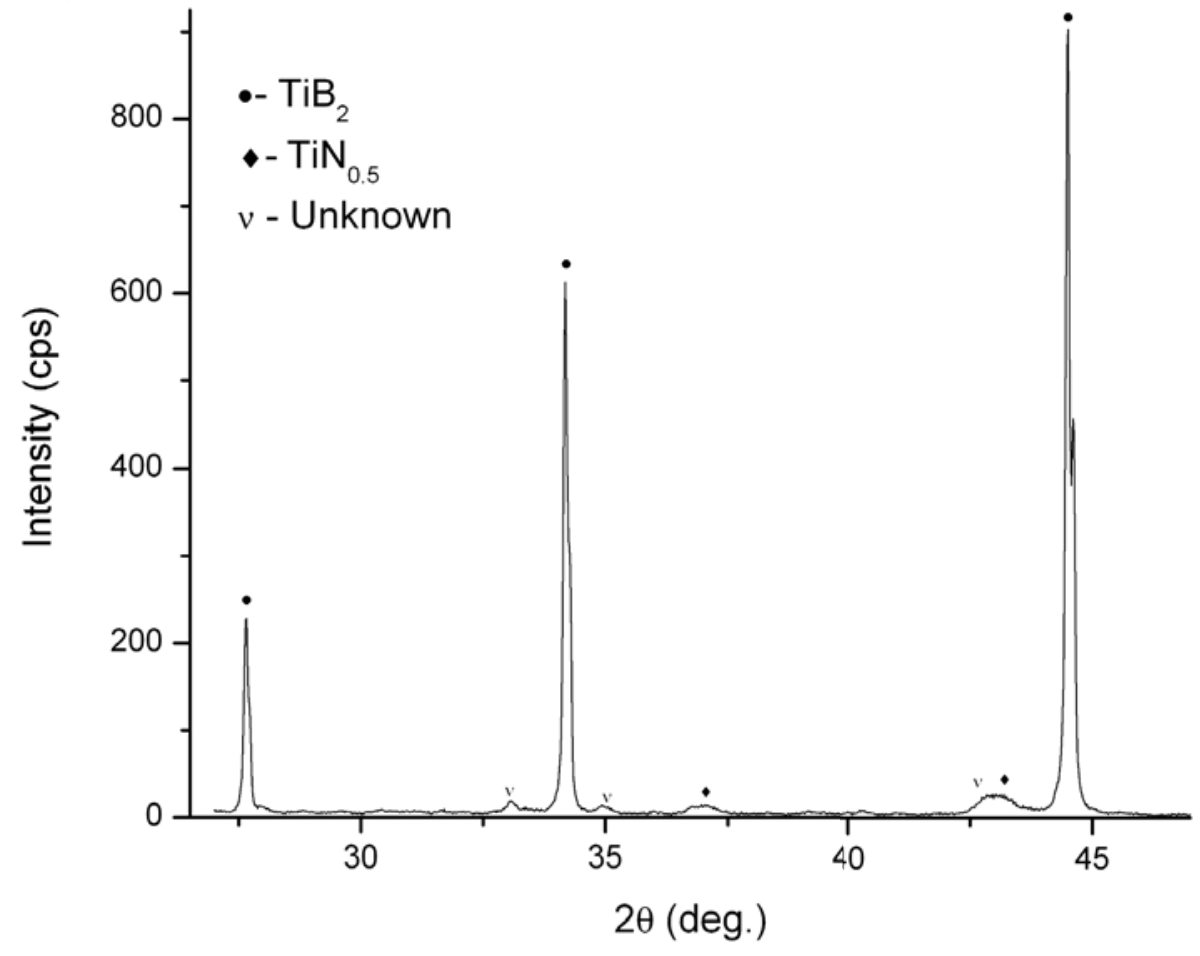

Figure 9.2 Ti-B, 0.25 total initiation aid wt. fraction, 0.80 internal fraction of total initiation aid, 0.85 wt. fraction $\mathrm{KNO}_{3}$ initiation aid 


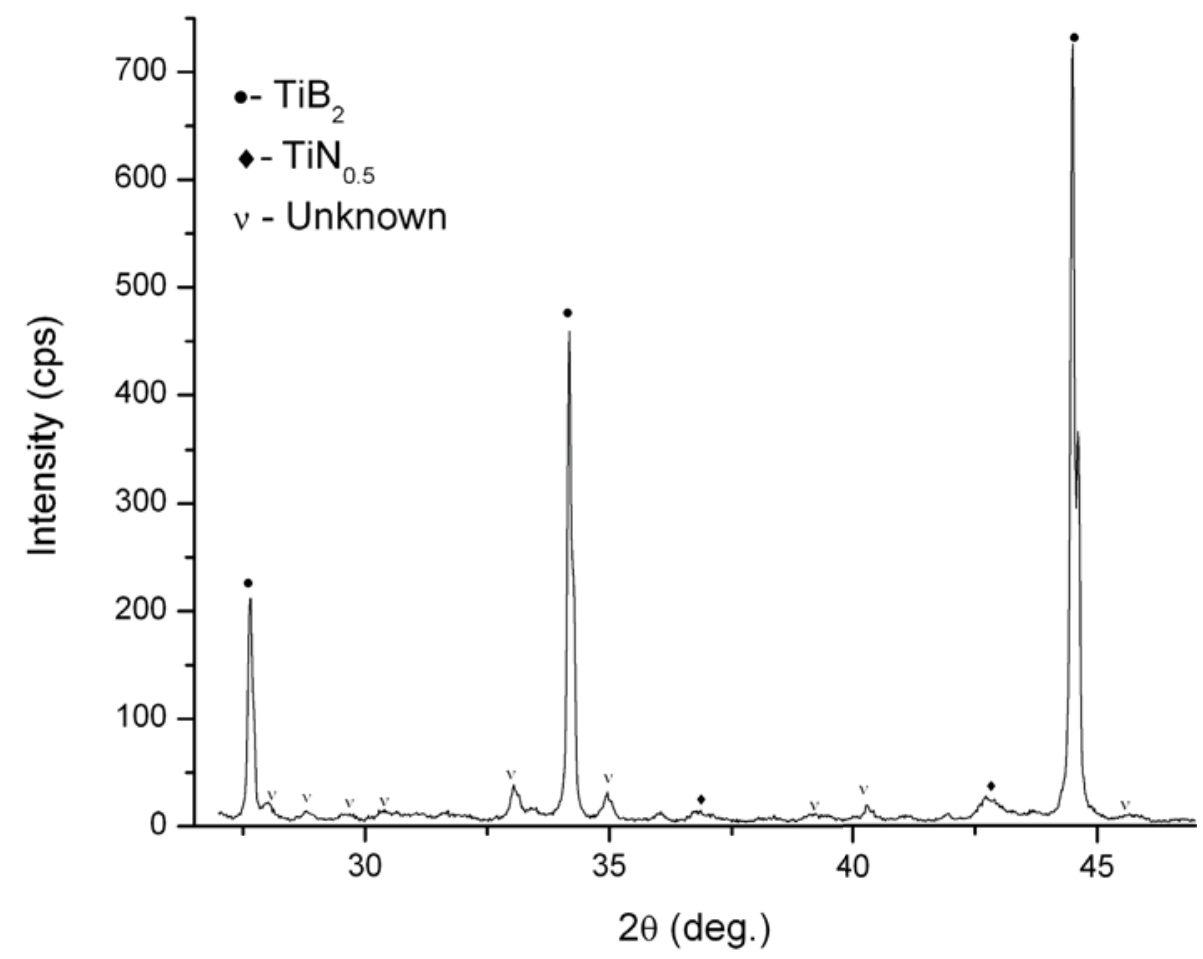

Figure $9.3 \mathrm{Ti}-\mathrm{B}, 0.50$ total initiation aid wt. fraction, 0.80 internal fraction of total initiation aid, $0.85 \mathrm{wt}$. fraction $\mathrm{KNO}_{3}$ initiation aid



Figure 9.4 Ti-Al-B, 0 vol. $\% \mathrm{TiB}_{2}, 0.375$ total initiation aid wt. fraction, 0.80 internal fraction of total initiation aid, 0.85 wt. fraction $\mathrm{KNO}_{3}$ initiation aid 


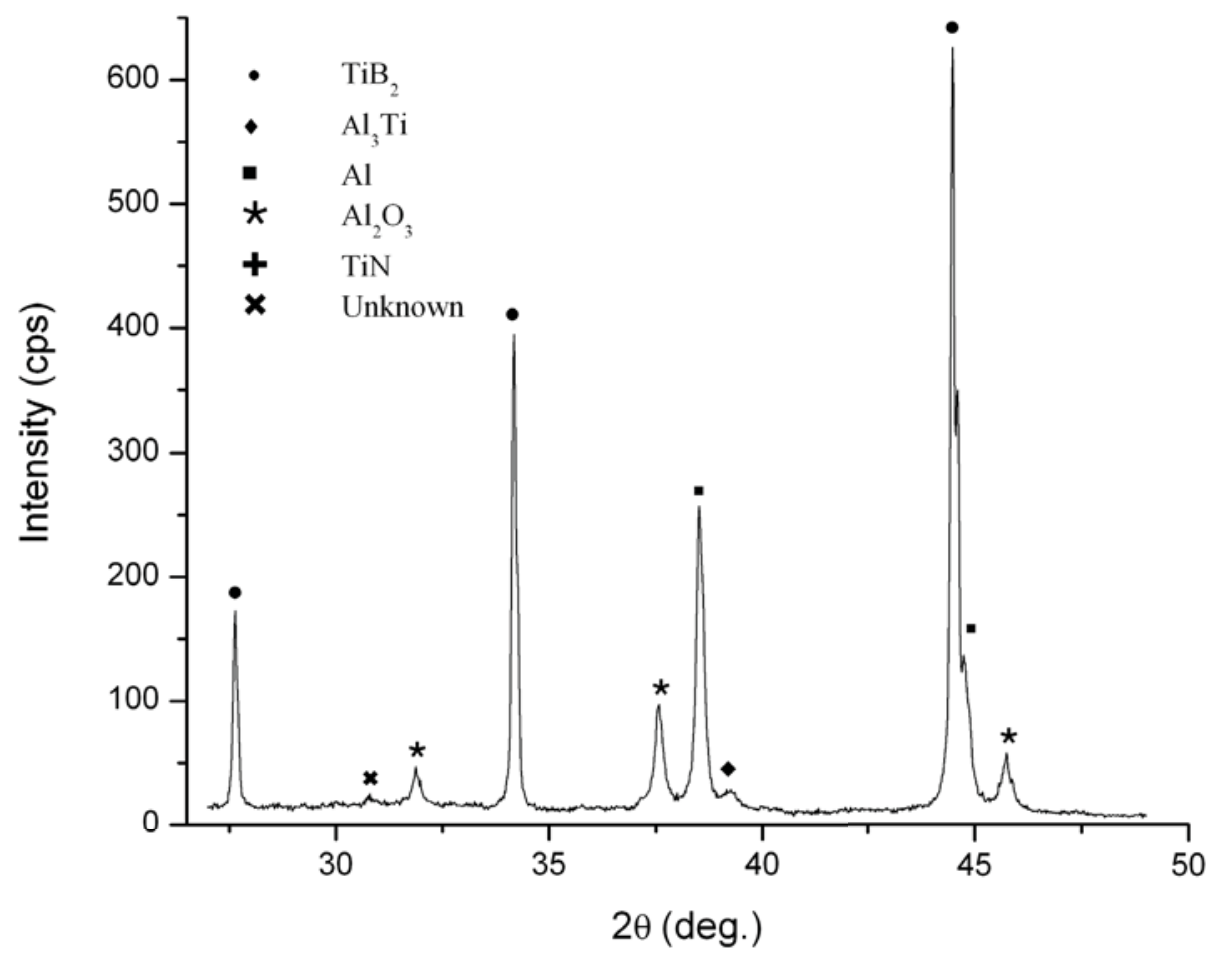

Figure 9.5 Ti-Al-B, 0 vol. $\% \mathrm{TiB}_{2}, 0.50$ total initiation aid wt. fraction, 0.80 internal fraction of total initiation aid, 0.85 wt. fraction $\mathrm{KNO}_{3}$ initiation aid



Figure 9.6 Ti-Al-B, 0 vol. $\% \mathrm{TiB}_{2}, 0.625$ total initiation aid wt. fraction, 0.80 internal fraction of total initiation aid, 0.85 wt. fraction $\mathrm{KNO}_{3}$ initiation aid 


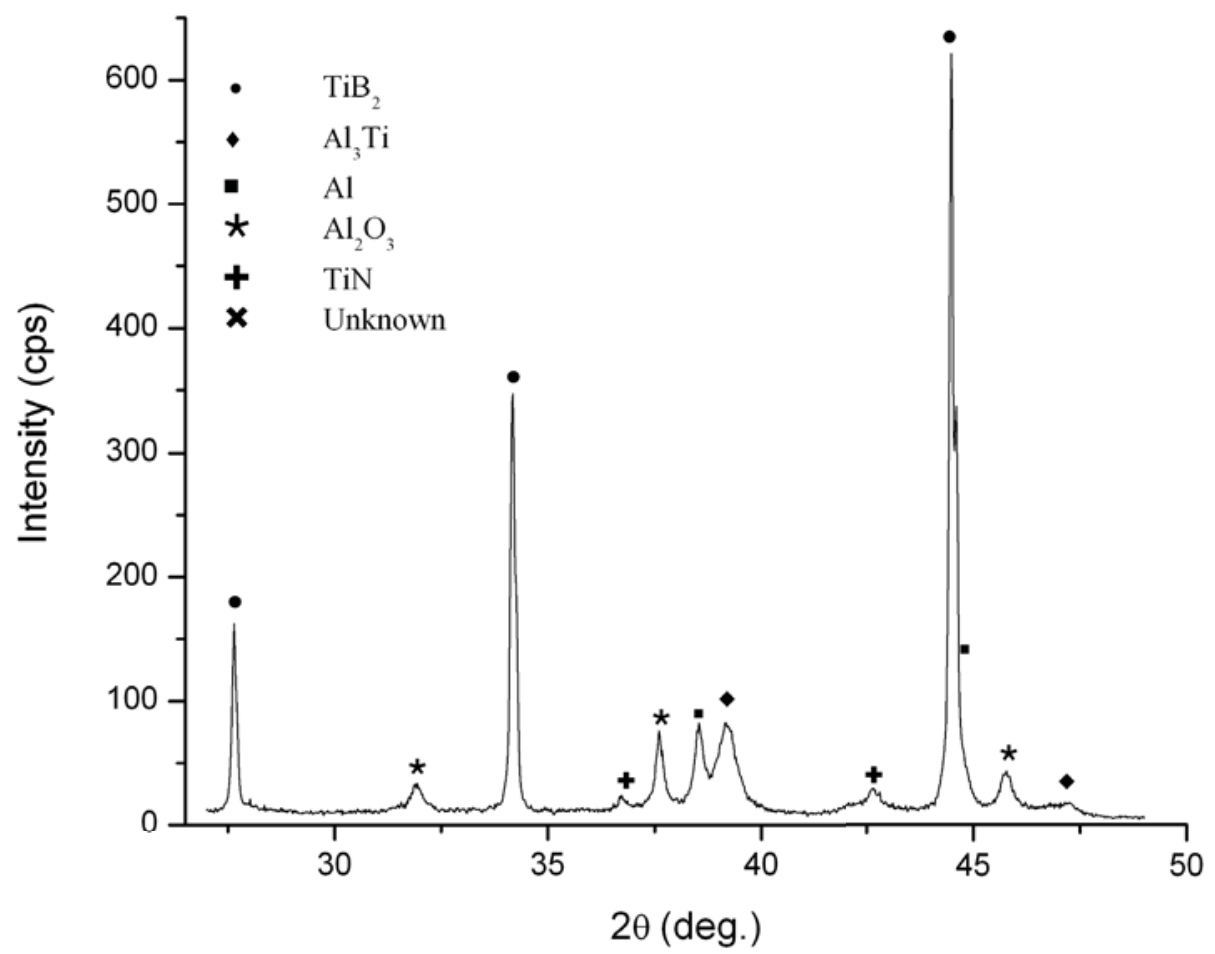

Figure 9.7 Ti-Al-B, 20 vol. $\% \mathrm{TiB}_{2}, 0.25$ total initiation aid wt. fraction, 0.80 internal fraction of total initiation aid, 0.85 wt. fraction $\mathrm{KNO}_{3}$ initiation aid

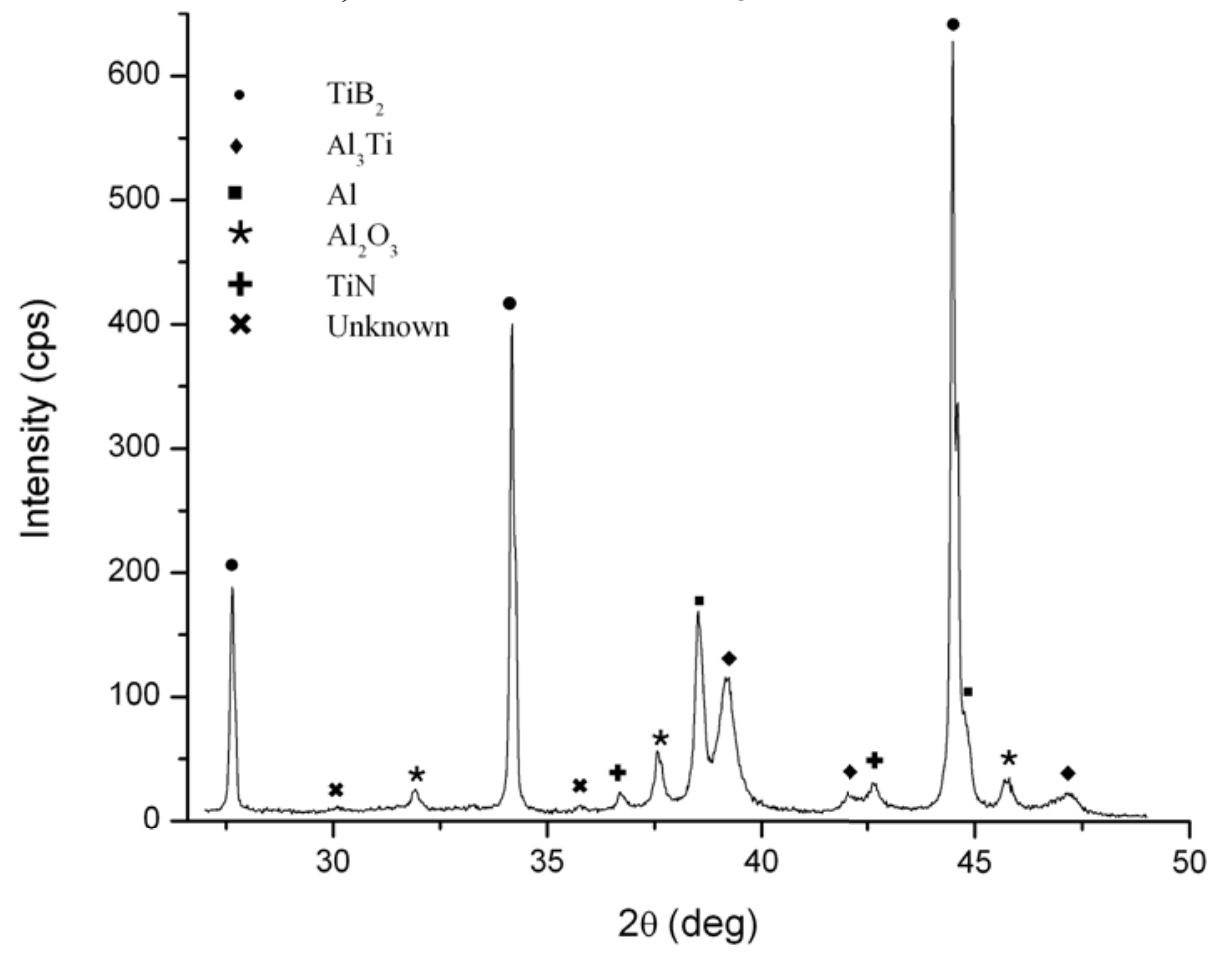

Figure 9.8 Ti-Al-B, 20 vol. \% $\mathrm{TiB}_{2}, 0.375$ total initiation aid wt. fraction, 0.80 internal fraction of total initiation aid, 0.85 wt. fraction $\mathrm{KNO}_{3}$ initiation aid 


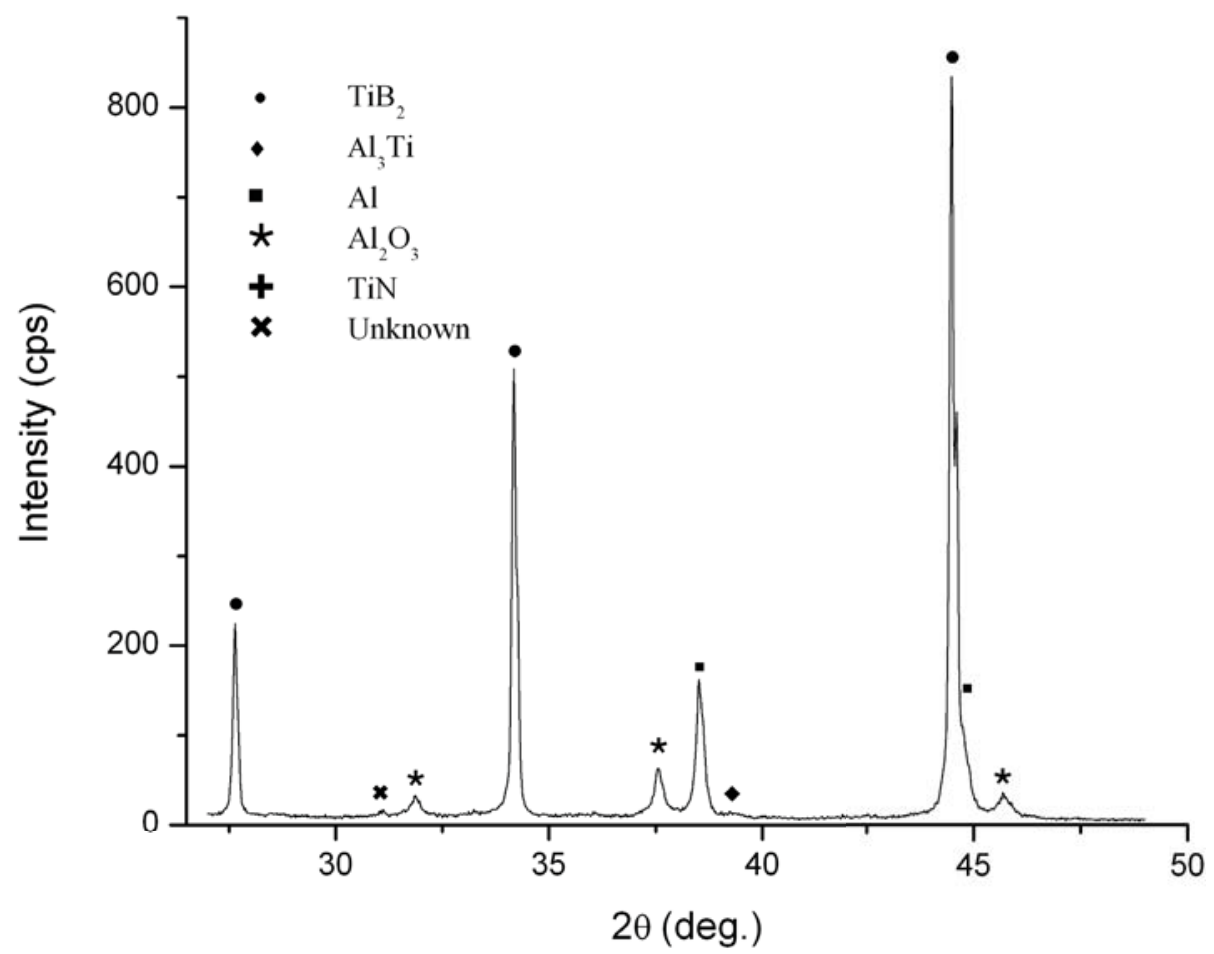

Figure 9.9 Ti-Al-B, 20 vol. $\% \mathrm{TiB}_{2}, 0.50$ total initiation aid wt. fraction, 0.80 internal fraction of total initiation aid, 0.85 wt. fraction $\mathrm{KNO}_{3}$ initiation aid



Figure 9.10 Ti-Al-B, 40 vol. $\% \mathrm{TiB}_{2}, 0.25$ total initiation aid wt. fraction, 0.80 internal fraction of total initiation aid, 0.85 wt. fraction $\mathrm{KNO}_{3}$ initiation aid 


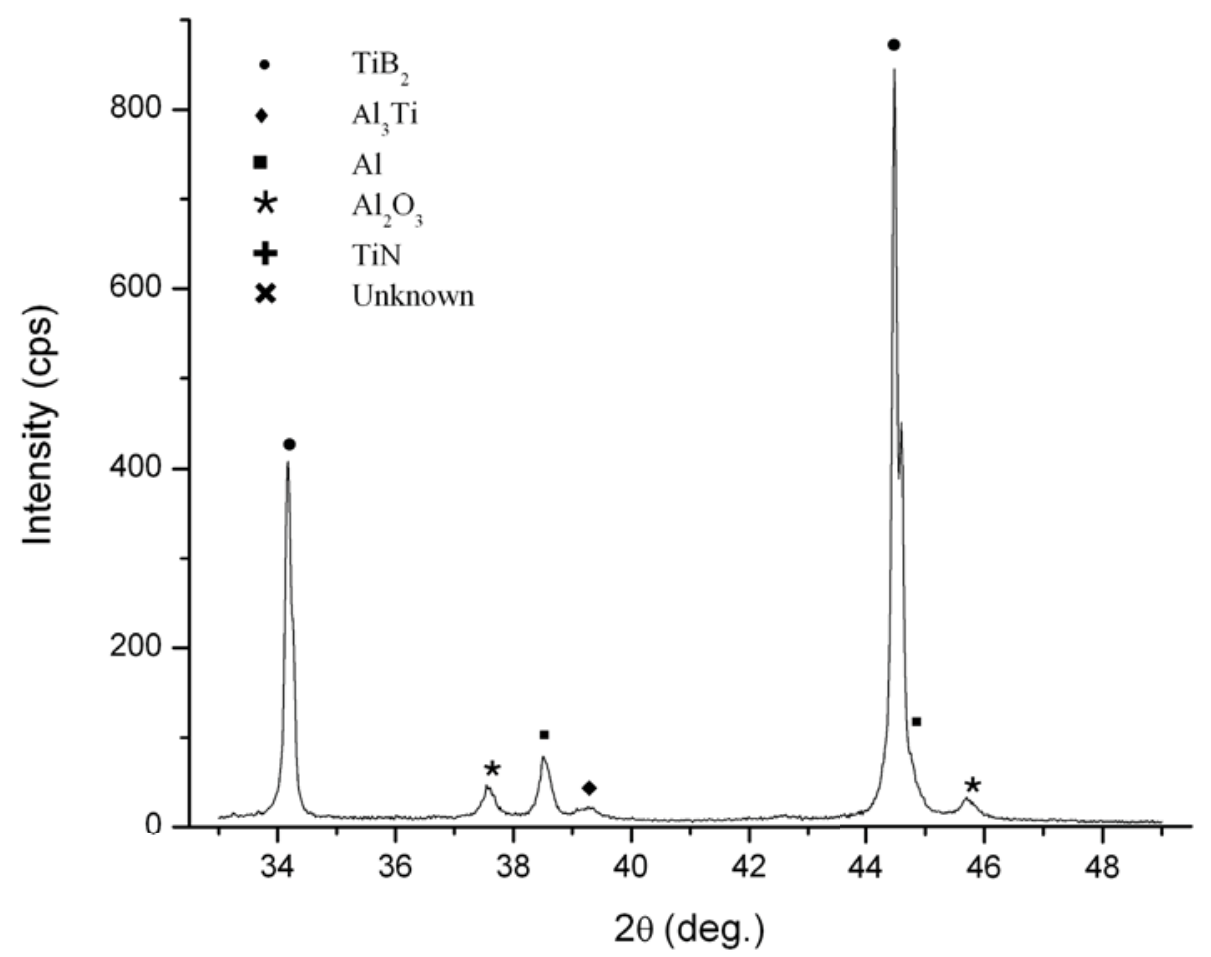

Figure 9.11 Ti-Al-B, 40 vol. $\% \mathrm{TiB}_{2}, 0.375$ total initiation aid wt. fraction, 0.80 internal fraction of total initiation aid, 0.85 wt. fraction $\mathrm{KNO}_{3}$ initiation aid

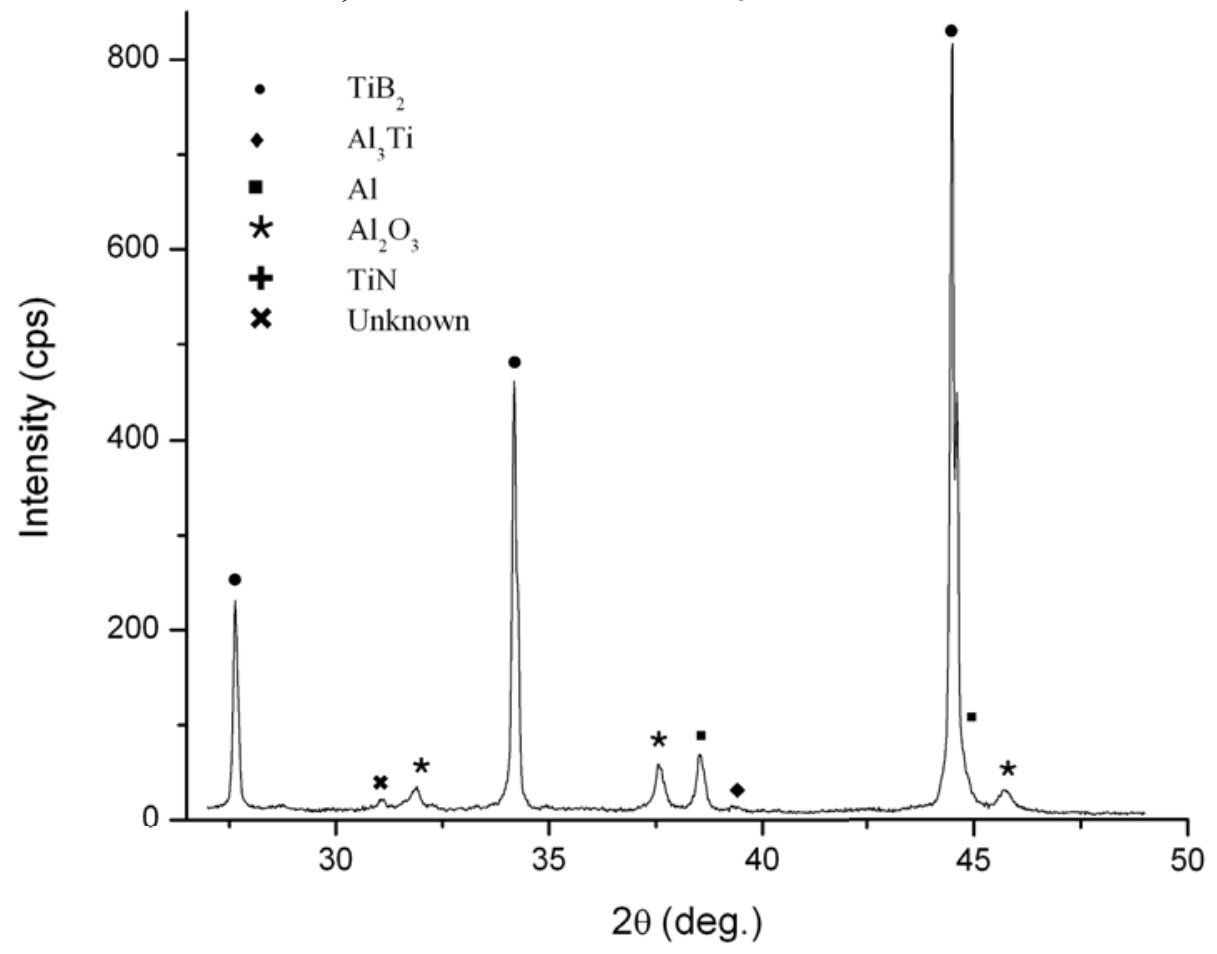

Figure 9.12 Ti-Al-B, 40 vol. \% $\mathrm{TiB}_{2}, 0.50$ total initiation aid wt. fraction, 0.80 internal fraction of total initiation aid, 0.85 wt. fraction $\mathrm{KNO}_{3}$ initiation aid 